\title{
Critical Review of Inundation Mapping Procedures for Floodplain Management
}

Richard M. Wise

West Virginia University

Follow this and additional works at: https://researchrepository.wvu.edu/etd

\section{Recommended Citation}

Wise, Richard M., "Critical Review of Inundation Mapping Procedures for Floodplain Management" (2011). Graduate Theses, Dissertations, and Problem Reports. 309.

https://researchrepository.wvu.edu/etd/309

This Thesis is protected by copyright and/or related rights. It has been brought to you by the The Research Repository @ WVU with permission from the rights-holder(s). You are free to use this Thesis in any way that is permitted by the copyright and related rights legislation that applies to your use. For other uses you must obtain permission from the rights-holder(s) directly, unless additional rights are indicated by a Creative Commons license in the record and/ or on the work itself. This Thesis has been accepted for inclusion in WVU Graduate Theses, Dissertations, and Problem Reports collection by an authorized administrator of The Research Repository @ WVU. For more information, please contact researchrepository@mail.wvu.edu. 


\title{
Critical Review of Inundation Mapping Procedures for Floodplain Management
}

\author{
By \\ Richard M. Wise, EIT \\ Thesis submitted to the \\ College of Engineering and Mineral Resources \\ at \\ West Virginia University \\ in partial fulfillment of the requirements \\ for the degree of \\ Master of Science \\ in \\ Civil and Environmental Engineering \\ Dr. John D. Quaranta, Ph.D., P.E., Chair \\ Dr. Hema Siriwardane, Ph.D., P.E. \\ Dr. Leslie Hopkinson, Ph.D.
}

Department of Civil and Environmental Engineering

Morgantown, West Virginia

2011

KEYWORDS: Paper Inundation Mapping, Virtual Inundation Mapping, FEMA, Floodplain Management, National Flood Insurance Program, HEC-RAS, Hydrologic Modeling, Simulated Dam Failure, HEC-GeoRAS, Terrain Tiles, ArcGIS, Google Earth, Critical Infrastructure Sectors 


\section{ABSTRACT \\ Critical Review of Inundation Mapping Procedures for Floodplain Management}

\section{Richard M. Wise}

Inundation mapping is a major component of floodplain management, providing critical information as to the consequences of potential failures of flood control structures, such as dams. To develop inundation maps, a dam and river system are modeled with engineering computer programs, and a simulation of the dam failure is performed to generate data for the flood. This output data is input into other programs to develop inundation maps. Inundation maps have traditionally been produced in a paper format, but recent advances in computer modeling have provided the capability for virtual inundation maps. Thus, these mapping methods need to be investigated to determine the applications and relevance to floodplain management.

The goal of this research is to advance the development and use of inundation maps by floodplain managers and emergency agencies. In this work, a simulation of a potential dam failure was performed for a candidate river system, and the inundation maps were created using two procedures: Terrain Tiles and Google Earth. An analysis of the strengths and weaknesses of each mapping procedure was conducted. The Terrain Tiles procedure has advantages in displaying critical information, such as arrival times and water depths. However, this mapping procedure is more labor-intensive, and the online file sharing may not be accessible for all users. The strengths of the Google Earth procedure include two-dimensional and three-dimensional views for analysis, user-friendly file sharing, and the inclusion of built-in critical infrastructure and terrain data. Drawbacks of this procedure are that the inundation must still be generated in ArcGIS, that the display of critical information is not as clear, and that the online file sharing may pose security issues. Thus, the Terrain Tiles procedure should be used for the development of emergency response measures, while the Google Earth procedure should be used by emergency responders in the event of an actual emergency. 


\section{Acknowledgments}

I would like to recognize Dr. John D. Quaranta for his insight and guidance for the duration of this work, and I am grateful that he served as my advisor. I wish to thank Dr. Leslie Hopkinson and Dr. Hema Siriwardane for being members of my research advisory committee. I would also like to acknowledge the work performed by Mr. Andrew Darnell and Mr. Brian Lavigne in the completion of this work.

I thank the United States Army Corps of Engineers for their contributions to this research, including financial support, data, and overall guidance that led to the completion of the work. Additionally, I would like to thank Wheeling Jesuit University for supporting this research effort. 


\section{Table of Contents}

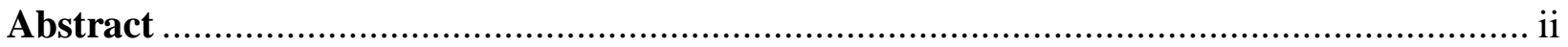

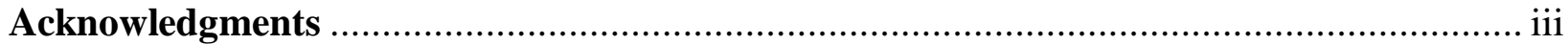

List of Tables and Figures.......................................................................................... vii

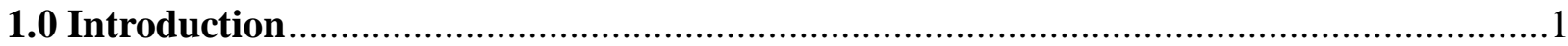

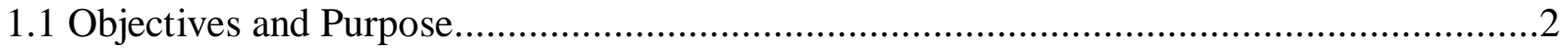

1.2 Work Scope

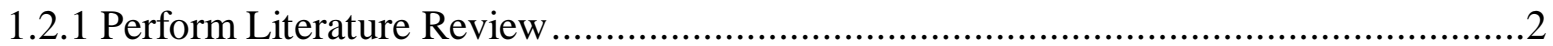

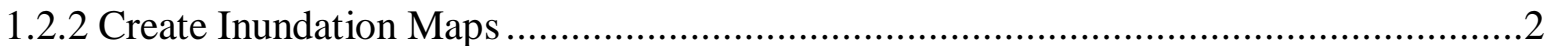

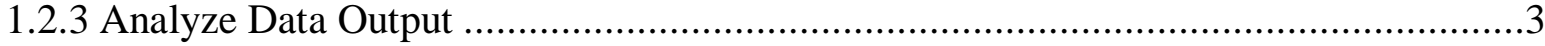

1.2.4 Provide Recommendations...................................................................................

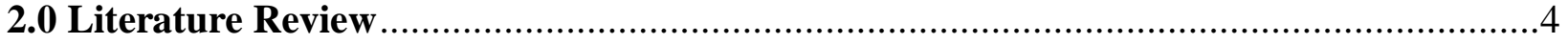

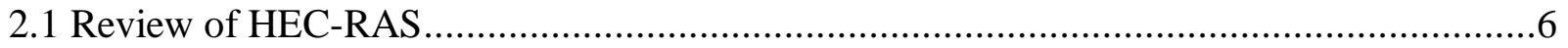

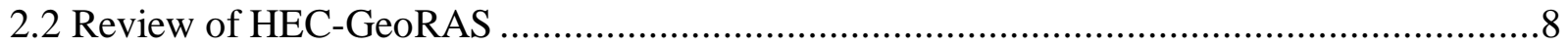

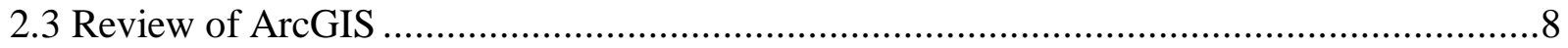

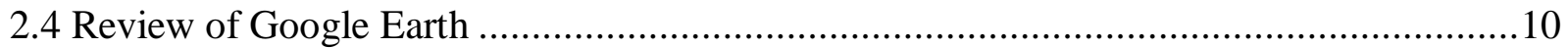

3.0 Hydrologic Modeling and Inundation Mapping Procedures ........................................12

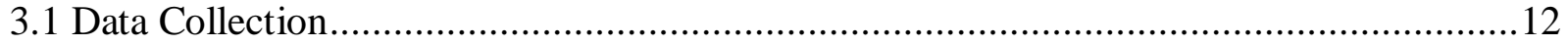

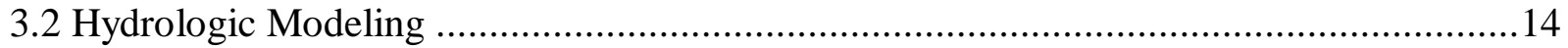

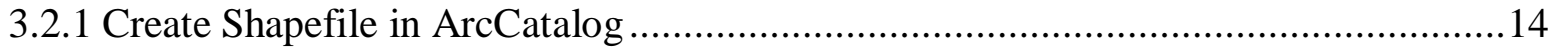

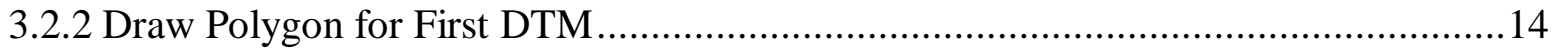

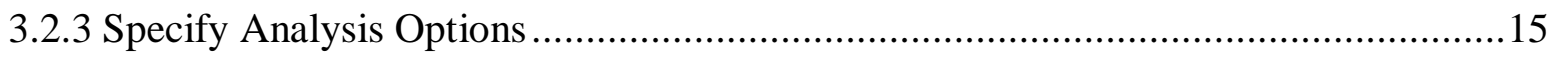

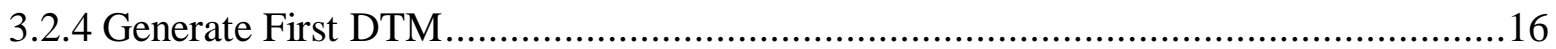

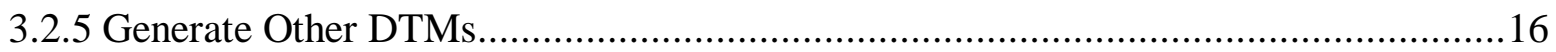

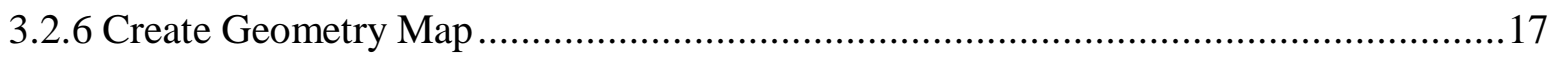

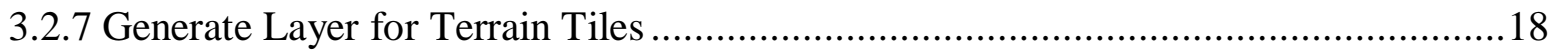

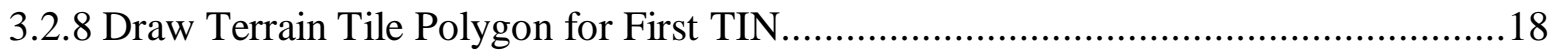

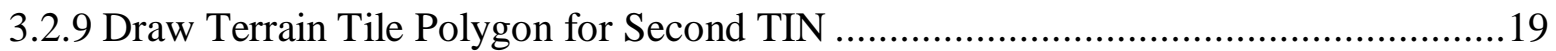

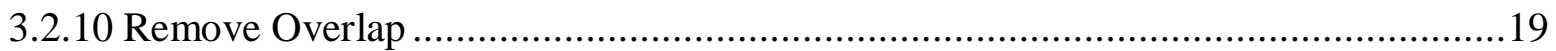

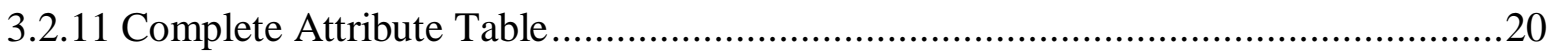

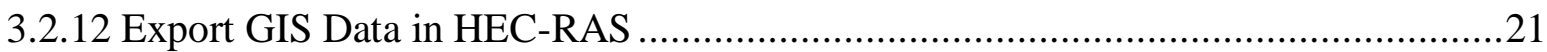

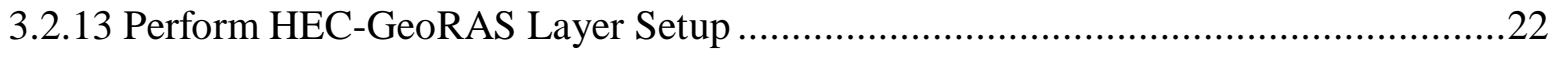

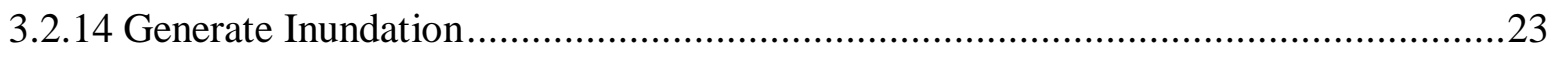

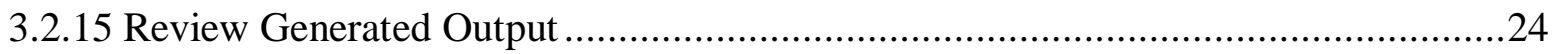




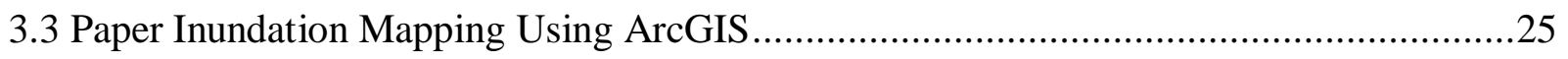

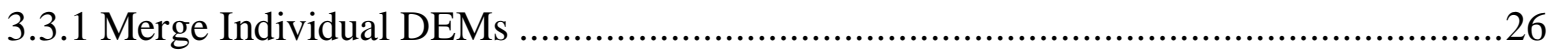

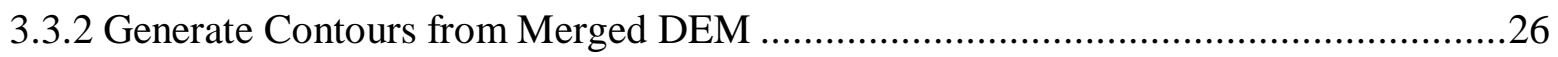

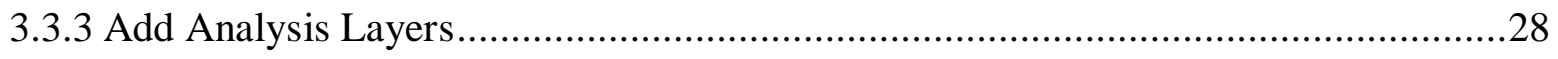

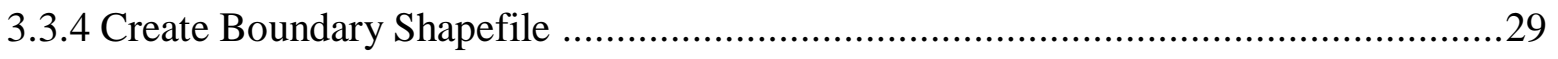

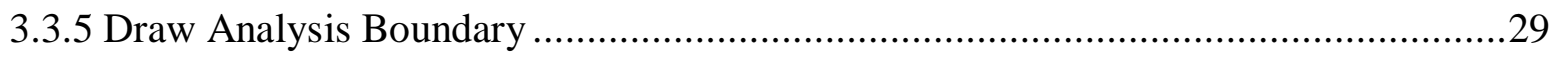

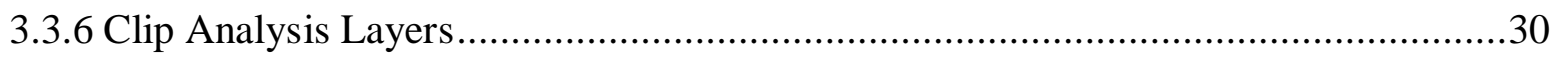

3.3.7 Label and Assign Symbology to Analysis Layers ....................................................

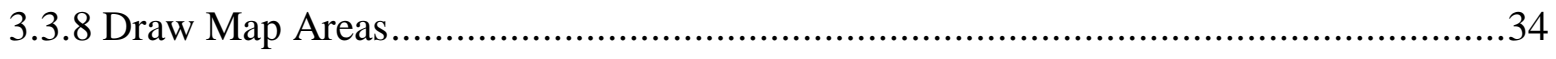

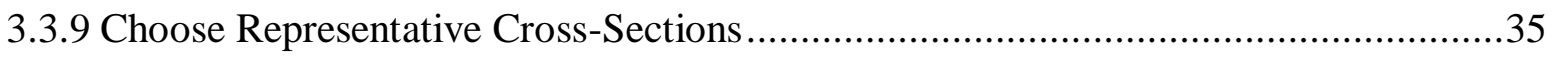

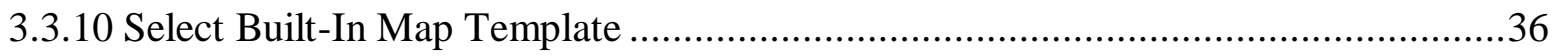

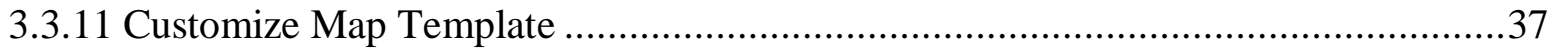

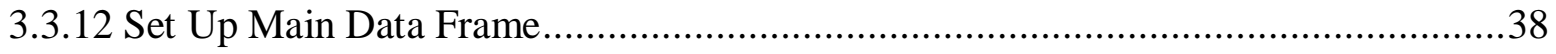

3.3.13 Arrange Main and Minor Data Frames ....................................................................

3.3.14 Add Essential Map Components ………………................................................ 40

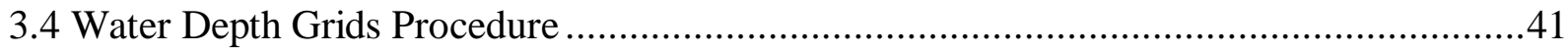

3.4.1 Mosaic Depth Grids ........................................................................................

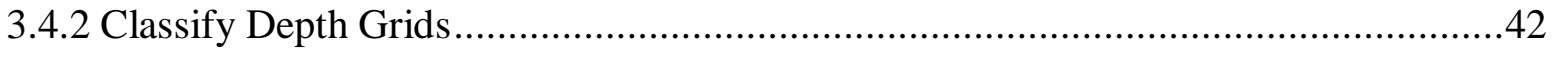

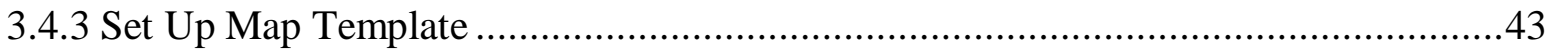

3.5 Virtual Inundation Mapping Using Google Earth ............................................................4

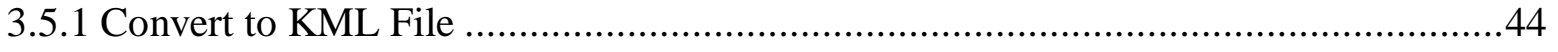

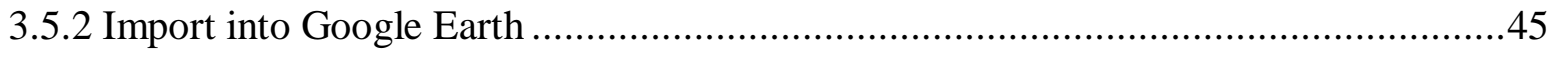

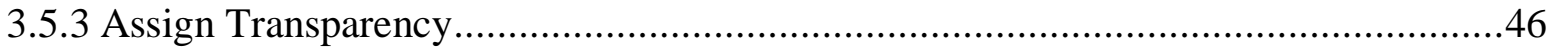

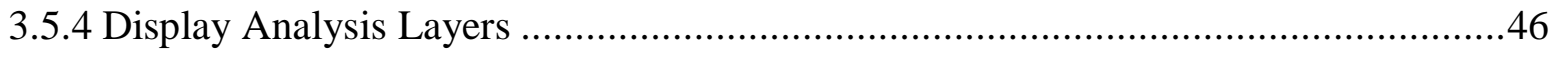

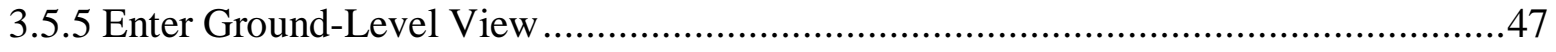

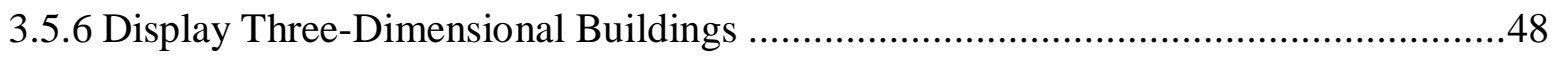

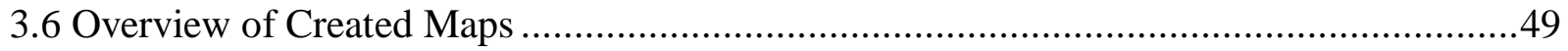

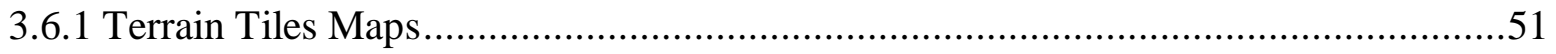

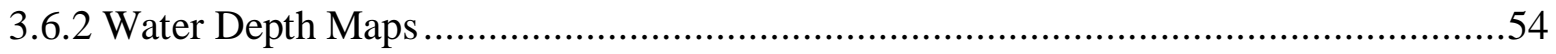

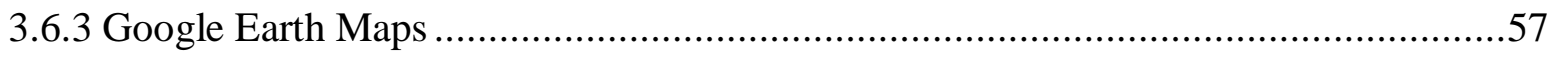

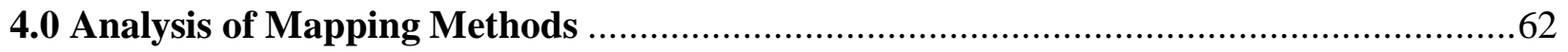

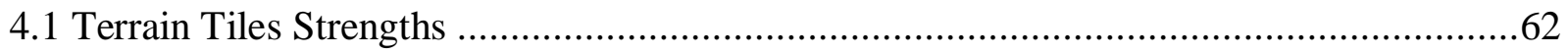

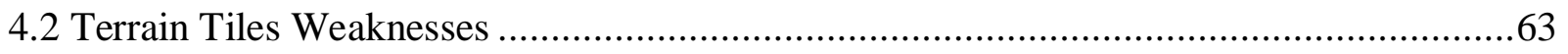

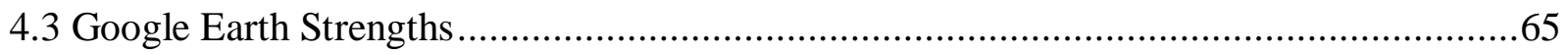


4.4 Google Earth Weaknesses ..........................................................................67

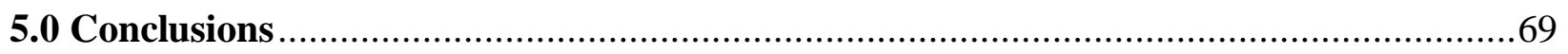

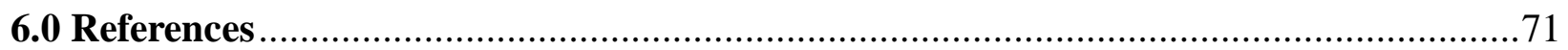




\section{List of Tables and Figures}

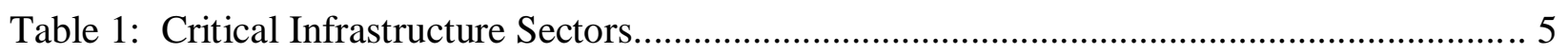

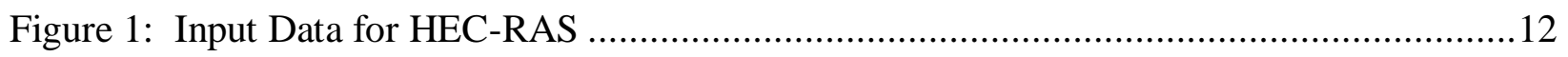

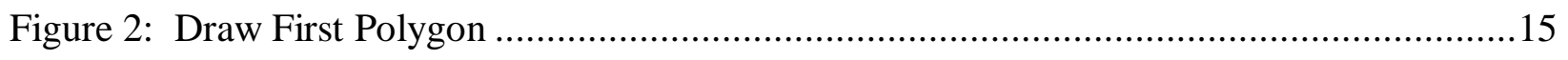

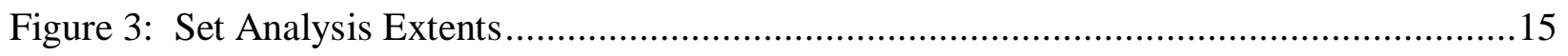

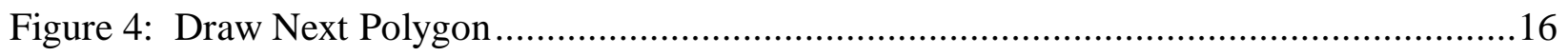

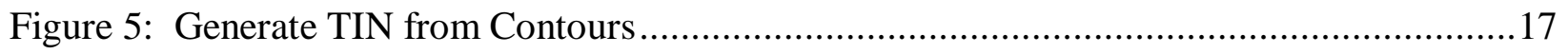

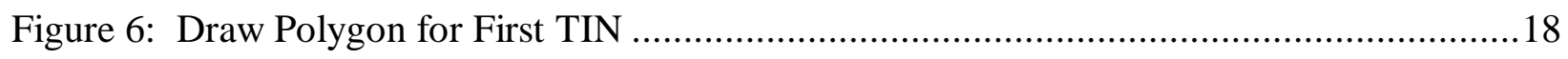

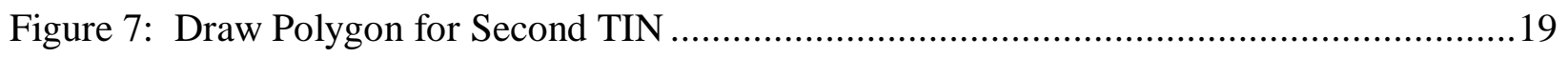

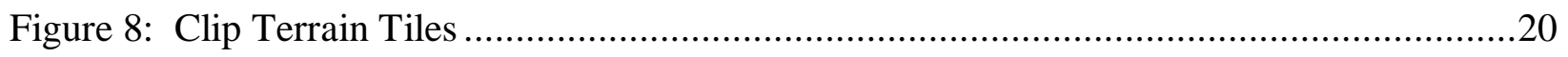

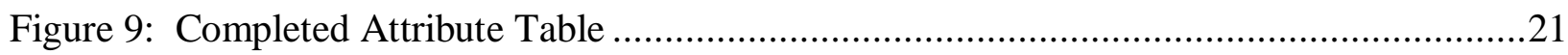

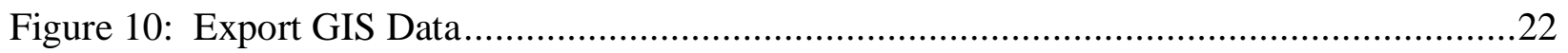

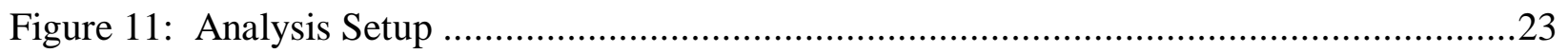

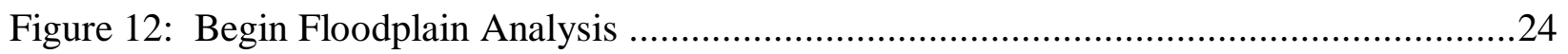

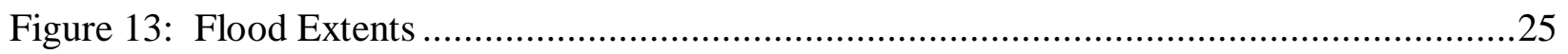

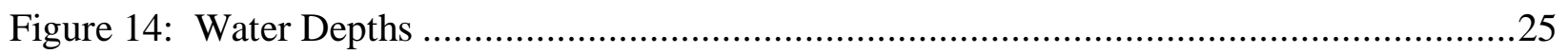

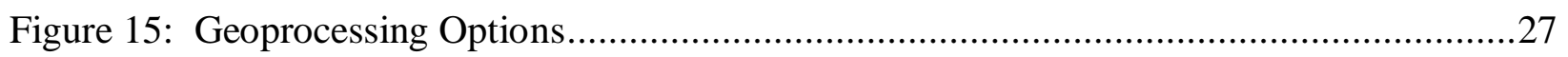

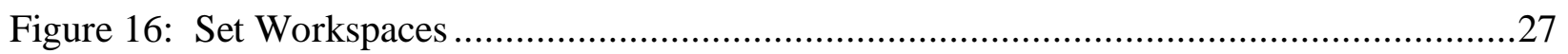

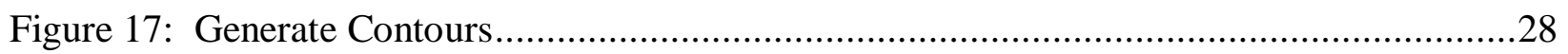

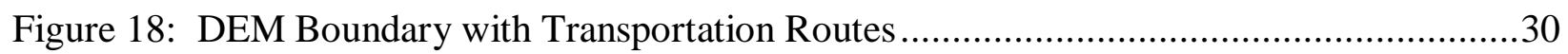

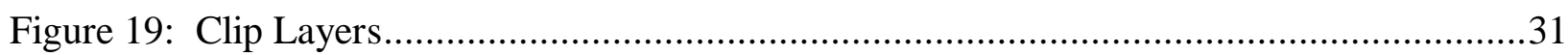

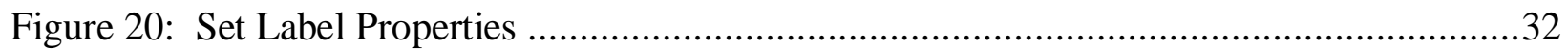

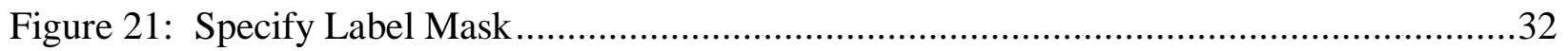

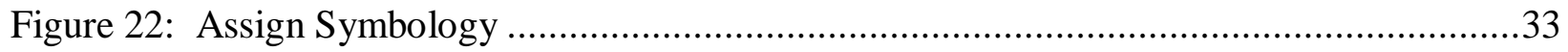

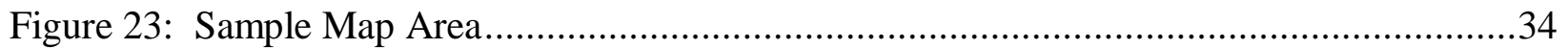

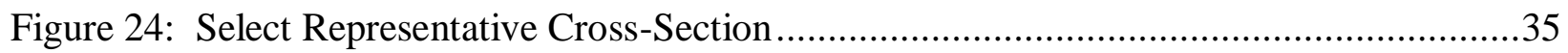

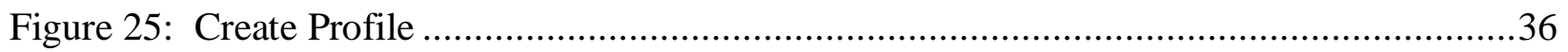

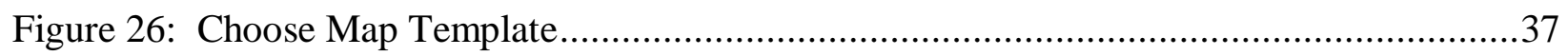

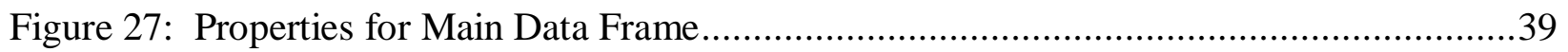

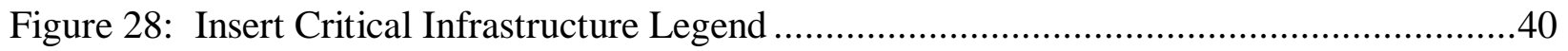

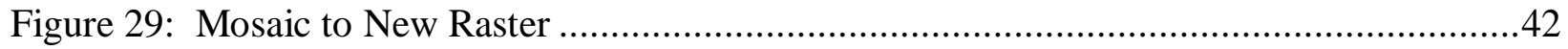

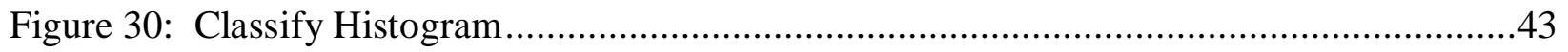

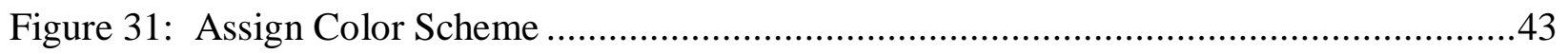

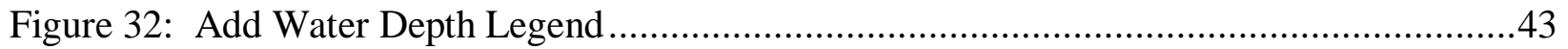




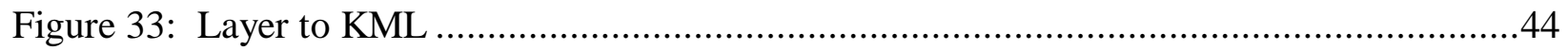

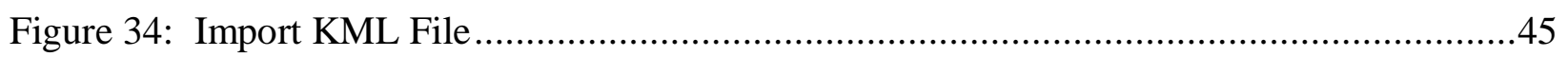

Figure 35: Inundation with Assigned Transparency ............................................................46

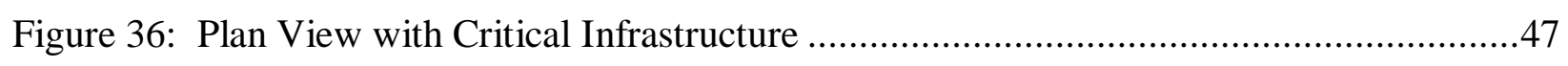

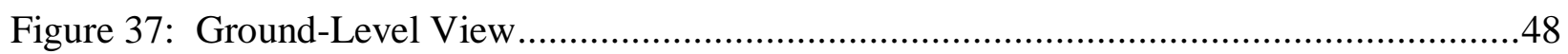

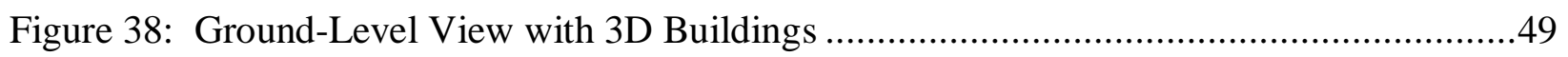

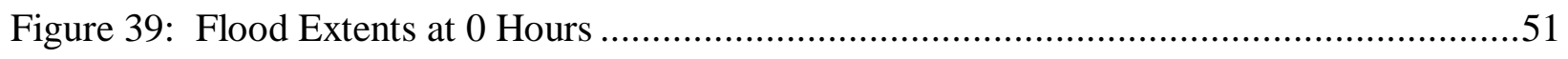

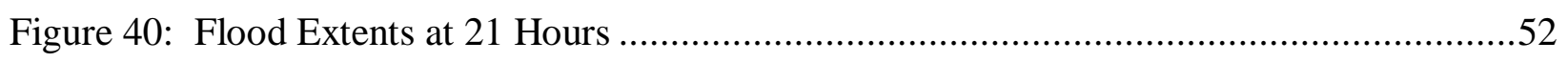

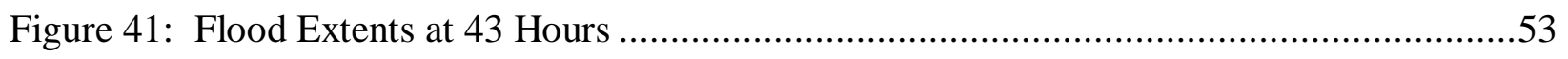

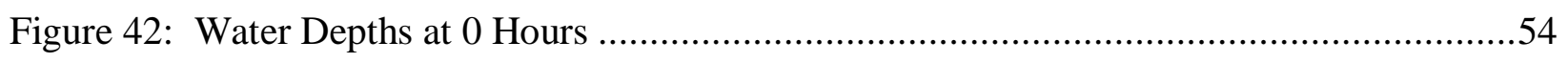

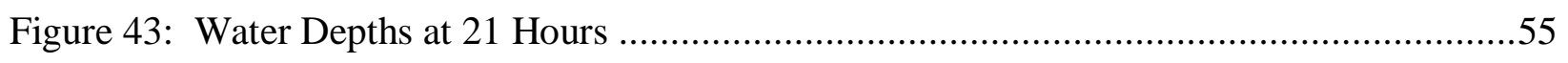

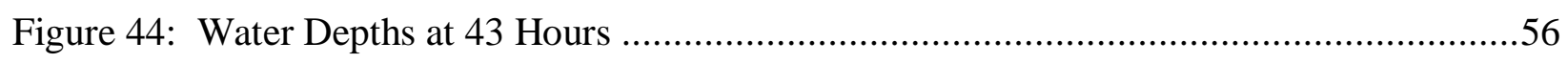

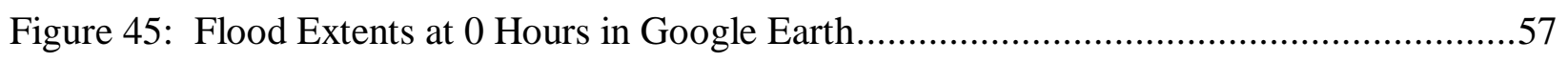

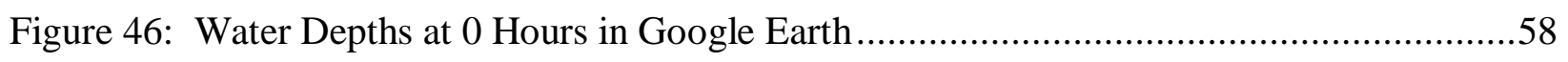

Figure 47: Flood Extents at 21 Hours in Google Earth......................................................59

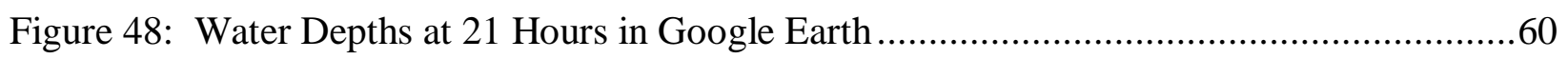

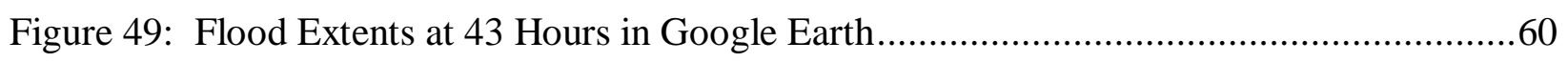

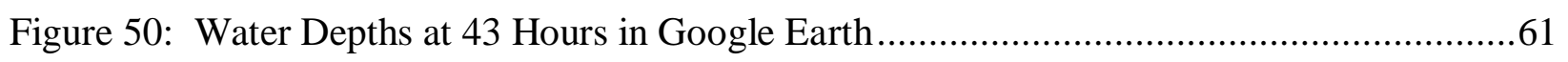

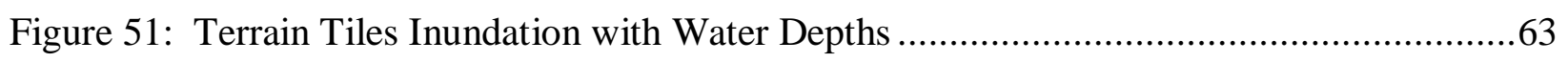

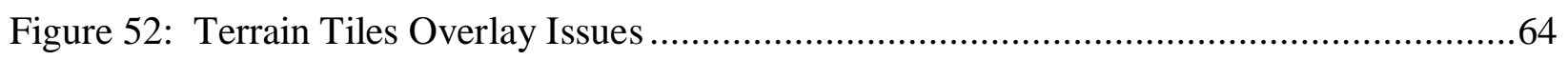

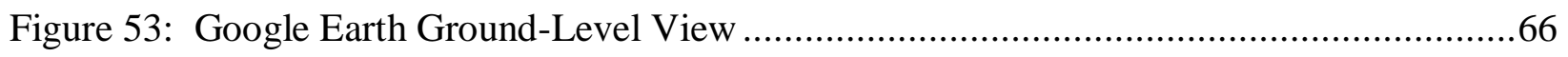

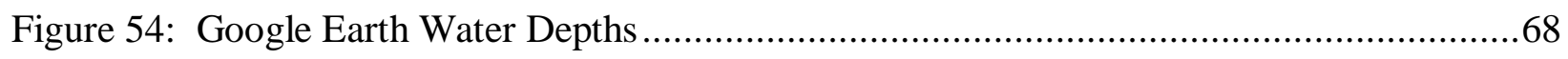




\subsection{Introduction}

Flood control is a vital safeguard in society, protecting the public from the devastation to property and health caused by high water levels. A key component of flood control is the use of dams to control flow on major rivers. The United States Army Corps of Engineers (USACE) manages 569 dams throughout the United States. However, these dams have a design life of 50 years, and a majority of the dams are approaching or have exceeded this design life (ERDC, 2010). Therefore, the USACE is committed to evaluating these structures for risk of potential failure, integrating risk reduction methods, and communicating and understanding these risks (USACE, 2008).

Planning for a potential dam failure requires an understanding of the effects of the flood in order for proper mitigation measures to be implemented. A useful tool for visualizing these effects is inundation mapping. The development of inundation maps involves several steps, beginning with the modeling of the structure and river networks in computer software. The output data is then input into other computer programs for the creation of the maps. Inundation maps are typically produced as paper maps, but recent technological advances provide the capability to create virtual maps. Since virtual inundation maps offer new methods of presentation and analysis of flood impacts, an assessment of the strengths and weaknesses of paper and virtual maps needs to be performed to determine the appropriate applications of each in floodplain management. This research consists of four tasks: i) conduct literature reviews on current software for floodplain mapping, ii) generate inundation for a dam failure and produce paper and virtual maps, iii) identify strengths and weaknesses for each mapping procedure and determine applications in floodplain management, and iv) provide recommendations for further development. 


\subsection{Objectives and Purpose}

The objectives of this work are to examine the key differences in the development and use of paper and virtual inundation maps. Additional objectives are to discuss the computer programs used in the creation of inundation maps (HEC-RAS, HEC-GeoRAS, ArcGIS, and Google Earth); to identify input data and generated output; and to perform data analysis based on the functionality, strengths and weaknesses, and need for further development and refinement. The main purpose of this research is to advance the development and use of inundation maps by floodplain managers and emergency agencies.

\subsection{Work Scope}

The research process is divided into four separate tasks comprising the work scope. The work scope is outlined in more detail in the following sections.

\subsubsection{Perform Literature Review}

The purpose of the literature review is to establish the necessity of creating inundation maps for use in floodplain management. The literature review provides current guidelines and standardization practices developed by the Federal Emergency Management Agency (FEMA). Furthermore, relevant computer software used in the inundation mapping process are presented, and the applications of each program are discussed in regards to the research efforts.

\subsubsection{Create Inundation Maps}

The development of inundation maps involves several steps, beginning with data acquisition. Hydrologic events are used to simulate a dam failure, generating the resulting inundation as the flood moves downstream. Output data such as water elevations and flow rates are imported into mapping software, where the inundation is visualized. The inundation is then 
processed in either a paper or virtual format for analysis and use by floodplain engineers and emergency responders. In this work, two mapping procedures are outlined to establish the steps for creating both paper and virtual inundation maps.

\subsubsection{Analyze Data Output}

The outputs from each mapping procedure are analyzed using several criteria related to the functionality in the development of emergency response measures. These criteria involve the ease of development for each mapping procedure, the manner in which critical information is presented in each map, and the accessibility of the maps to multiple agencies and audiences. Based on these criteria, the strengths and weaknesses of each mapping procedure are determined, leading to an evaluation of the proper applications of each map in floodplain management.

\subsubsection{Provide Recommendations}

The significant results of this research are discussed, including the advantages and disadvantages of each mapping procedure in relation to floodplain management practices. Appropriate applications for each mapping procedure are then detailed. Lastly, a discussion of future development and possible improvements is presented. 


\subsection{Literature Review}

Floodplain management serves a vital purpose in society, protecting public property and health, maintaining flood control, preserving water quality for communities, and establishing emergency response protocols (Bond, 2009). These practices are outlined in the National Flood Insurance Program (NFIP), managed by FEMA. The NFIP provides flood insurance for almost 20,000 communities across the United States and helps to reduce future flood damage through the development of flood hazard maps (FEMA, 2010). These maps communicate the risks and potential impacts of floods, enabling communities to prepare for such disasters. Therefore, flood mitigation efforts rely on the creation of inundation maps in order to develop appropriate response measures for crisis situations, including dam failures.

The results of a dam failure are devastating to communities downstream, having widespread impacts on critical infrastructure. Inundation maps depicting the estimated flood extents and water surface elevations provide an understanding of the effects to critical infrastructure. Thus, inundation maps enable floodplain engineers and emergency responders to develop appropriate evacuation and mitigation protocols. In order to aid the display of infrastructure in inundation maps, FEMA has established a classification system of critical infrastructure sectors depicted in Table 1 (DHS, 2008). 


\begin{tabular}{|c|c|}
\hline Sector-Specific Agency & CI/KR Sector \\
\hline $\begin{array}{l}\text { Department of Agriculture } \\
\text { Department of Health and Human Services }{ }^{4}\end{array}$ & Agriculture and Food \\
\hline Department of Defense & Defense Industrial Base \\
\hline Department of Energy $^{5}$ & Energy \\
\hline Department of Health and Human Services & Public Health and Health Care \\
\hline Department of the Interior & National Monuments and Icons \\
\hline Department of the Treasury & Banking and Finance \\
\hline Environmental Protection Agency & Drinking Water and Water Treatment Systems \\
\hline $\begin{array}{l}\text { Office of Cyber Security and Telecommunications } \\
\text { Transportation Security Administration } \\
\text { Transportation Security Administration/U.S. } \\
\text { Coast Guard } \\
\text { Immigration and Customs Enforcement/Federal } \\
\text { Protective Service }\end{array}$ & $\begin{array}{l}\text { Chemical } \\
\text { Commercial Facilities } \\
\text { Dams } \\
\text { Emergency Services } \\
\text { Nuclear Reactors, Materials, and Waste } \\
\text { Information Technology } \\
\text { Telecommunications } \\
\text { Postal and Shipping } \\
\text { Transportation Systems } \\
\\
\text { Government Facilities }\end{array}$ \\
\hline \multicolumn{2}{|c|}{$\begin{array}{l}{ }^{3} \text { The Department of Agriculture is responsible for agriculture and food (meat, poultry, and egg products). } \\
{ }^{4} \text { The Department of Health and Human Services is responsible for food other than meat, poultry, and egg products. } \\
\text { The Energy Sector includes the production, refining, storage, and distribution of oil, gas, and electric power, excep } \\
\text { for commercial nuclear power facilities. } \\
{ }^{6} \text { The U.S. Coast Guard is the SSA for the maritime transportation mode. } \\
{ }^{7} \text { As stated in HSPD-7, the Department of Transportation and the Department of Homeland Security collaborate on } \\
\text { all matters relating to transportation security and transportation infrastructure protection. }\end{array}$} \\
\hline
\end{tabular}

Table 1: Critical Infrastructure Sectors

By producing inundation maps showing the flood extents at consecutive times after a dam failure, the inundation's arrival times to important areas and critical infrastructure are determined. These arrival times are key components of Emergency Action Plans, helping emergency responders to coordinate mitigation measures at the optimal time for various locations downstream. Because of the crucial information contained within inundation maps, these maps play an integral role in floodplain management and dam safety.

Several engineering software programs are used for the development of time-stepped inundation maps, including HEC-RAS, HEC-GeoRAS, ArcGIS, and Google Earth. First, the dam and river system are modeled in HEC-RAS, and a hydrologic event is used to simulate the dam failure. Next, the generated HEC-RAS data is processed using HEC-GeoRAS, and tools in ArcGIS are used to create paper inundation maps. An alternate mapping method is to export the inundation into Google Earth for the development of virtual maps, which is the focus of this research. 


\subsection{Review of HEC-RAS}

Created by the USACE, HEC-RAS is engineering software that models systems of both natural and man-made channels. Once the geometry data for the network is set up, HEC-RAS simulates water flow through the network using one-dimensional hydraulic calculations. HECRAS contains the capability to perform various analyses using four separate modules: steady flow, unsteady flow, sediment transport, and water quality (USACE, 2011B).

The steady flow module performs calculations for river systems where the flow is gradually varied with subcritical, supercritical, or mixed flow profiles. These calculations are based on Manning's equation, although the momentum equation is used to provide flow data around bridge piers, at river confluences, and at hydraulic jumps. HEC-RAS also allows structures located in the floodplain, such as culverts and weirs, to be included in the analysis. Because of these features, the steady flow module is useful for performing studies involving floodplain analysis (USACE, 2011B).

Similar to the steady flow module, the unsteady flow module computes flow data for an entire river network. However, this module is designed to perform calculations for systems where the water surface profiles and flow characteristics vary with time. The unsteady flow module has the capability to incorporate various flow conditions, including subcritical flow, supercritical flow, mixed flow, drawdowns, and hydraulic jumps. Furthermore, the unsteady flow module enables users to input floodplain obstructions such as bridges, culverts, and weirs into the simulation. Due to the capabilities contained within this module, the unsteady flow module is suitable for simulating the overtopping and failure of dams, water releases from dam operations, and flow through pumping stations and pipe systems (USACE, 2011B). 
The sediment transport module simulates scour and deposition in river channels over time. Hence, this module is used to study the effects that changes in the flow rate through the channel or the modification of the channel's cross-sectional geometry have on scour and deposition. Further applications of the sediment transport module include simulating the scour of river channels as a result of extreme floods, assessing the deposition of soil in reservoirs, and determining the impacts dredging may have on deposition (USACE, 2011B).

The water quality module provides capabilities for environmental analyses of rivers and streams. The analyses contained within the module are carbonaceous biological oxygen demand, dissolved oxygen, algae, dissolved phosphorus, and dissolved nitrogen. As a result, the water quality module is a vital tool for the determination of the purity of water for consumption and the preservation of ecosystems (USACE, 2011B).

Once the appropriate module has been selected and the simulation has been performed, HEC-RAS allows users to create graphics and reports of the output data. For instance, HECRAS produces graphics of the channel geometry, such as the river network and cross-section profiles. Additionally, rainfall and flow data such as hydrographs and water velocities are contained within tables in HEC-RAS. Another tool in HEC-RAS, RAS Mapper, provides the capability to use the generated output data for the purpose of inundation mapping within HECRAS (USACE, 2011B).

While HEC-RAS contains many features and a wide variety of analysis capabilities, only a select few are useful for the purposes of this research. Since the unsteady flow module performs hydraulic calculations for flow characteristics that change over time, this HEC-RAS simulation provides the most realistic depiction of the flood's movement downstream after the dam failure. 


\subsection{Review of HEC-GeoRAS}

HEC-GeoRAS is a program compatible with both HEC-RAS and ArcGIS Desktop, providing a means to transfer data between the two computer programs. Developed by the USACE, HEC-GeoRAS is a software extension for ArcGIS Desktop that allows for the import of GIS data into HEC-RAS and the visualization of HEC-RAS output in ArcGIS Desktop. HECGeoRAS contains tools for digitizing river networks in ArcGIS Desktop, with capabilities for assigning station values, flow paths, and river names. Further capabilities include the development of cross-sectional cut lines and the input of elevation values. Once the river network is digitized, the geometry data is imported into HEC-RAS, where hydraulic simulations are performed for the river system. The HEC-RAS output data is then visualized and processed by HEC-GeoRAS for a variety of applications, including flood hazard mapping, damage calculations, and emergency response (USACE, 2011A).

The capabilities contained within HEC-GeoRAS are crucial to the creation of timestepped inundation maps. The geometry data for the river network is generated in ArcGIS Desktop using HEC-GeoRAS, providing the input data for HEC-RAS. Hydrologic events are used to simulate the dam failure, and HEC-RAS produces output data for the resulting inundation. HEC-GeoRAS is then used to visualize the output data in ArcGIS Desktop, where tools in both HEC-GeoRAS and ArcGIS Desktop are utilized to process the data for the inundation and to develop the inundation maps.

\subsection{Review of ArcGIS}

Created by the Environmental Systems Research Institute, Inc. (ESRI), ArcGIS is a computer system used for displaying geographic data. ArcGIS has a multitude of uses in today's 
society, including processing geographic data, developing and analyzing maps, and disseminating geographic information. ArcGIS Desktop, ArcGIS Server, ArcGIS Explorer, ArcGIS.com, ArcGIS online, and Mobile GIS are several programs that comprise ArcGIS. Each program provides users with unique processing functions. ArcGIS Desktop is a software program that allows users to create maps on computers with a Windows operating system. After the maps are developed, ArcGIS Server, ArcGIS Explorer, ArcGIS.com, and ArcGIS online are used in combination to allow users to upload, publish, and share the maps online. Mobile GIS allows for users to then access uploaded material in the field using mobile phones, Tablet PCs, and advanced GPS data collectors (ESRI, 2011A).

The main computer program used for GIS tasks such as developing maps and analyzing data is ArcGIS Desktop. ArcGIS Desktop comprises several key components to perform these tasks, including ArcCatalog, ArcGlobe, ArcMap, ArcScene, ArcToolbox, and ModelBuilder. ArcCatalog is a tool that allows for proper file management and the organization of GIS data. ArcMap is a tool where the GIS data is compiled and analyzed. In ArcMap, the concept of overlaying features is used, allowing for points and other data to be displayed on background imagery or terrain. This information is then stored by ArcMap in a map document where analyses are performed by ArcToolbox. All the tools developed by the ESRI to process geographic data are contained within ArcToolbox. Data analysis is performed by using these tools individually or by combining the tools into a flow chart format using ModelBuilder. The combining of processing tools in ModelBuilder is helpful when the data analysis follows a set procedure and requires repetition. In addition to these different components, ArcGIS Desktop has customization capabilities through extensions that offer advanced analysis functions. Two of these extensions, Spatial Analyst and 3D Analyst, provide the ability to analyze three- 
dimensional terrain data. Because the overlay function in ArcMap only allows for geographic data to be viewed in a two-dimensional plane, ArcGlobe and ArcScene are used to project geographic data in a three-dimensional environment. Therefore, ArcGIS Desktop provides a set of capabilities that enables users to visualize and process geographic data for a multitude of applications (ESRI, 2011B).

ArcGIS Desktop is an important program in the creation of inundation maps. Once a program such as HEC-RAS is used to perform hydraulic modeling and export the data, ArcMap and HEC-GeoRAS are used for visualizing and processing the results. Once the flood has been developed, other layers such as aerial photography or topography, locations of critical infrastructure, and transportation routes are supplemented to the map to provide spatial referencing and to serve as a basis for the analysis of the flood's impacts. The creation of these maps provides emergency agencies with a visualization of the flood's effects and allows for the coordination of emergency management procedures. Therefore, ArcGIS Desktop is vital for the development of inundation maps.

\subsection{Review of Google Earth}

Google Earth is a virtual globe and map program developed by Google. This program is available in three different versions: Google Earth, Google Earth Pro, and Google Earth Enterprise. Google Earth is a free version of the software, while Google Earth Pro and Google Earth Enterprise contain additional professional tools that must be purchased. The basic features of Google Earth include the ability to explore geographic information, view three-dimensional buildings, and upload data for display. By viewing models on the virtual globe, users can visualize how projects would appear in actuality, which enables users to better understand the 
impacts the projects would have on existing features. Google Earth also offers methods of sharing created maps and information online. Maps uploaded to Google Earth can be shared with the Google Earth Community and accessed using Android phones and tablets, iPhones, and iPads. Thus, Google Earth provides an environment for a deeper analysis and visualization than plans or paper maps offer (Google, 2011).

Google Earth has many features that are useful for the purposes of this work. Once the inundation extents have been developed using ArcGIS Desktop, the inundation is exported into a format compatible with Google Earth. By importing this data into Google Earth, the flood is displayed on existing imagery, and the resulting interactive map provides further analysis than the two-dimensional view offered by ArcMap. As a result, Google Earth provides another means of visualizing the effects of a dam failure, which makes this computer program an effective means of inundation mapping. 


\subsection{Hydrologic Modeling and Inundation Mapping Procedures}

Since the input data is identical for the development of paper and virtual inundation maps, this data is first presented. Next, the data processing procedure is outlined, and the methods for creating the paper and virtual maps are discussed.

\subsection{Data Collection}

For this research effort, the United States Army Corps of Engineers developed a HECRAS project file of a candidate dam and river system. This model contains several failure scenarios for the dam, as well as key data for the river network, including the following: river centerlines, cross-sections along the rivers depicting channel geometry, water storage areas, and bank points along the rivers outlining where the floodplain begins. This input data is represented in Figure 1, where the river centerlines are dark blue lines, the cross-sections are green lines, the storage areas are light blue regions, and the bank points are red dots.

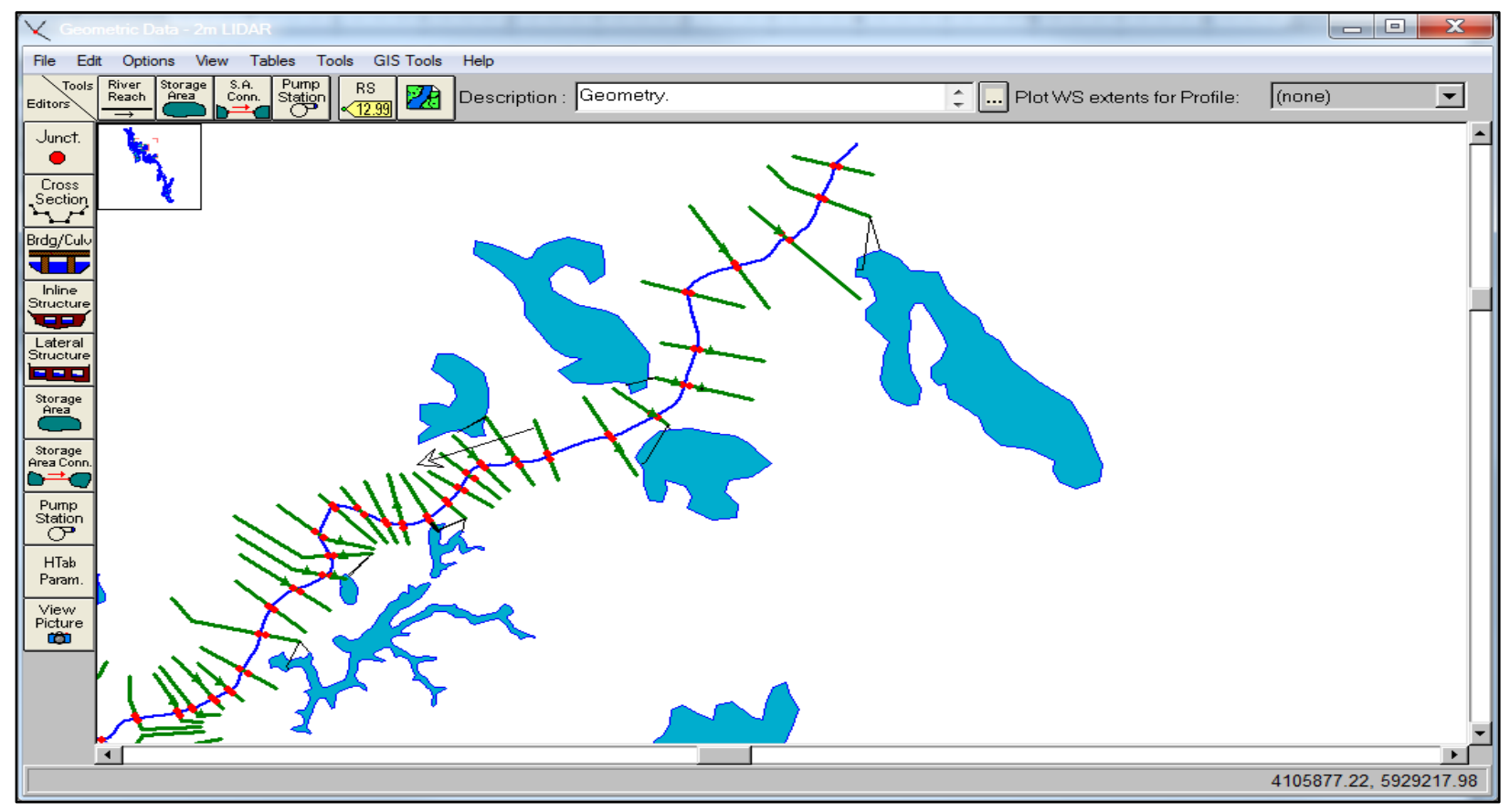

Figure 1: Input Data for HEC-RAS 
After acquiring the HEC-RAS model from the USACE, the data contained within the model was verified by performing a visual inspection to assess the accuracy of the data for the purposes of this research. Since the data derived from field measurements of the dam and river system could not be confirmed precisely, the cross-section profiles of the rivers were examined to ensure the geometry conformed to topography consistent with the study area. Once the data was determined to be accurate, the remaining data required for the analysis was obtained.

In addition to the HEC-RAS model, the USACE supplied terrain data based on Light Detection and Ranging (LiDAR). The elevations obtained from LiDAR were processed into bare earth Digital Elevation Models (DEMs) composed of grids with three separate spatial resolutions: 30 -meter, 10-meter, and 2-meter. Since the spatial resolution refers to the dimension of each grid within the DEM, the 2-meter DEMs are chosen as the basis for this research in order to obtain a level of accuracy of two meters for the inundation. The North American Datum of 1983 (NAD83) is the coordinate system of the DEMs, and the Albers equalarea conic projection is used to model the study area on a two-dimensional surface with minimal distortion. In order to analyze the impacts of the inundation, critical infrastructure data for the study area was acquired from the USACE. For the creation of paper maps, background imagery was downloaded from the West Virginia GIS Technical Center in the form of aerial photography, transportation routes, and shapefiles of United States counties and cities (WVGISTC, 2011). After procuring this input data, the steps in the development of paper and virtual inundation maps are detailed. 


\subsection{Hydrologic Modeling}

Since an entire river network has an extensive amount of data that needs to be processed, the Terrain Tiles procedure is utilized to segment the network into smaller areas for analysis. Thus, in this procedure, Digital Terrain Models (DTMs) are produced from the DEMs, and the tools contained within HEC-GeoRAS are used to process the inundation based on the individual DTMs.

\subsubsection{Create Shapefile in ArcCatalog}

The first step in the process of developing DTMs is creating a polygon shapefile. This step is completed in ArcCatalog, where the new shapefile is given a name and coordinate system. With these attributes assigned to the shapefile, ArcMap is opened to begin the process of creating the DTMs from the DEMs.

\subsubsection{Draw Polygon for First DTM}

In a blank ArcMap document, the DEMs, the polygon shapefile, the river centerline, and the cross-section cut lines are added to facilitate the process of creating the DTMs. After adding this data, polygons are drawn to delineate the boundaries of the DTMs. Using the Sketch Tool from the Editor Toolbar, an area is drawn around the first DEM that encompasses the entire DEM section and corresponding cross-sections without intersecting any lines representative of the cross-sections. Figure 2 demonstrates how the polygon shapefile is drawn around the first DEM section and between the cross-sections. 


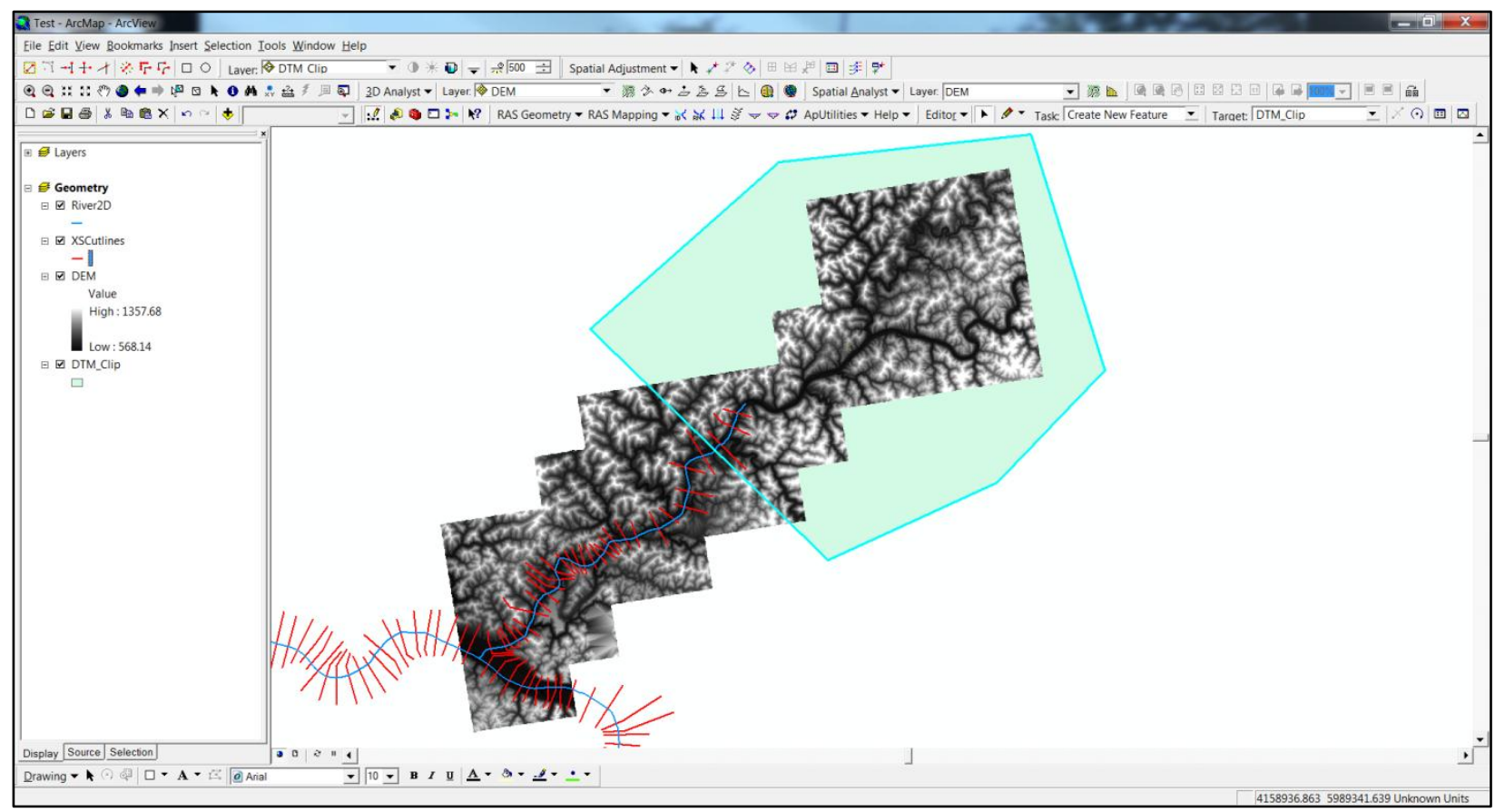

Figure 2: Draw First Polygon

\subsubsection{Specify Analysis Options}

Once the polygon is drawn, the next step is to specify the analysis options of the shapefile. Figure 3a displays the General tab, which allows for the analysis mask to be changed to the polygon shapefile. Figure $3 b$ shows the Extent tab; in this tab, the extent of the analysis is specified as the polygon shapefile, and the DEM is chosen as the snap extent. Lastly, Figure 3c illustrates the Cell Size tab, which allows for the cell size of the analysis to be set as the DEM.

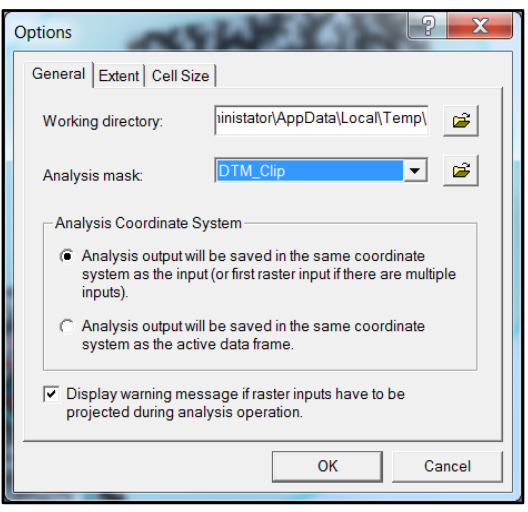

a

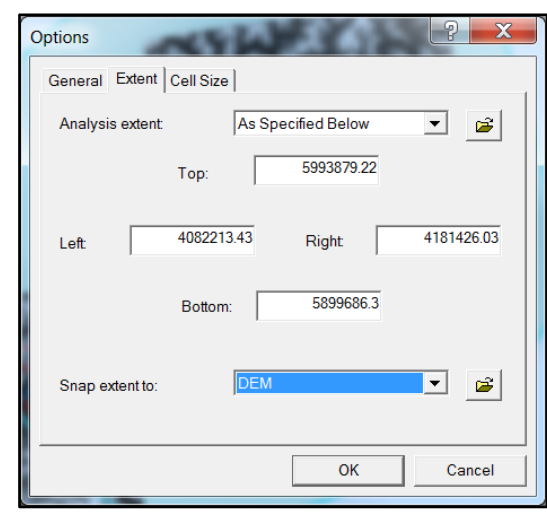

b

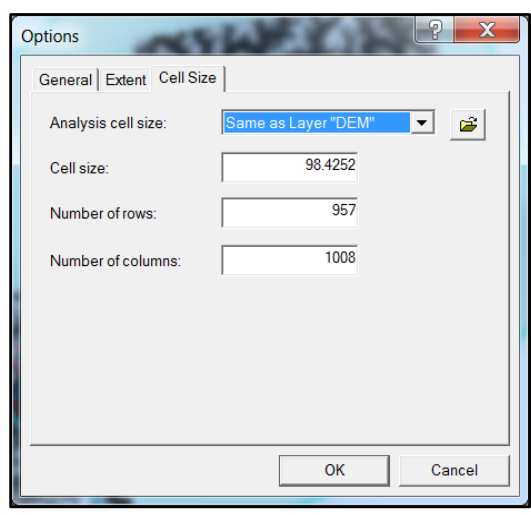

c

Figure 3: Set Analysis Extents 


\subsubsection{Generate First DTM}

After the analysis options of the shapefile are selected, the Raster Calculator Tool is used to create the DTM. Once created, the DTM appears as a layer in ArcMap. The layer is then saved using the Make Permanent Tool. Saving the layer ensures that in later steps HECGeoRAS can process the data through a proper file path and directory.

\subsubsection{Generate Other DTMs}

With the layer saved, the polygon drawn for the creation of the first DTM is deleted. Next, the Sketch Tool is used to draw the second polygon around the next DEM section, ensuring to overlap a portion of the first DTM and that the cross-sections are not intersected by the boundary. Figure 4 shows the second polygon drawn to overlap a portion of the clipped DTM without intersecting the cross-sections.

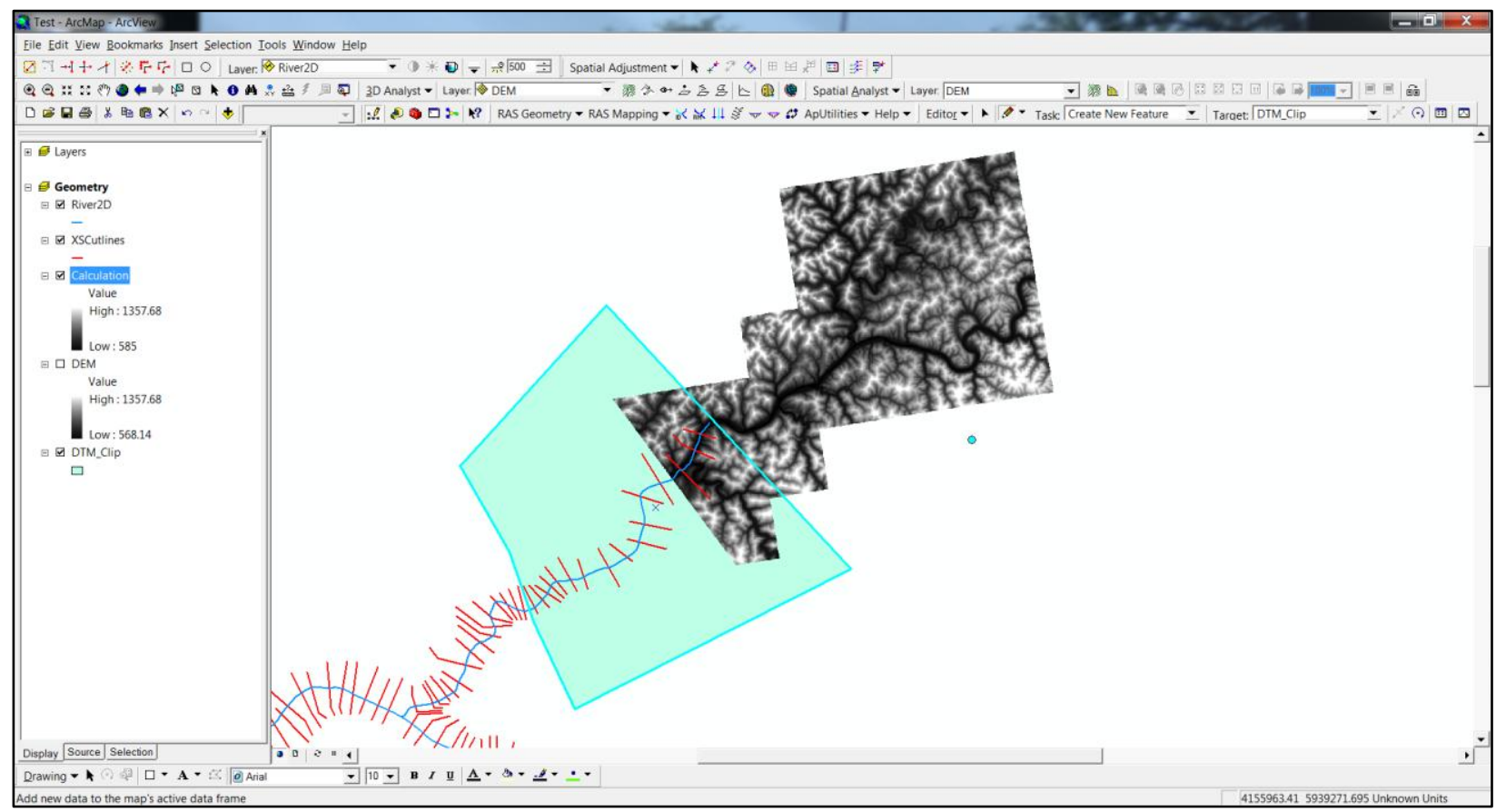

Figure 4: Draw Next Polygon

These steps are repeated for the rest of the DEM. For HEC-GeoRAS to process this data, the DTMs must have Triangulated Irregular Networks (TINs) created from contours. In order to 
create contours of a specified interval, the Contour Tool from Spatial Analyst is used. With the contours created, the TIN is then generated using the Create/Modify TIN category in the 3D Analyst Toolbar. In the Create TIN From Features dialog box, presented in Figure 5, the contours are assigned as the source for creating the TIN, and the file path for the generated TIN output is specified.

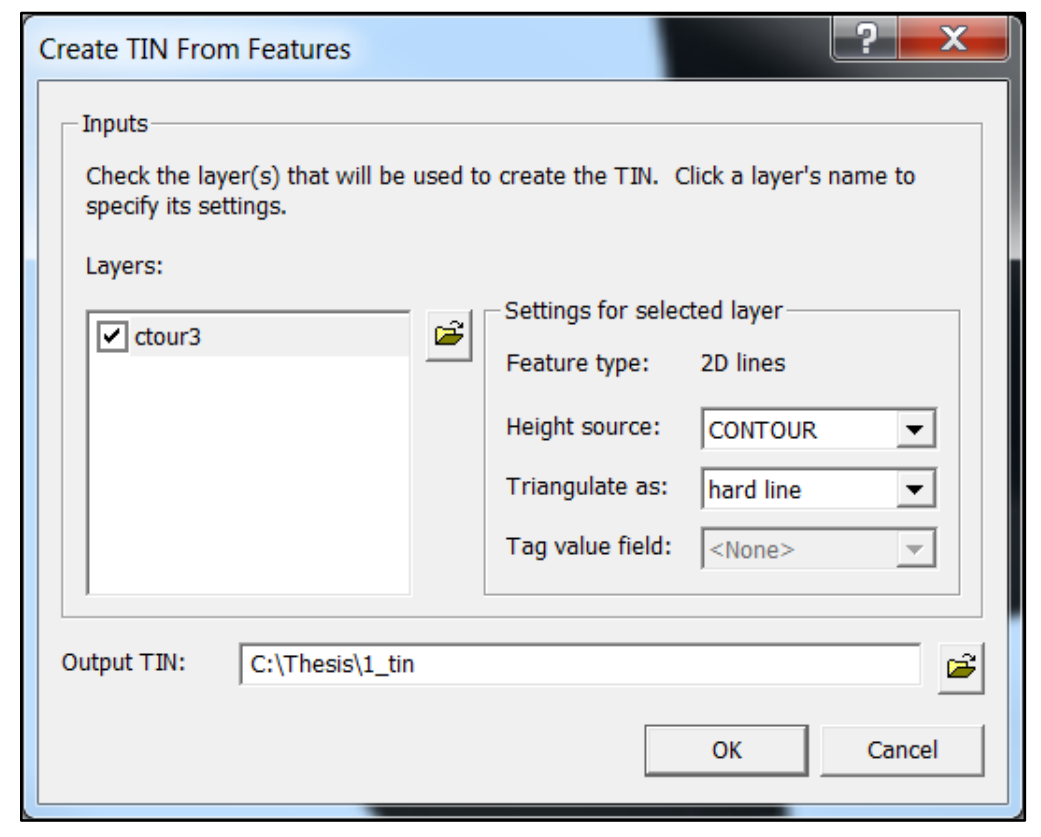

Figure 5: Generate TIN from Contours

These steps are repeated for each of the DTMs until a TIN has been generated for each. The TINs are then saved, and HEC-GeoRAS processing can begin.

\subsubsection{Create Geometry Map}

To produce an inundation from DTMs and TINs in ArcMap, the multiple terrain function of HEC-GeoRAS is used. The process starts when ArcMap is opened and saved. Next, the ApUtilities menu in HEC-GeoRAS is used to add a new map. This new map is given the name Geometry to denote that this map layer is used to set up the geometry for the analysis.

With the new map set up, the TINs that were created previously are added to the document. Although the addition of the TINs is not required by HEC-GeoRAS, this step is 
useful in guaranteeing that all the TINs overlap. Furthermore, the cross-section cut lines and river centerline are added to provide more data for the analysis to be performed.

\subsubsection{Generate Layer for Terrain Tiles}

Once this data has been added, the boundaries of the analysis are set using HEC-

GeoRAS. This step involves choosing the Terrain Tiles Tool from RAS Geometry. The Terrain Tiles Tool then generates a layer that is given the name of TerrainTiles.

\subsubsection{Draw Terrain Tile Polygon for First TIN}

After the Geometry map contains the newly created TerrainTiles layer, the Sketch Tool is used to draw polygons along the study area, and HEC-GeoRAS is used to process the data contained within the polygons. The process of creating terrain tiles is simplified by displaying one TIN at a time and drawing a polygon around the TIN and corresponding cross-sections, as demonstrated by Figure 6.

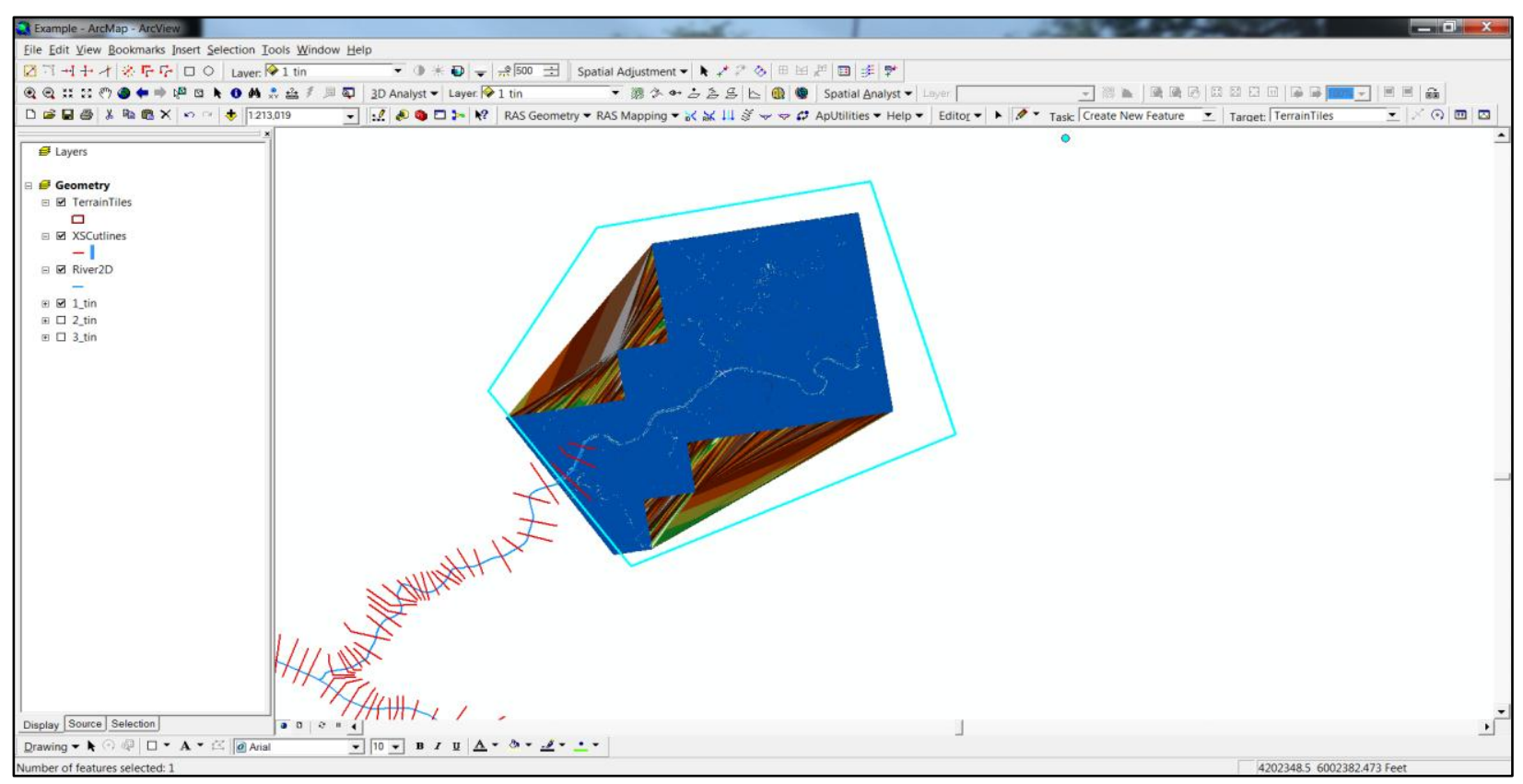

Figure 6: Draw Polygon for First TIN 


\subsubsection{Draw Terrain Tile Polygon for Second TIN}

With the first terrain tile drawn, the second TIN is turned on, while the first TIN is no longer displayed. Next, a check for a continuous analysis is implemented by confirming that the first polygon contains the lead edge of the second TIN. Once the check is performed, the Sketch Tool is then used to draw the second polygon, ensuring that the first polygon is overlapped.

Figure 7 represents the display after the second polygon is drawn.

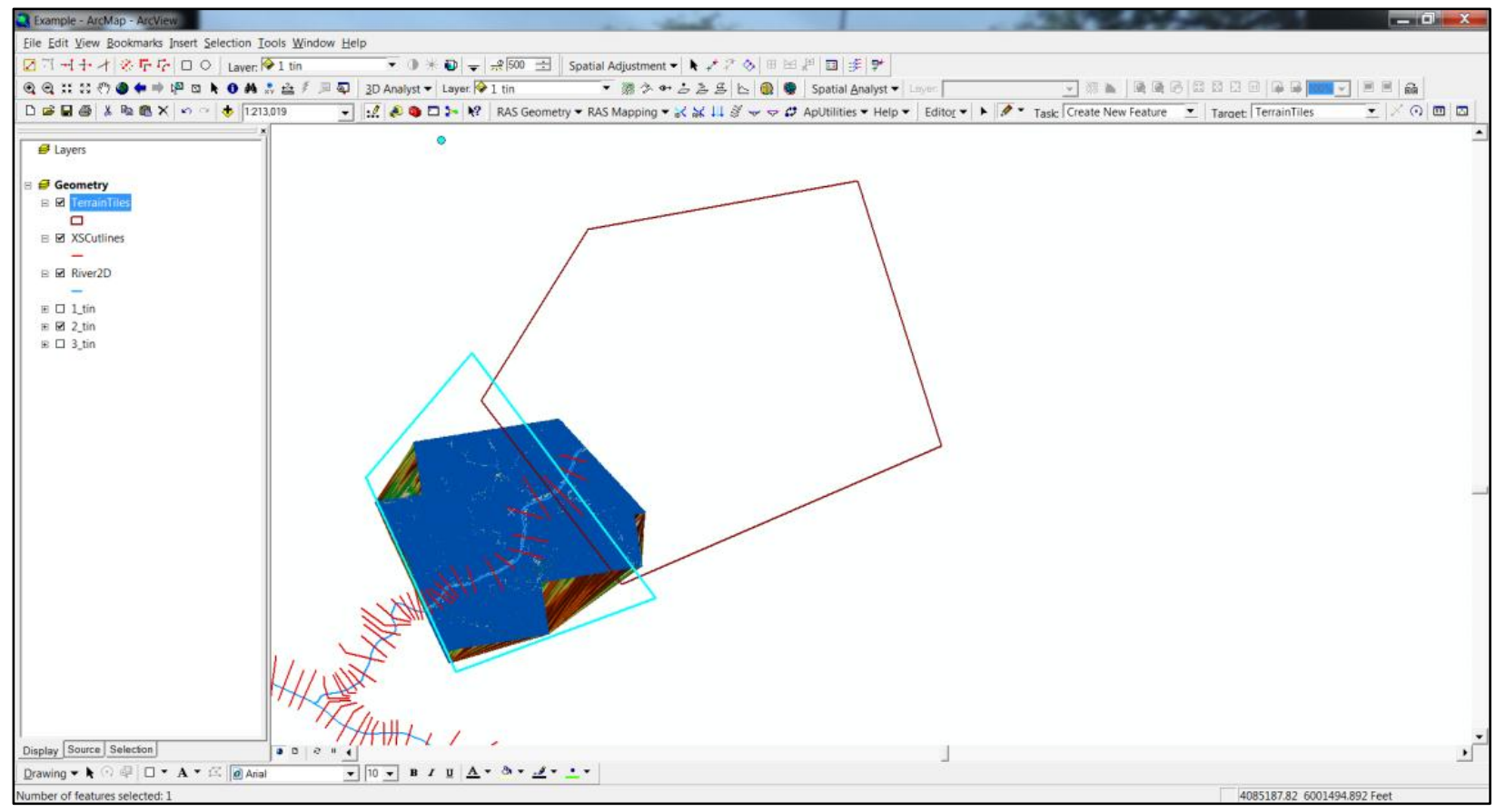

Figure 7: Draw Polygon for Second TIN

\subsubsection{Remove Overlap}

Once the second polygon is created, the overlap between the first and second polygons is removed. The Clip Tool from the Editor Toolbar is chosen to accomplish this task. To eliminate any gaps that may interfere with the analysis, zero is entered for the buffer distance inside the Clip dialog box, and the overlap area is discarded, as shown by Figure 8. 


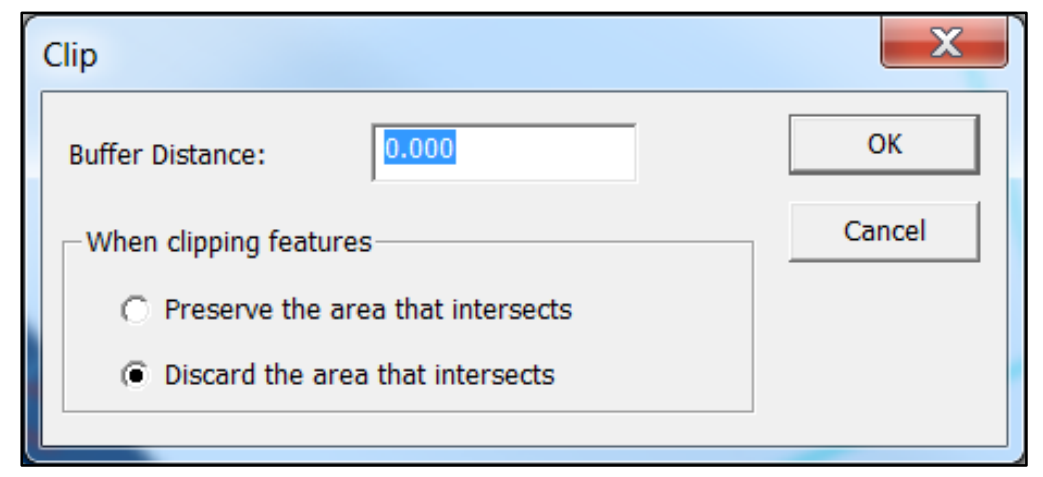

Figure 8: Clip Terrain Tiles

Once these features are specified and the dialog box is closed, the boundary of the second polygon is joined with the edge of the first polygon. This process is then followed for the remaining TINs.

\subsubsection{Complete Attribute Table}

Once the terrain tiles are drawn for the entire study area, the TerrainTiles layer is rightclicked in the Table of Contents, and the Attribute Table is opened. Within the TerrainTiles Attribute Table, three columns need to be populated with various data and file path information. To identify the terrain data as a TIN, a number one is placed in the TerrainType column for all the polygons. For file management purposes, the TileName column is populated with the names of the TINs that correspond with the specific polygons, allowing for HEC-GeoRAS to identify the specific TIN. Lastly, the file path is set for each polygon in the TileDirectory column, which allows HEC-GeoRAS to locate the TINs once the data processing begins. An example TerrainTiles Attribute Table that has been populated is shown in Figure 9. 


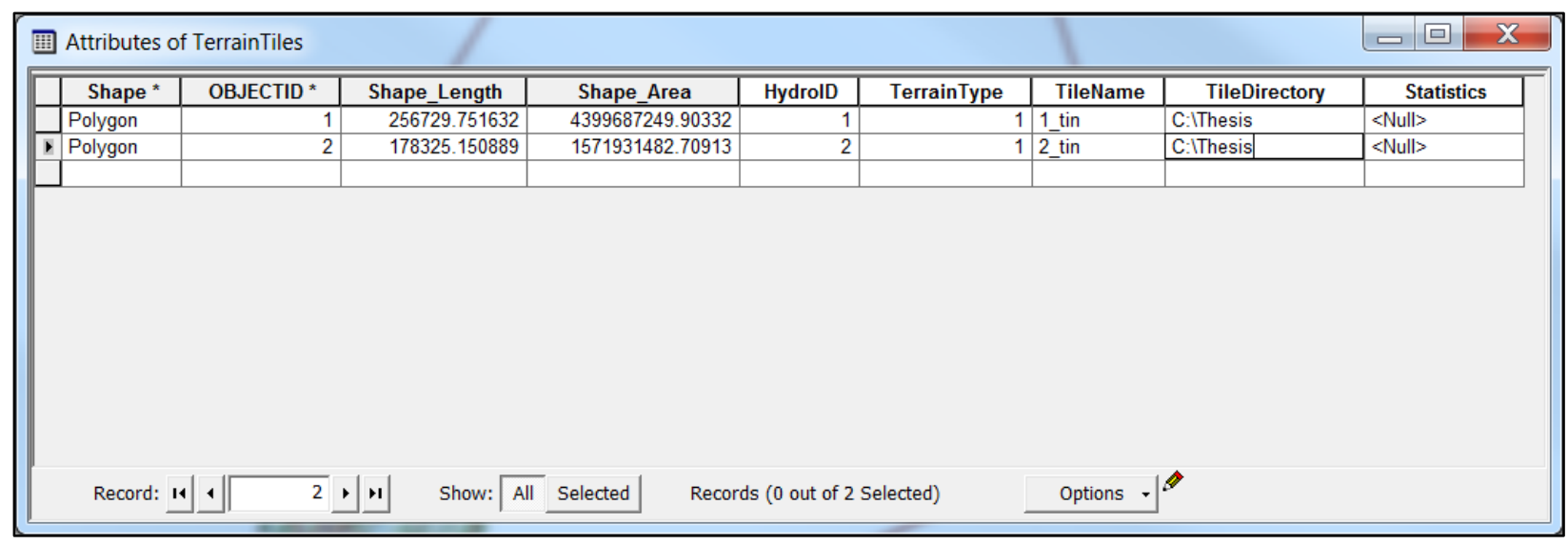

Figure 9: Completed Attribute Table

After the Attribute Table has been populated, a check is performed to confirm that the river cross-sections are contained within specific polygons and that the polygons have corresponding TINs. Next, the terrain tiles are digitized by choosing Stop Editing and saving the edits.

\subsubsection{Export GIS Data in HEC-RAS}

Once the terrain tiles have been created, the HEC-RAS data is needed to start the analysis. To import the HEC-RAS data into ArcMap, the dam failure scenario is simulated in HEC-RAS, and the scenario's output intervals are chosen. For this specific failure scenario, an output is created for every hour. Once the output data is created, the Export GIS Data function in the HEC-RAS File menu is chosen, displaying the options for exporting the data, as depicted in Figure 10. 


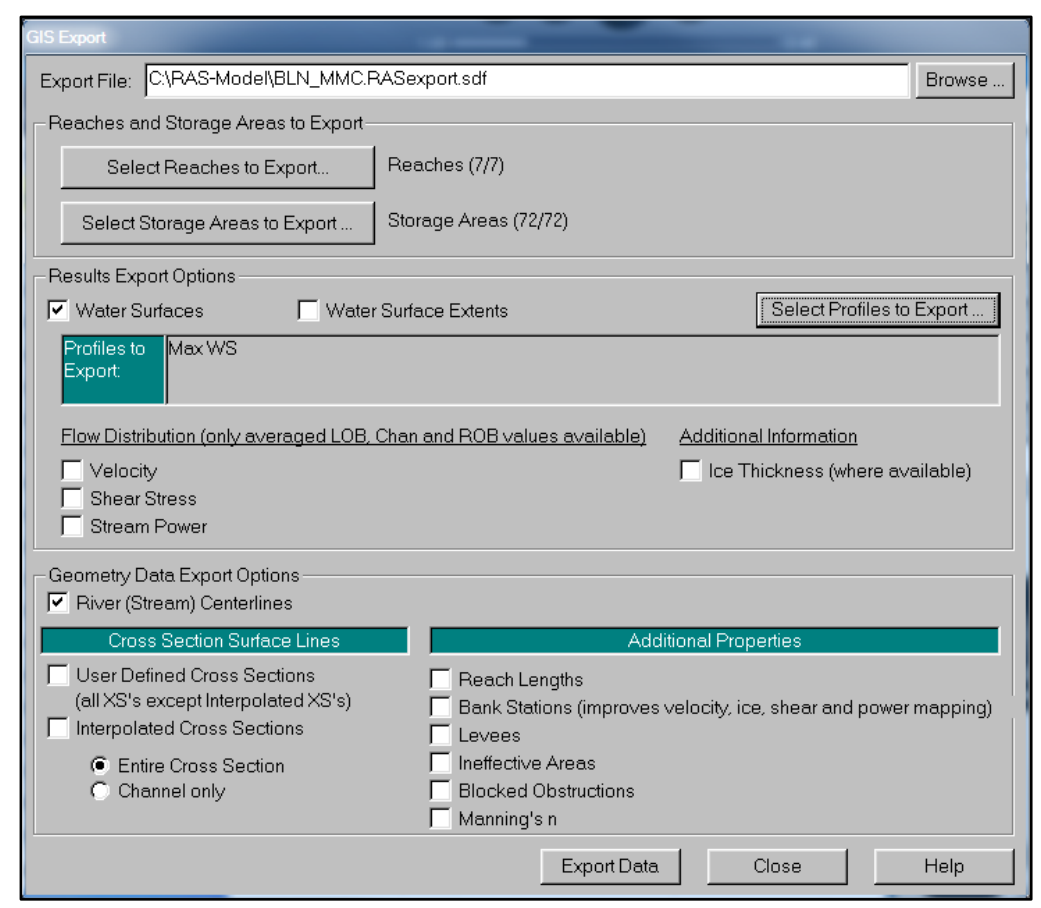

Figure 10: Export GIS Data

At the top of the dialog box, the export file is given a file destination. Next, the river reaches and storage areas are chosen using the Select Reaches to Export and Select Storage Areas to Export functions, respectively. The output profile to be exported is then chosen, and the data is exported to the file destination by selecting Export Data.

\subsubsection{Perform HEC-GeoRAS Layer Setup}

After the data is exported from HEC-RAS, the exported file needs to be converted to a file format that is compatible with HEC-GeoRAS. This step is completed by opening the ArcMap file that contains the terrain tiles and choosing the Import RAS SDF File Tool. The exported data is then converted to an XML file format. With the data file converted, the analysis layer is set up by choosing Layer Setup from the RAS Mapping menu; the resulting dialog box is illustrated in Figure 11. 


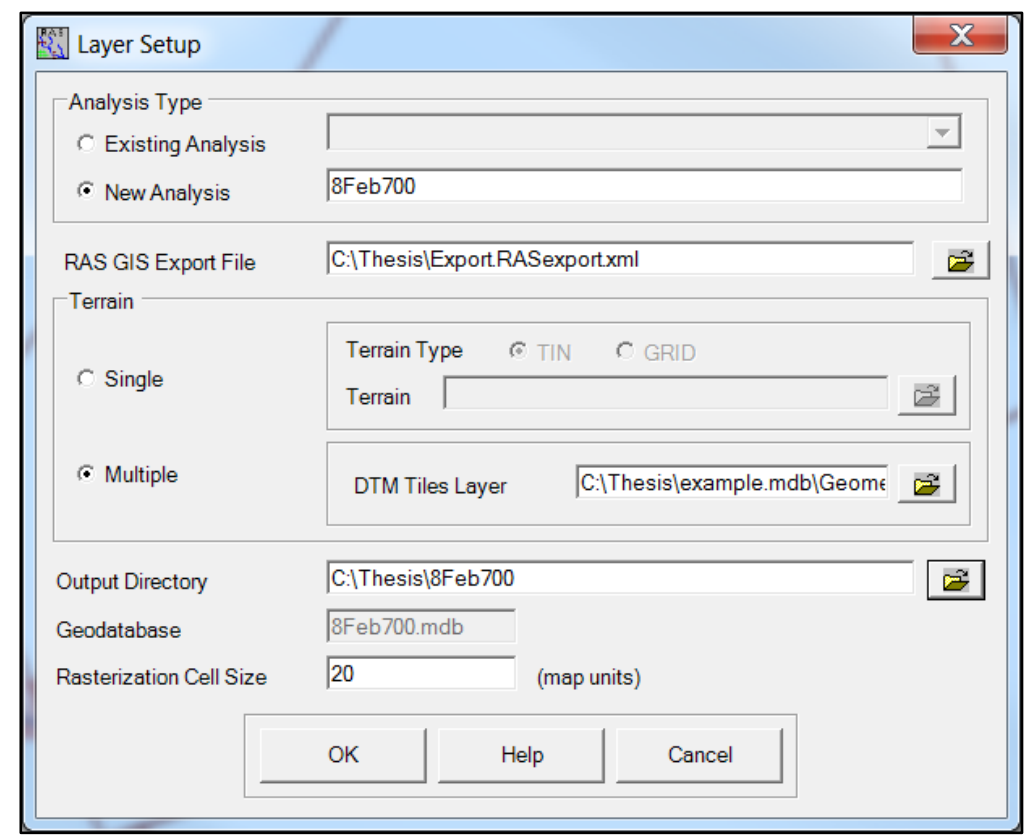

Figure 11: Analysis Setup

In the Layer Setup dialog box, the analysis type is determined to be either a new or existing analysis. In this research effort, the analysis type is a new analysis, and an arbitrary name is assigned to the analysis. Next, the RAS GIS Export File is chosen to be the XML file created in the previous step. Since there are multiple terrain tiles for the analysis, the terrain data is set to the Multiple option, and the DTM Tiles Layer is set to the location of the TerrainTiles dataset. Lastly, an Output Directory is given for the data produced during the analysis, and OK is selected to complete the Layer Setup.

\subsubsection{Generate Inundation}

After the layer is set up, the next step is to import the HEC-RAS data into ArcMap. Using the RAS Mapping dropdown, Import RAS Data is chosen, opening the dialogue box which contains importing options. In this dialog box, either a New or Classic (Personal) Geodatabase can be specified to import the HEC-RAS data. For this application, the Classic Geodatabase option is chosen for a faster importing time. Next, OK is selected, and the HECRAS data is visualized in ArcMap. With the bounding polygon, cross-sections, river centerlines, 
and storage areas displayed, a Water Surface TIN is created from these features. To accomplish this task, Inundation Mapping is selected from the RAS Mapping menu to open the Water Surface Generation dialog box. In the Water Surface Generation dialog box, the profile of the water surface imported from HEC-RAS is selected, and the options pertaining to the layer's output are all chosen with the exception of Merge Floodplain Features, as this option merges the output into a single entity. Selecting OK creates the Water Surface TIN for the profile. After the TIN is generated, the inundation is then created. This step is accomplished by choosing Inundation Mapping under RAS Mapping and selecting the Floodplain Delineation Using Rasters Tool. In the resulting dialog box, illustrated by Figure 12, the water surface profile for the analysis is chosen, and Merge Floodplain Features is left unchecked; OK is selected to generate the inundation.

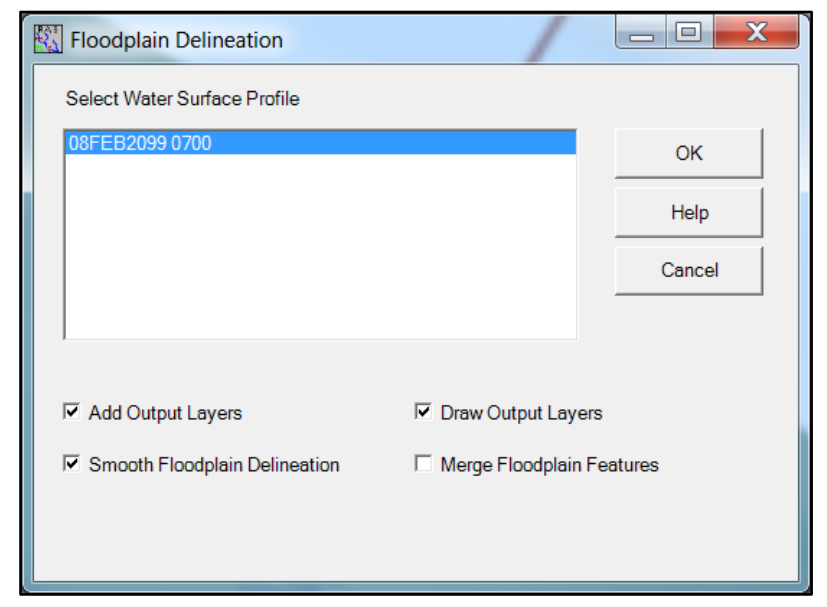

Figure 12: Begin Floodplain Analysis

\subsubsection{Review Generated Output}

Two separate inundations are created when the HEC-GeoRAS analysis has been completed. The first inundation, shown in Figure 13, represents the flood extents with a solid-fill polygon. The second inundation, displayed in Figure 14, shows a higher level of detail into the depths of the flood waters by the use of darker variations of the same color. 


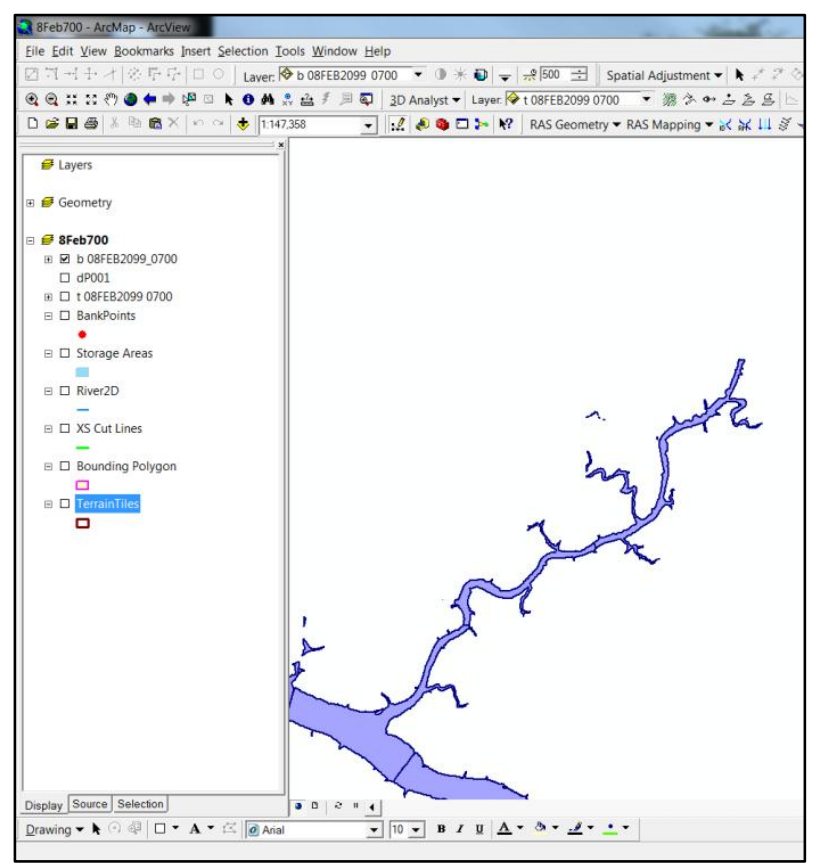

Figure 13: Flood Extents

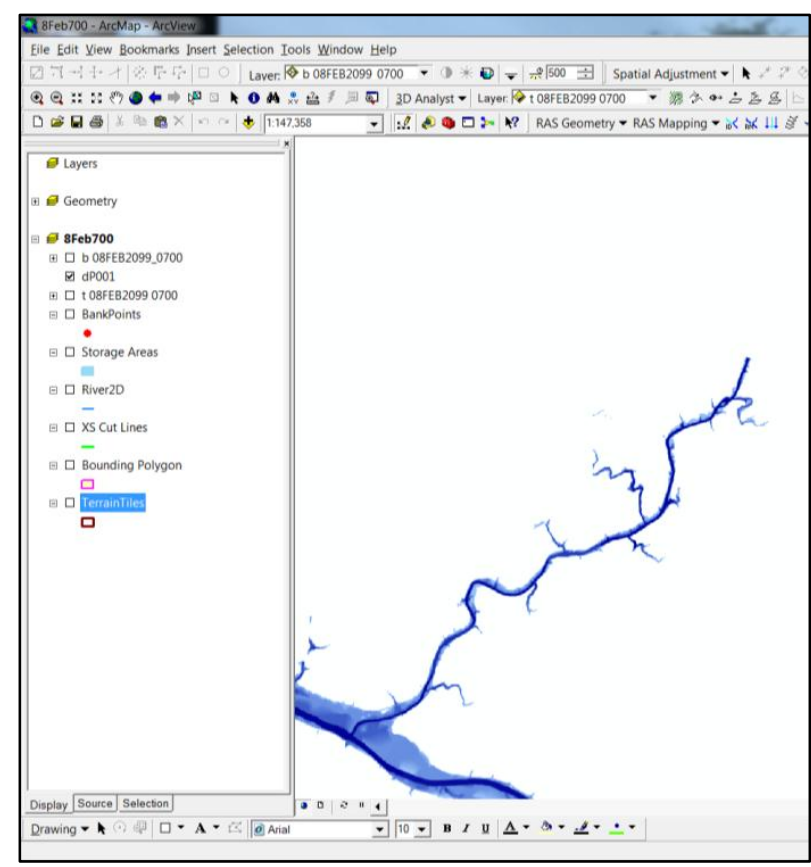

Figure 14: Water Depths

For this research, HEC-GeoRAS was used to create the inundation encompassing the river network for each time step of the analysis. The processing time for each time step ranged from 18 to 48 hours depending on the amount of data. The file sizes for the inundation were between 170 and 200 gigabytes, with an average size of 190 gigabytes. Once the inundation is generated for the study area, the process of creating paper or virtual inundation maps begins.

\subsection{Paper Inundation Mapping Using ArcGIS}

The tools in ArcGIS Desktop are used to create paper inundation maps based on the inundation polygon. In this procedure, background imagery is used to provide a spatial reference for the inundation and to facilitate the analysis of the flood's impacts. The steps for the creation of paper inundation maps are outlined in the following sections. 


\subsubsection{Merge Individual DEMs}

In order to provide a context for the inundation extents, the inundation polygon is overlain on either aerial photography or contours. Due to the additional insight into water depths provided by topography, contours are used for the background of the inundation maps in this research. To facilitate the creation of contours over the entire study area, the individual DEMs are first merged together. Thus, the DEMs are added into ArcMap using the Add Data function, and ArcToolbox is expanded to reveal the Data Management Tools category. In this category, the tool Mosaic to New Raster is chosen, and the individual DEMs are selected in the dialog box. Also, Entire Study Area is input as the name of the resulting file, and the output location is specified. Once the Entire Study Area DEM is created, the file is added into the ArcMap document. The individual DEMs are no longer needed, and are removed from the document.

\subsubsection{Generate Contours from Merged DEM}

Once the terrain data for the entire study area is contained within a single DEM, contours are then generated based on this DEM. To shorten the processing time, the analysis environment is first specified. In ArcMap, Options is selected from the Tools dropdown menu, and the Geoprocessing tab is chosen in the dialog box, as shown in Figure 15. 


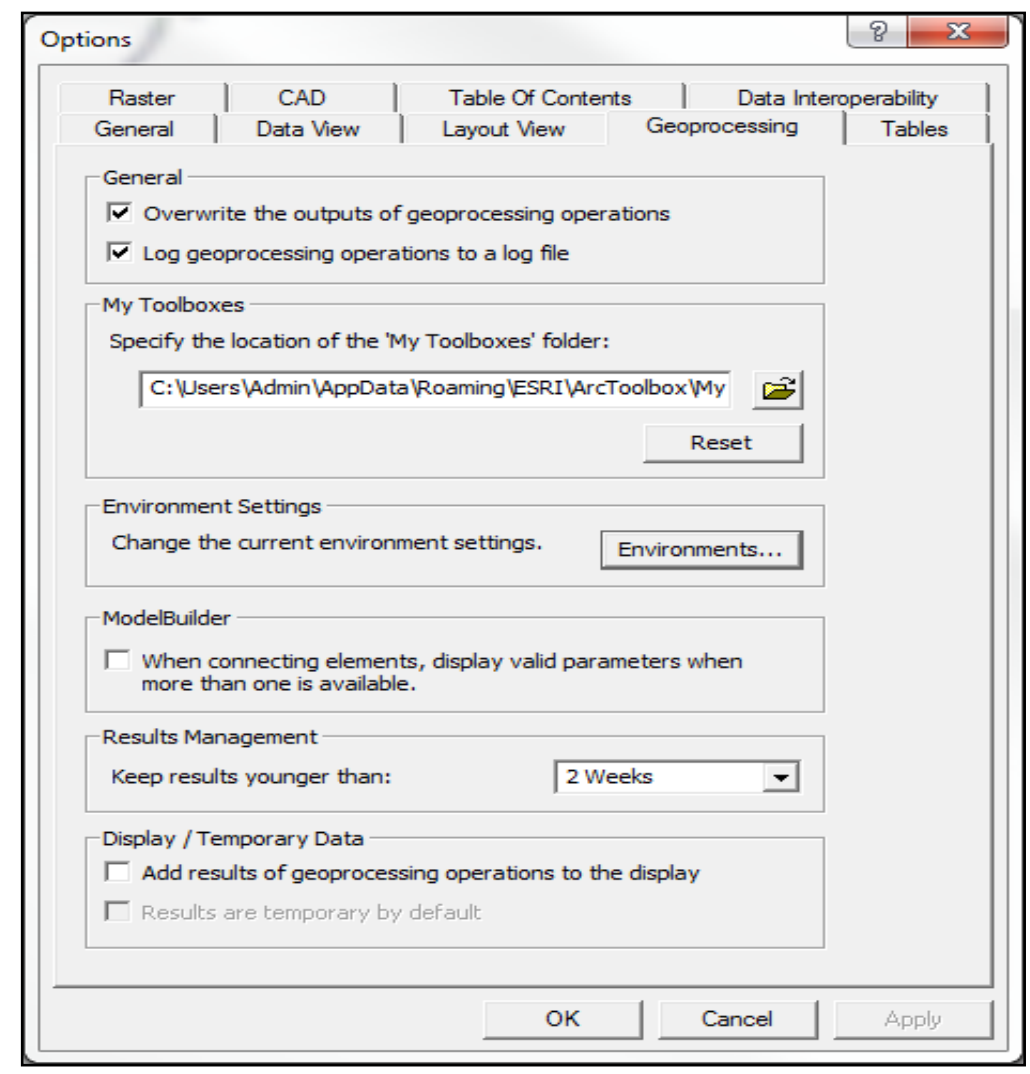

Figure 15: Geoprocessing Options

In the Environment Settings category, Environments is selected, opening the dialog box where the ArcMap workspaces are contained. Under General Settings, the Current Workspace and the Scratch Workspace are specified as the full path to the folder where the Entire Study Area DEM is located, as illustrated in Figure 16.

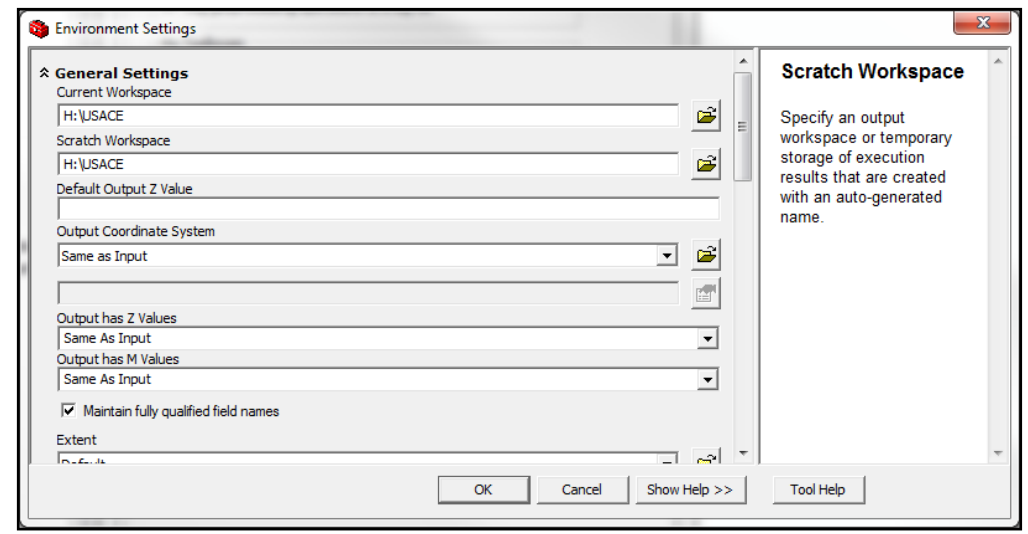

Figure 16: Set Workspaces 
Once the workspaces are selected, the contours are generated. Using the Spatial Analyst dropdown menu, Contours is chosen from the Surface Analysis category. Figure 17 depicts the Contour dialog box, where the Input surface is defined as the Entire Study Area DEM and the interval for the contours is chosen. For this research, a Contour interval of 50 feet is used for the effective display of contours at the scale of the inundation maps. Furthermore, the output directory is specified as the folder where the Entire Study Area DEM is located. Selecting OK generates the contours in the ArcMap document, overlain on the Entire Study Area DEM.

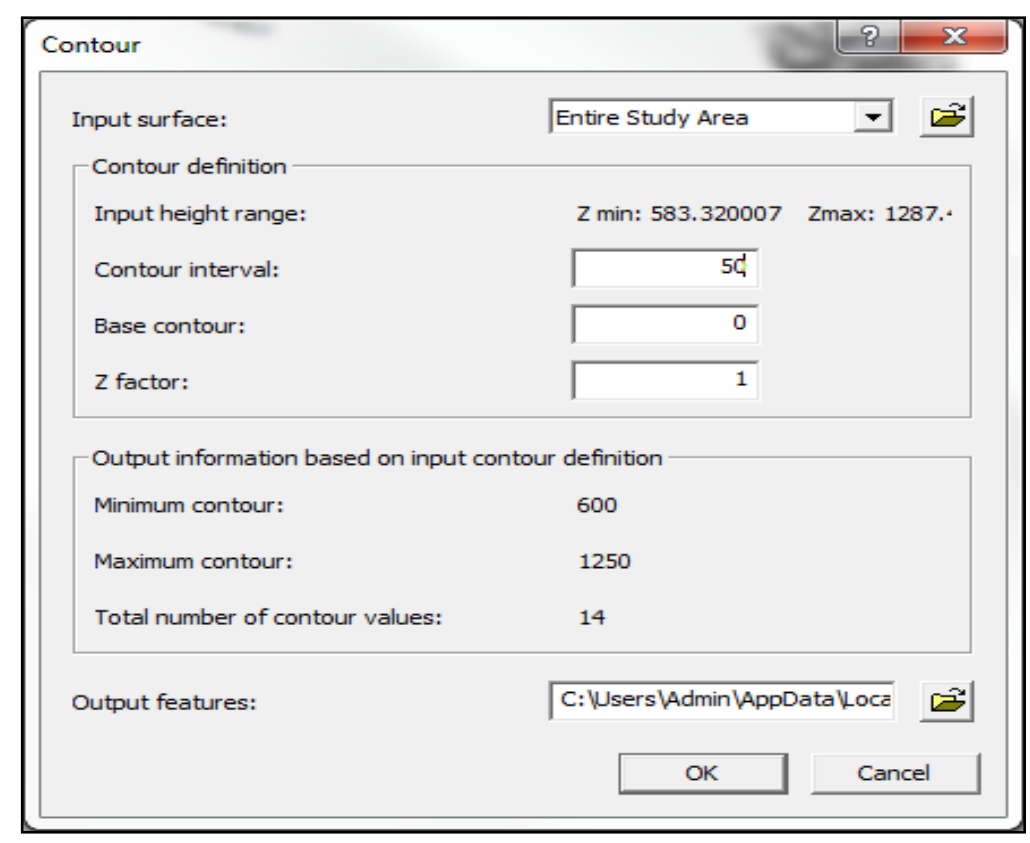

Figure 17: Generate Contours

\subsubsection{Add Analysis Layers}

Since the contours provide the necessary elevation data, the Entire Study Area DEM is removed from the ArcMap document. In order to provide further details on the impacts of the inundation, transportation routes, critical infrastructure, and cities are added to the document using the Add Data function. For this research, the transportation routes selected for inclusion in the maps are interstates, US routes, state routes, and minor roads such as county routes. The data 
contained within the road, infrastructure, and cities layers extends beyond the scope of the study area. Therefore, these layers are clipped to eliminate extraneous data.

\subsubsection{Create Boundary Shapefile}

In order to clip these layers, a polygon shapefile is created in ArcCatalog. After selecting the folder where the new shapefile is saved, the New menu is chosen from the File dropdown, and Shapefile is selected. In the dialog box, Boundary is entered as the name for the shapefile, and polygon is chosen as the Feature Type. Also, the coordinate system for the shapefile is selected to be consistent with the other files composing the maps by choosing Edit. In the Spatial Reference Properties dialog box, Import is used to select the coordinate system and projection of the Entire Study Area DEM. Once the shapefile is created, ArcCatalog is closed, and the process continues in ArcMap.

\subsubsection{Draw Analysis Boundary}

The Boundary shapefile is added into the ArcMap document using the Add Data function, and the Editor Toolbar is used to clip the layers. Start Editing is chosen from the Editor dropdown, and in the dialog box, the Boundary shapefile is specified as the Target layer. Using the Sketch Tool, a polygon is drawn around the outer edge of the Entire Study Area DEM. Since the purpose of clipping the layers is to limit the data to the study area, the polygon is drawn as

close to the edge of the DEM as possible. Figure 18 demonstrates this procedure by depicting the extents of the transportation routes, drawn in the colors found in the Table of Contents, in relation to the Entire Study Area DEM and boundary polygon, shown in light blue. 


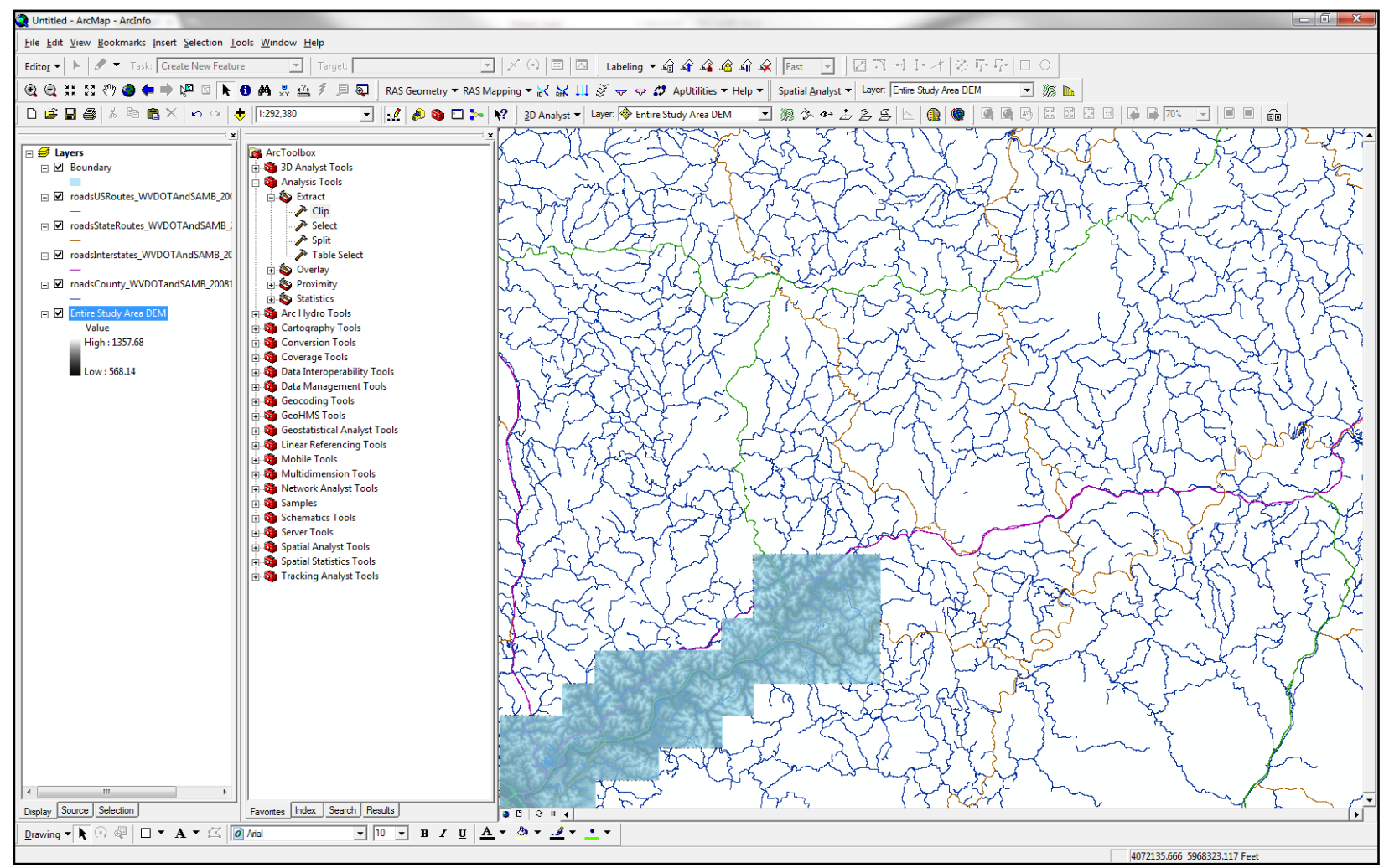

Figure 18: DEM Boundary with Transportation Routes

\subsubsection{Clip Analysis Layers}

After sketching the boundary polygon, the next step is to save the polygon for use in the clipping process. Thus, the Editor dropdown menu is used to select Save Edits, and ArcToolbox is opened. Under the Analysis Tools category in ArcToolbox, the Extract category is expanded, revealing the Clip Tool. This tool is used to clip each of the individual layers to the extents of the boundary polygon. Figure 19 demonstrates the clipping process for the US routes. The Input Features are specified as the US routes layer, while the Boundary shapefile is selected as the Clip Features. After choosing the output location and providing a name for the file in Output Feature Class, selecting OK creates a layer containing the clipped US routes. 


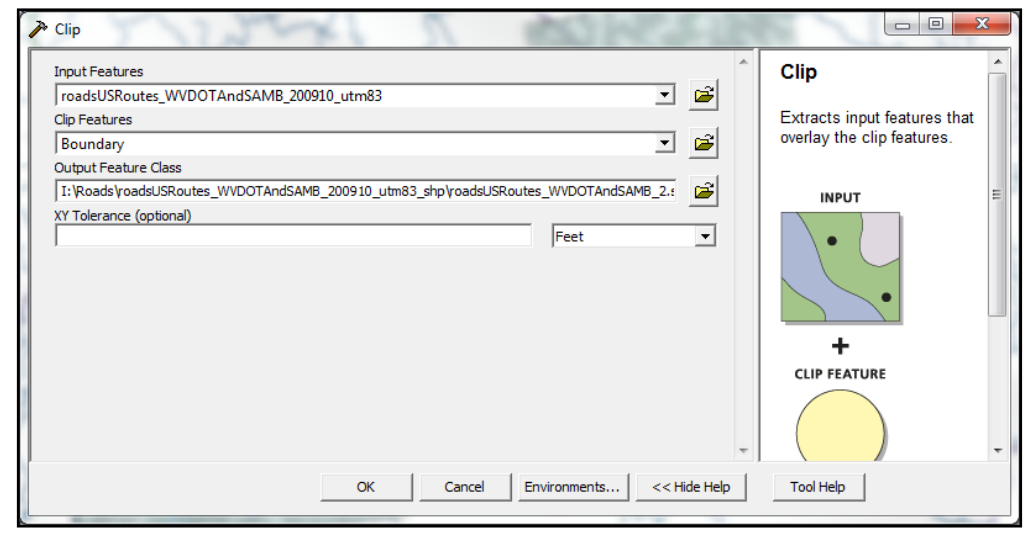

Figure 19: Clip Layers

This process is repeated to clip the remaining road layers, as well as the critical infrastructure and cities layers. Once the desired layers are clipped, the original layers and the Boundary shapefile are removed from the ArcMap document, and the clipped layers are added using the Add Data function.

\subsubsection{Label and Assign Symbology to Analysis Layers}

To enhance the display of the cities, transportation routes, and critical infrastructure, appropriate labels and symbols are assigned. To customize the appearance of the labels for the cities layer, the layer is double-clicked in the Table of Contents. Figure 20 shows the Layer Properties dialog box, where the Labels tab is used to set the properties for the labels, such as the font and size. For this research, Times New Roman is used as the font for the labels, with a font size of 20. 


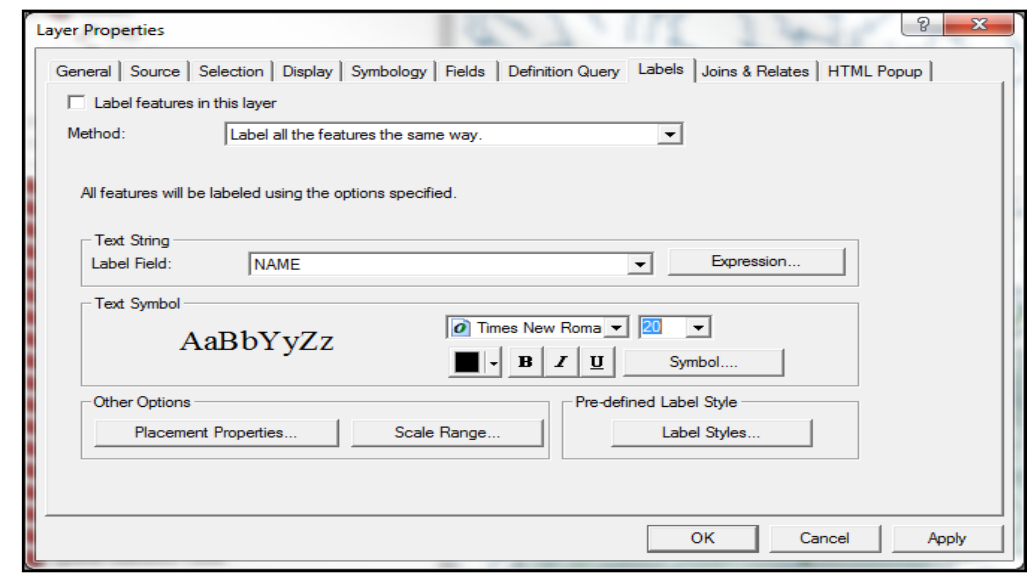

Figure 20: Set Label Properties

In order to ensure that the labels are visible when overlain on the background imagery, a mask is added. Under the Labels tab, Symbol is chosen, and in the resulting dialog box, Properties is selected. In the Properties dialog box, the Mask tab is selected, as shown in Figure 21. In order to include a mask with the labels, the Halo option is specified, along with the size of the mask. For this application, a size of 6 is used for the mask.

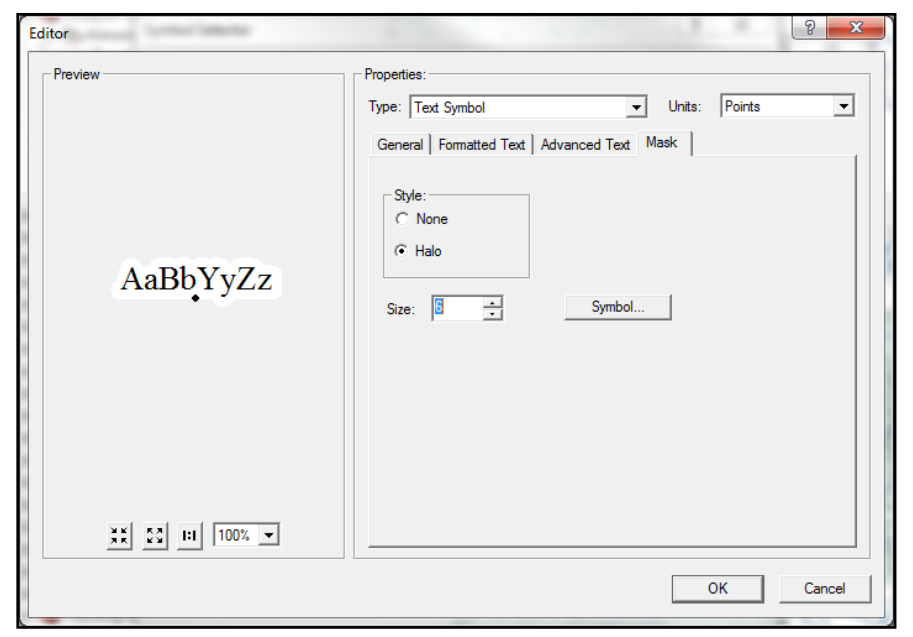

Figure 21: Specify Label Mask

Once the properties for the labels are set, the labels are displayed on the map by choosing Label Features from the menu that appears after the cities layer is right-clicked in the Table of Contents. This procedure is repeated to place labels on the transportation routes. For this research, the interstates, US routes, and state routes are labeled in Times New Roman, with a 
font size of 8 and a mask of size 2. Since the default placement of the labels may overlap critical information, the labels are converted to annotation to allow for the labels to be moved manually with the Select Elements Tool. This step is accomplished by right-clicking the desired layer in the Table of Contents and choosing Convert Labels to Annotation from the menu.

Due to the high concentration of critical infrastructure in the study area, the labels for the individual structures are not activated; instead, appropriate symbols are assigned to each critical infrastructure category to facilitate emergency response planning. For each category, the symbol is changed from a point to an icon consistent with the facilities in the category. In the Table of Contents, the point symbol for a critical infrastructure category is double-clicked. Figure 22 shows the Symbol Selector dialog box, where More Symbols is used to choose an appropriate icon from a collection of symbols common to a variety of industries. This process is repeated for the remaining critical infrastructure categories.

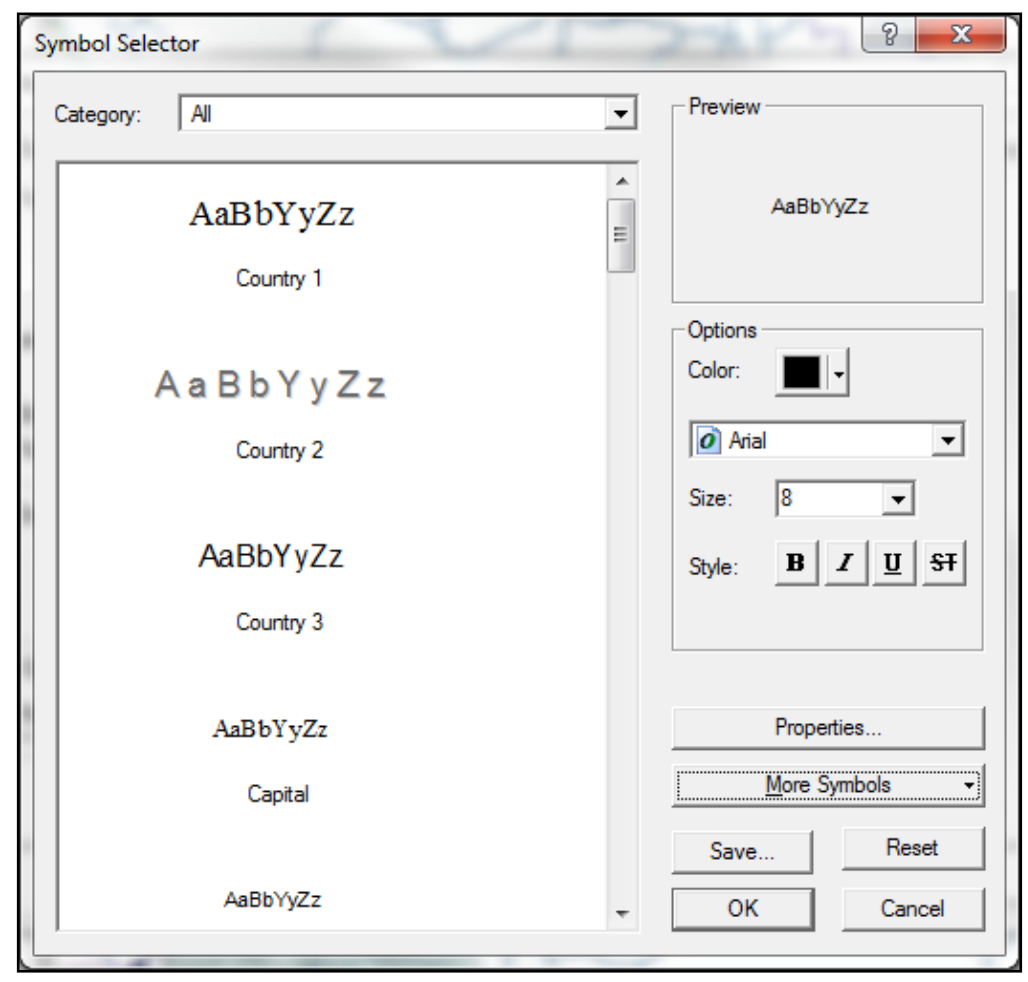

Figure 22: Assign Symbology 


\subsubsection{Draw Map Areas}

The scope of study area in this research does not allow for a sufficient level of detail to be displayed when the entire inundation is shown on a single map; thus, map areas with dimensions of 6-miles by 8-miles are used to map segments of the inundation. In order to create the map areas, a polygon shapefile is created in ArcCatalog following the same procedure associated with the Boundary shapefile. After creating the MapAreas shapefile, the shapefile is added into ArcMap using the Add Data function. The Editor Toolbar is used to select Start Editing, with the MapAreas shapefile as the Target layer. Using the Sketch Tool, a rectangle with a height of six miles and a length of eight miles is drawn, and the dimensions are verified by the Measure Tool, found in the Tools Toolbar. Figure 23 shows one map area of the inundation, specified by the 6-mile by 8-mile rectangle. After creating the map area, Save Edits in the Editor dropdown is chosen to save the map area.

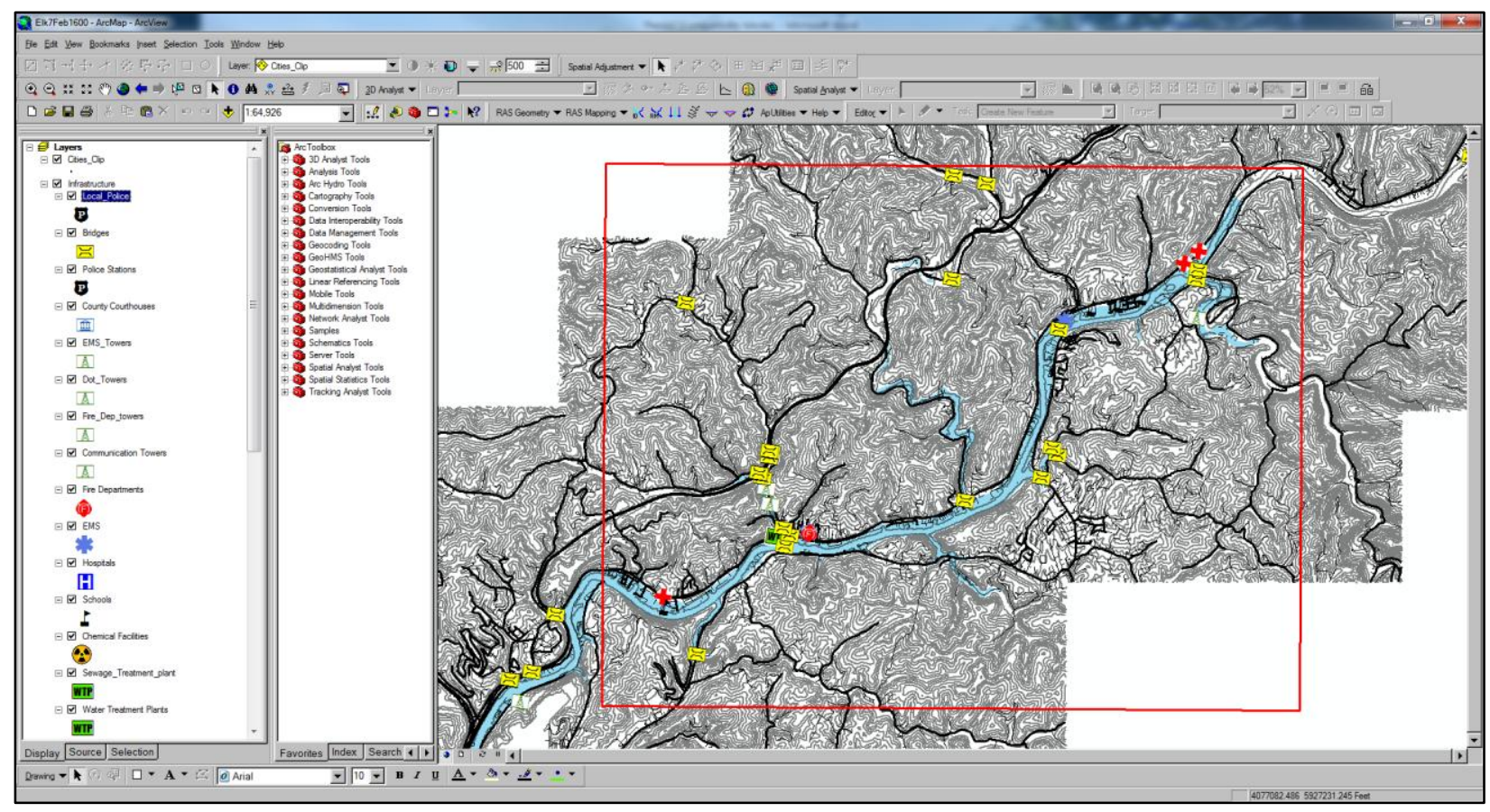

Figure 23: Sample Map Area 
Since the study area requires multiple map areas, the rectangle is selected and copied using the $\mathrm{Ctrl} \mathrm{C}$ keyboard command. Copies are then pasted into the ArcMap document with the Ctrl V keyboard command. Using the Select Elements Tool, the map areas are selected and moved to proper locations along the river. For this research, 23 map areas are needed to encompass the entire study area. Once the map areas are created and placed, Save Edits is chosen from the Editor dropdown, followed by Stop Editing.

\subsubsection{Choose Representative Cross-Sections}

To provide a visualization of the water surface elevation in relation to the channel profile, a representative cross-section is selected for each map area. The XS Cutlines layer is added into the ArcMap document using the Add Data function, and the symbol size is changed to zero to allow for only the representative cross-sections to be viewed. In the Table of Contents, the XS Cutlines layer is right-clicked, and Open Attribute Table is selected from the menu. Figure 24 shows the Attribute Table, where the representative cross-section is selected and displayed on the map by clicking the gray box to the left of the Shape category. For this research, representative cross-sections are selected based on the proximity to the center of the map area and the lack of overlap with critical infrastructure.

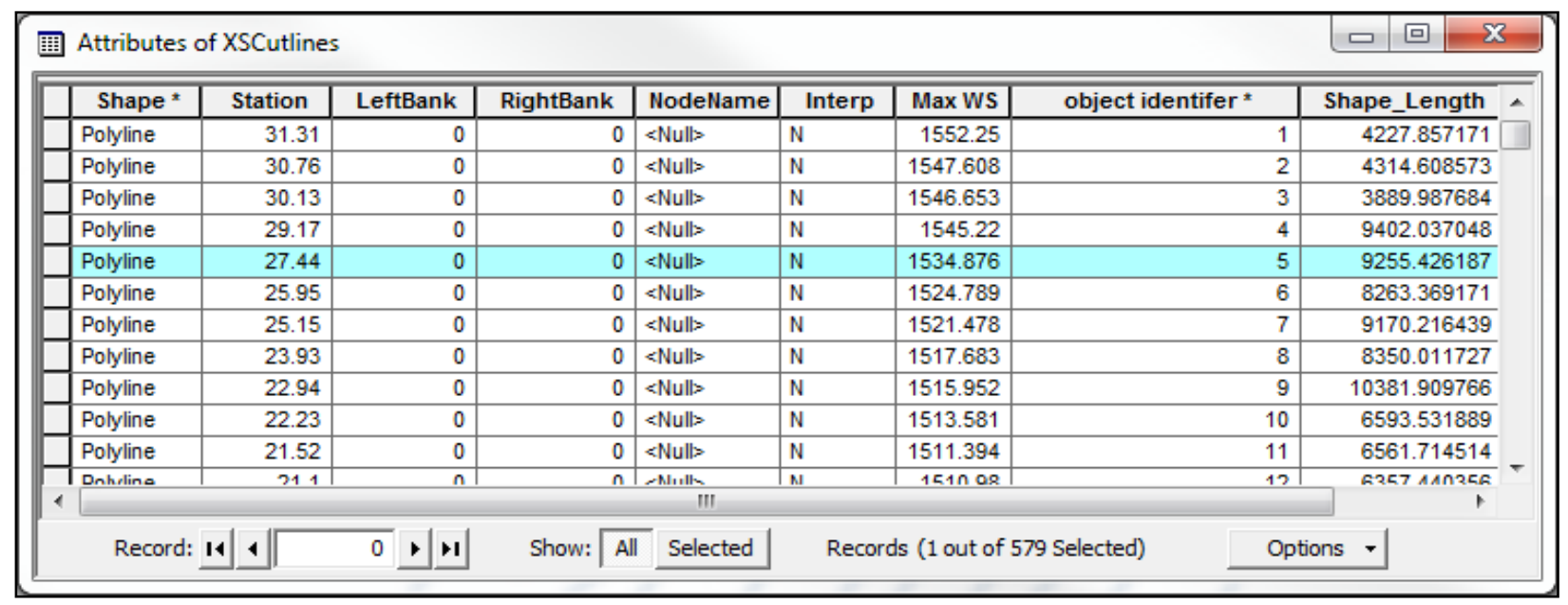

Figure 24: Select Representative Cross-Section 
Once the representative cross-sections are selected, HEC-RAS is used to create plots of the cross-section profiles with the water levels in the river channels. After opening the dam failure simulation in HEC-RAS, Cross-Sections is chosen from the View dropdown. To specify the profile for the desired representative cross-section, the station number, river, and reach are selected in the dialog box. The Play function illustrates the water level rise and fall in the channel throughout the simulation; thus, this tool is used to display the water elevation at a specific time, since the water level in the channel needs to be consistent with the inundation shown in the map. Once the desired time period is chosen, a screenshot of the profile is taken, and Paint is used to crop the image, as illustrated in Figure 25. After cropping, the image file is saved for import into the inundation map.

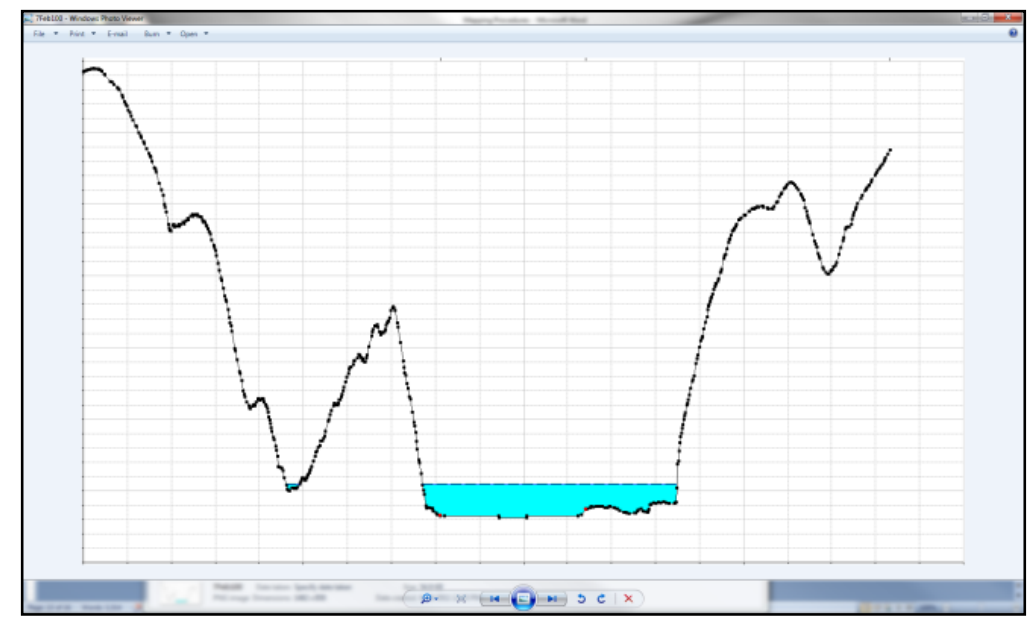

Figure 25: Create Profile

\subsubsection{Select Built-In Map Template}

In order to create inundation maps based on the map areas, the ArcMap environment is changed to Layout View by clicking the icon in the lower left-hand corner. Once in Layout View, the map is organized by choosing a template. Change Layout is selected, opening the Select Template dialog box. This dialog box contains several built-in map templates, and for this research, LandscapeModernInset is used, as shown in Figure 26. 


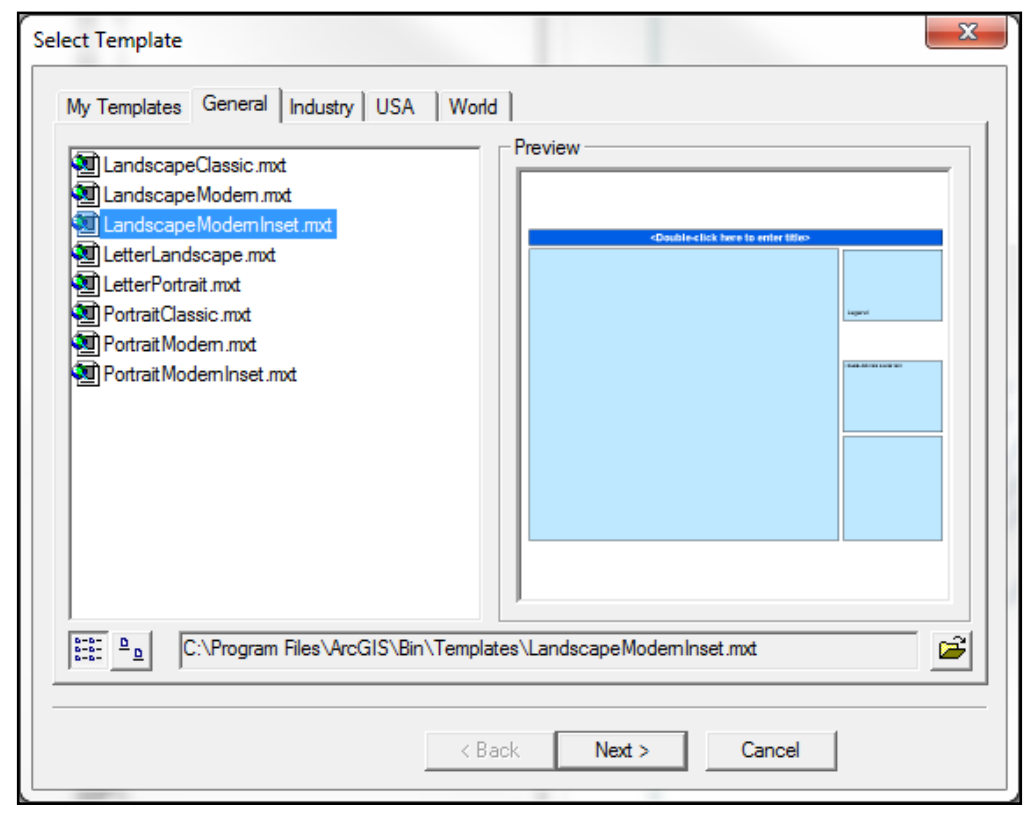

Figure 26: Choose Map Template

Once the template is selected, the page size for the inundation maps is specified by choosing Page and Print Setup under the File dropdown. In the dialog box, the page size is selected, and the orientation for the maps is specified. Since these properties differ from the default setup, Scale Map Elements proportionally to changes in Page Size is selected to ensure that distortion of the data layers does not occur.

\subsubsection{Customize Map Template}

Since the template contains preset data frames, the template is modified in order to suit the format for the inundation maps. ArcMap displays page rulers along the top and left-hand side of the layout, and by clicking on the rulers, guides are placed that allow the extents of the data frames to be aligned. Because the study area contains multiple map areas, another data frame is placed in the map to show the location of the current map area in relation to the entire study area. Since Layout View is used solely for the creation of the maps, the data frame must first be created in Data View. Once in Data View, the Insert dropdown is used to select Data Frame, which inserts a new data frame into the ArcMap document. After double-clicking on the 
new data frame, Entire is entered as the name for the data frame, and the Add Data function is used to add the MapAreas, inundation polygon, and Unites States counties layers. To differentiate between the map areas, each map area is assigned a number. For this application, the map areas are numbered from 1 to 23 , starting with the map area containing the dam and progressing downstream. After switching back to Layout View, the Entire data frame is displayed in the minor data frame on the map, and the template is saved.

\subsubsection{Set Up Main Data Frame}

Once the minor data frame is set up as a spatial reference for the map, the main data frame is modified for the proper display of the inundation. When working in Data View, the display of data is consistent with the page instead of the coordinate system. However, Layout View references the coordinate system when displaying data, which causes the map areas created in Data View to be skewed in relation to the data frame. Thus, the map areas are aligned with the data frame by modifying the display properties of the data frame. In Layout View, the main data frame is selected and right-clicked upon, and Properties is chosen from the Options dropdown. In Data Frame Properties, shown in Figure 27, the General tab is used to specify the Rotation for the data frame. For this research, a Rotation of -9.1 is used to align the map areas with the data frame. 


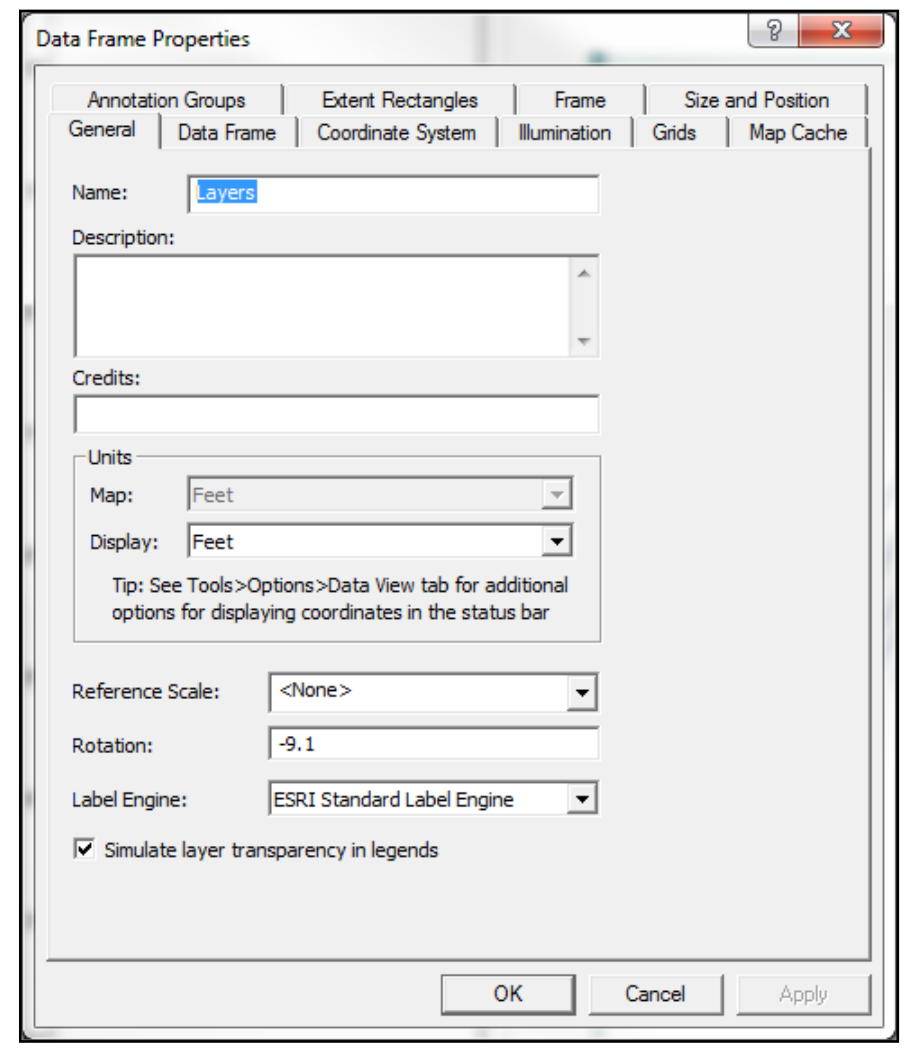

Figure 27: Properties for Main Data Frame

\subsubsection{Arrange Main and Minor Data Frames}

After the rotation for the data frame is set, the first map area is displayed by aligning the rectangle's sides with the data frame boundary. The scale is also specified to ensure that the entire map area is displayed in the data frame. Since the MapAreas rectangles may interfere with the display of information, the layer is turned off once the placement of the map area is complete. To show the location of the map area in the minor data frame, the Entire data frame is right-clicked in the Table of Contents, and Activate is chosen. In order to highlight the current map area, the Attribute Table for the MapAreas layer is opened, and the gray box to the left of the first map area is selected. By highlighting the map area, the minor data frame displays the location of the river segment in the main data frame in relation to the entire river. 


\subsubsection{Add Essential Map Components}

In addition to the two data frames, the inundation maps are further customized by inserting legends, titles, and other map elements. In order to communicate the symbols used in the map, a legend is created for the critical infrastructure. Using the Insert dropdown, Legend is selected, opening the dialog box displayed in Figure 28. In the dialog box, the critical infrastructure layers to be included in the legend are moved to the Legend Items section. After choosing a legend template, the legend is added to the map and placed in a desired location.

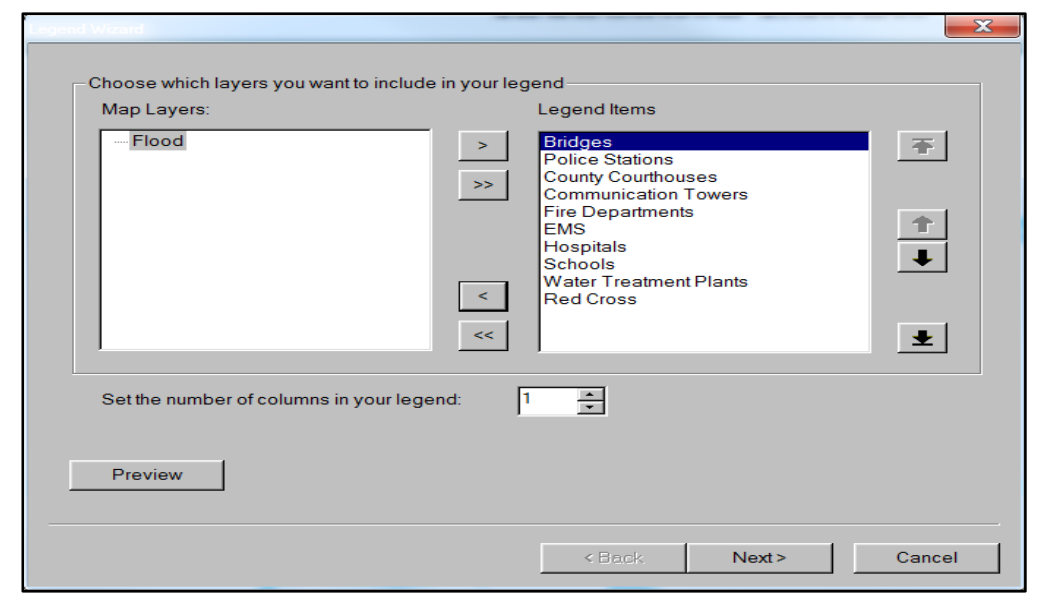

Figure 28: Insert Critical Infrastructure Legend

To avoid confusion, another legend is created using the same procedure in order to indicate the color of the inundation polygon in the maps. Additional elements such as a bar scale and north arrow are added to provide context for the inundation maps. Under the Insert dropdown, Scale Bar and North Arrow are each used to add these elements. Furthermore, a title indicating the time step of the inundation map is specified. As a final step, the profile of the representative cross-section is added to the inundation map. Using the Insert dropdown, Picture is chosen, and the saved profile image is selected. After the profile is inserted, the image is double-clicked, and the desired dimensions are specified. Once these map elements are inserted, the first inundation map is complete. After saving the map, the second map area is displayed in 
the main data frame, and the procedure is repeated for the remaining map areas depicting the inundation for the time step. Once the set of maps for the time step is finished, the process is continued for the other time steps in the analysis.

\subsection{Water Depth Grids Procedure}

The Water Depth Grids procedure follows the same mapping process as the Terrain Tiles procedure, but uses the inundation with the water depth grids rather than the inundation polygon. Since the display properties of ArcMap allow for the classification and color-coding of the flood water depths, this procedure provides additional information on arrival times and flood impacts on critical infrastructure.

\subsubsection{Mosaic Depth Grids}

After opening a new ArcMap document, the Add Data function is used to add in the grid files that contain the water depths. In ArcToolbox, the Data Management Tools category is expanded, and Mosaic to New Raster is used to facilitate the processing of the data. In the Mosaic to New Raster dialog box, shown in Figure 29, the files are grouped together based on adjacency and proximity to cities, and recognizable names are given to each of the group files that are created. In addition, an output file location is chosen, which provides a means to manage and store the data. 


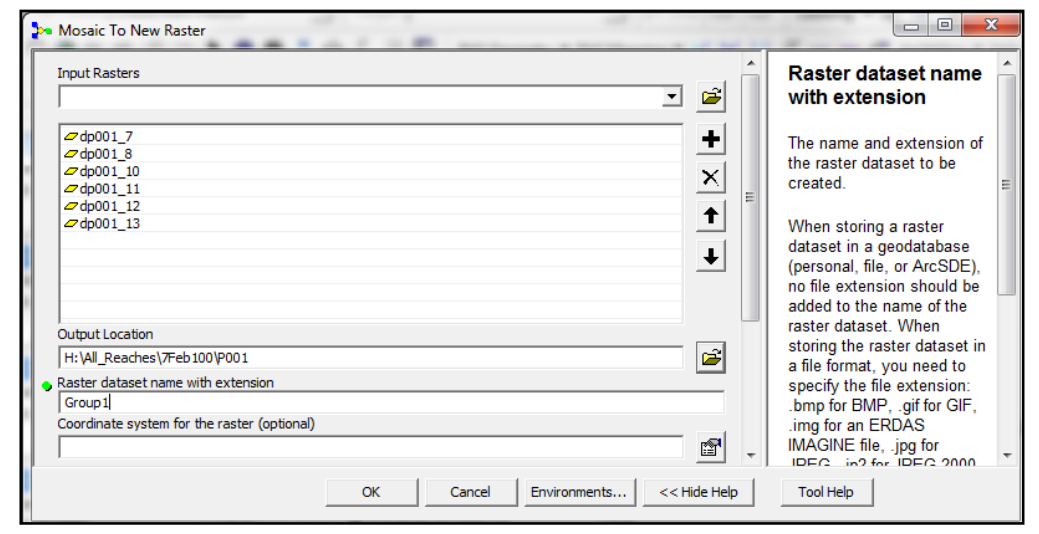

Figure 29: Mosaic to New Raster

\subsubsection{Classify Depth Grids}

After Mosaic to New Raster is complete, the group files are added into ArcMap using the Add Data function, and the individual files that make up the group files are removed. Next, the group files are classified to show the differing water depths. Each group file is right-clicked in the Table of Contents, and Properties is chosen from the menu. In the Layer Properties dialog box, the Symbology tab is selected. In the Symbology tab, illustrated by Figure 31, Classified is chosen, which requires the creation of a histogram. Once the histogram is created, the water depth intervals are changed by choosing Classify, as illustrated by Figure 30. For this application, the intervals are chosen as 0 to 5 feet, 5 to 10 feet, 10 to 20 feet, 20 to 30 feet, 30 to 40 feet, and greater than 40 feet. These intervals are based on the total depth of the flood. Next, the color ramp is changed from a Black to White color scheme to the Spectrum-Full Light color scheme, as shown in Figure 31, so that there is a clear differentiation in the water depth intervals. 


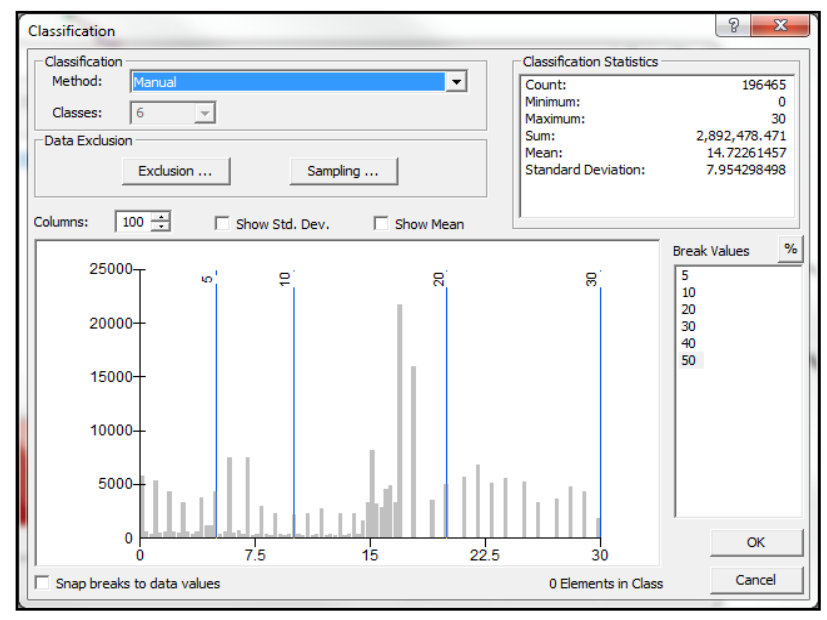

Figure 30: Classify Histogram

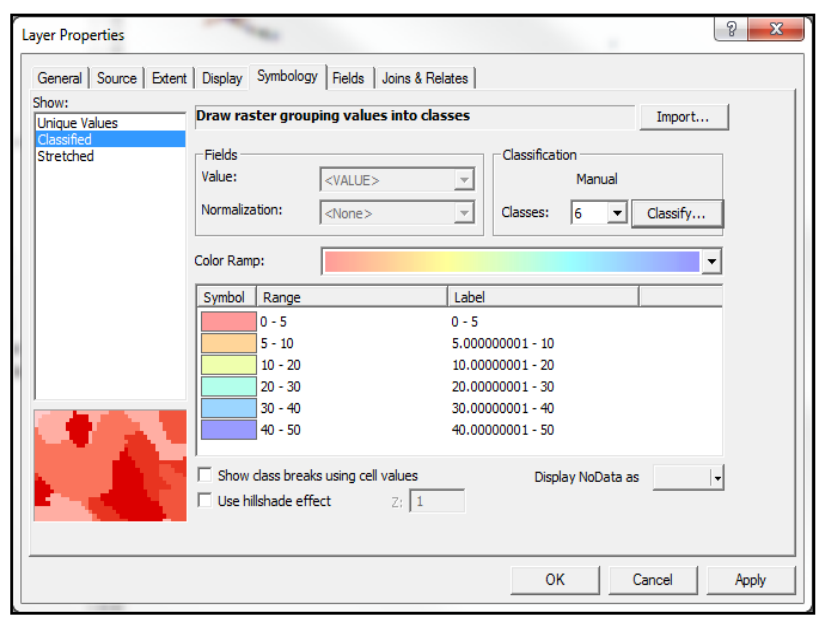

Figure 31: Assign Color Scheme

\subsubsection{Set Up Map Template}

The process of setting up the map template is the same as the one outlined in Section 3.3, except a water depth legend is inserted in place of the flood extents legend. To do this step, the Insert dropdown menu is selected, and Legend is chosen. Inside the Legend Wizard dialog box, shown in Figure 32, only one of the water depth grids is chosen, as all the grids have the same water depth intervals. After this step, a template for the legend is selected, and OK is clicked to insert the legend into the inundation map.

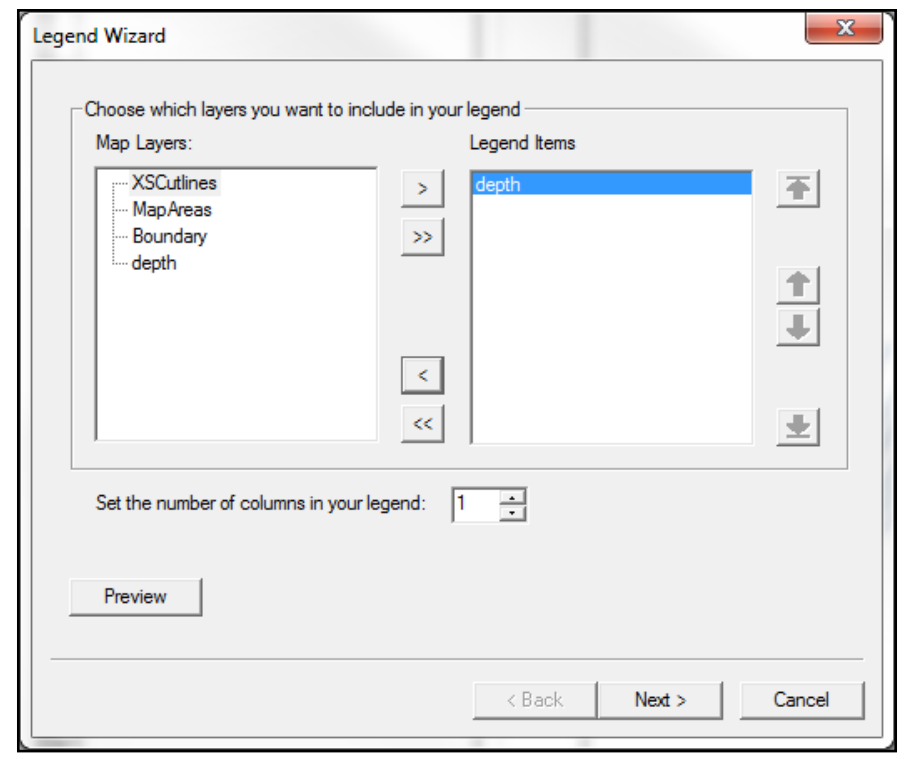

Figure 32: Add Water Depth Legend 


\subsection{Virtual Inundation Mapping Using Google Earth}

An alternative method to the process of making traditional paper maps is to import the inundation into Google Earth. Google Earth contains high-resolution aerial imagery and topography of the entire globe, and imported data is overlain on this background, providing a means of visualizing the data in a real-world environment. Since the inundation is exported from ArcMap at a one-to-one scale, the inundation boundaries in Google Earth are still accurate to within two meters. Therefore, the impacts of the dam failure on the areas downstream are analyzed at the same level of accuracy as in the paper maps.

\subsubsection{Convert to KML File}

Once the inundation has been generated in ArcMap, ArcToolbox is used to convert the file into a form that can be processed by Google Earth. In ArcToolbox, the 3D Analyst Tools category is expanded, followed by the Conversion category. Next, the To KML category is expanded, and the Layer to KML Tool is selected, which opens the Layer to KML dialog box, shown in Figure 33.

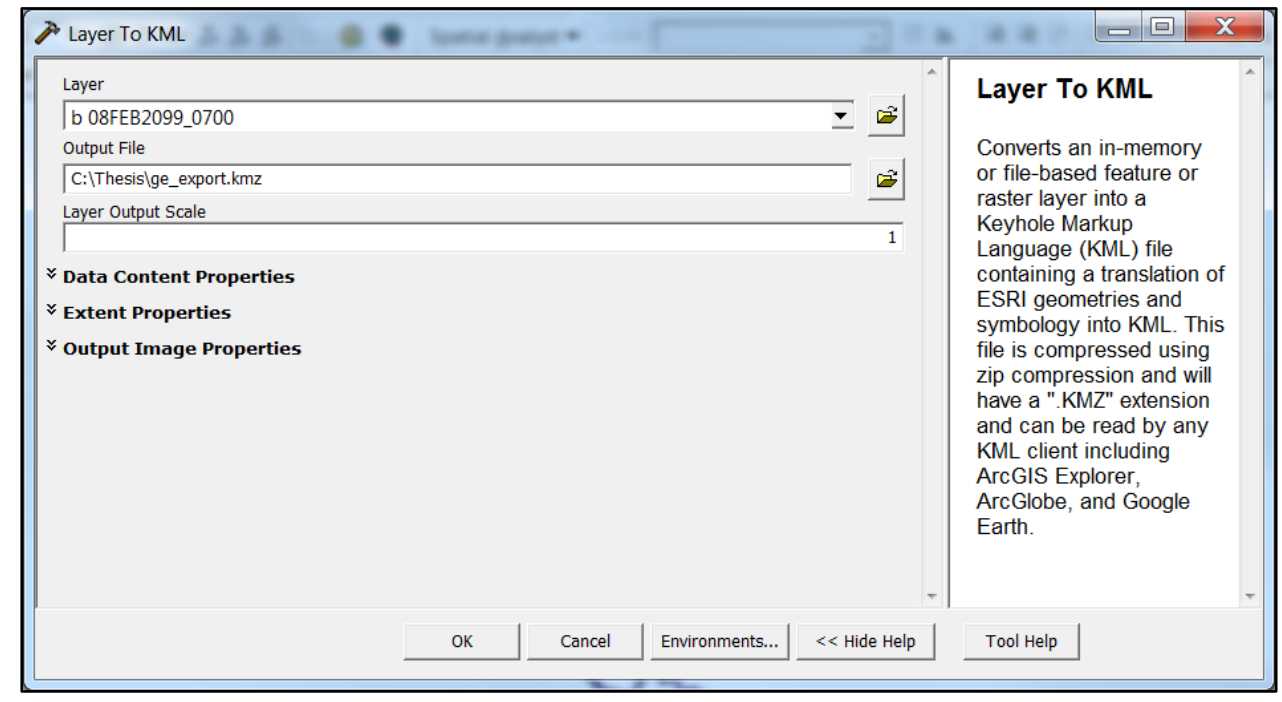

Figure 33: Layer to KML 
The layer to be converted is selected as the inundation, which is either the inundation polygon or the inundation with water depth grids. For the output file, the destination folder is specified, and a name for the KML file is given. The layer output scale represents the scale at which the layer is exported. In order to view the layer as the inundation would appear in actuality, the number one is entered for the output scale. Clicking OK converts the layer to a KML file and saves the file in the specified destination.

\subsubsection{Import into Google Earth}

Once the KML file has been created, the file is imported into Google Earth. After opening Google Earth, the File menu is used to select Open. In the dialog box, the KML file containing the inundation polygon is selected, and Open is clicked, as shown in Figure 34.

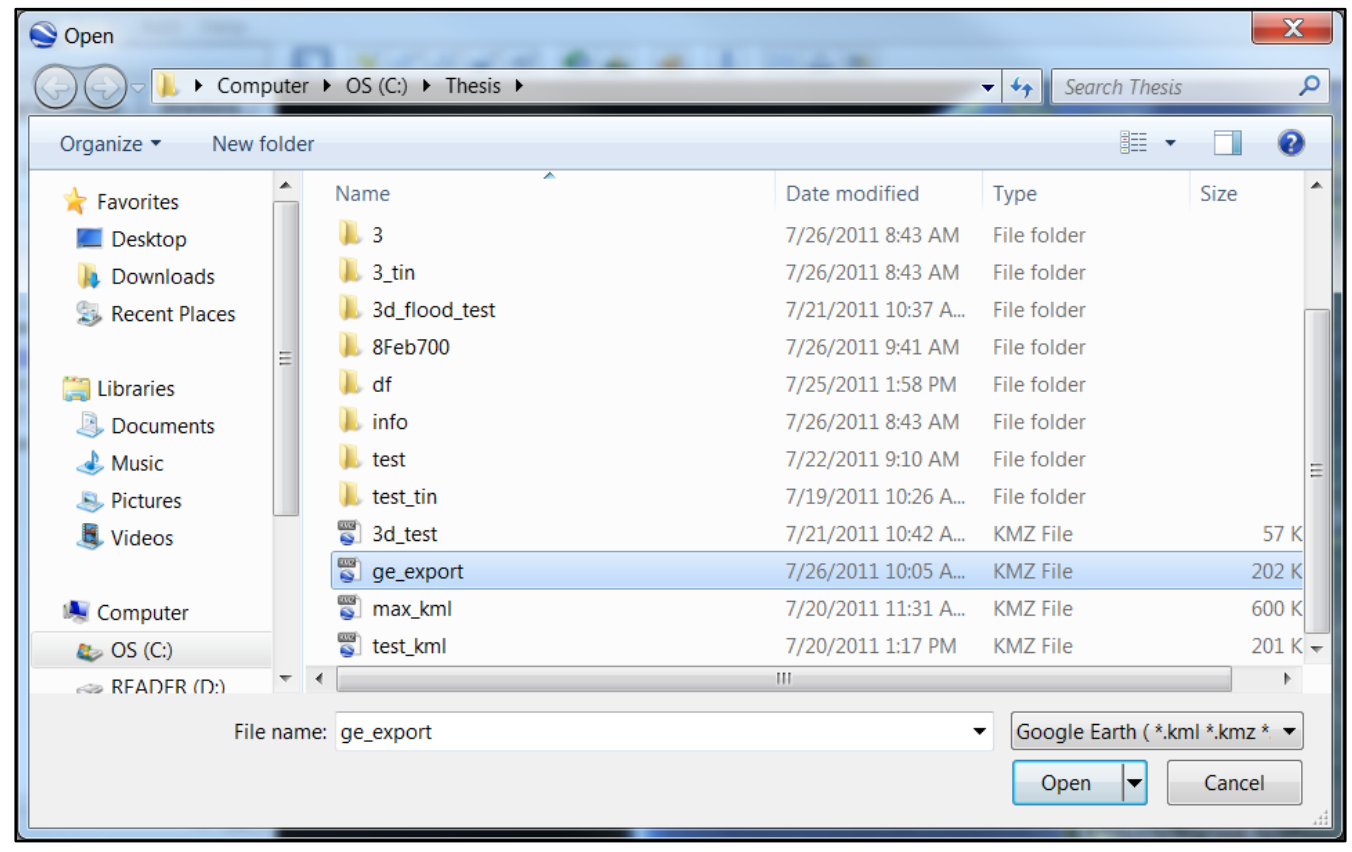

Figure 34: Import KML File

The ArcMap layer appears in the Temporary Places folder in the sidebar of Google Earth, and the inundation polygon is displayed at its correct geographic location on the virtual globe. 


\subsubsection{Assign Transparency}

The inundation polygon covers up the aerial images underneath, which may interfere with the analysis. In order to change this display, the slider located in the sidebar is used to assign a transparency to the inundation polygon so that the flooded areas can be seen through the inundation. Figure 35 shows the imported inundation with an assigned transparency displayed in Google Earth.

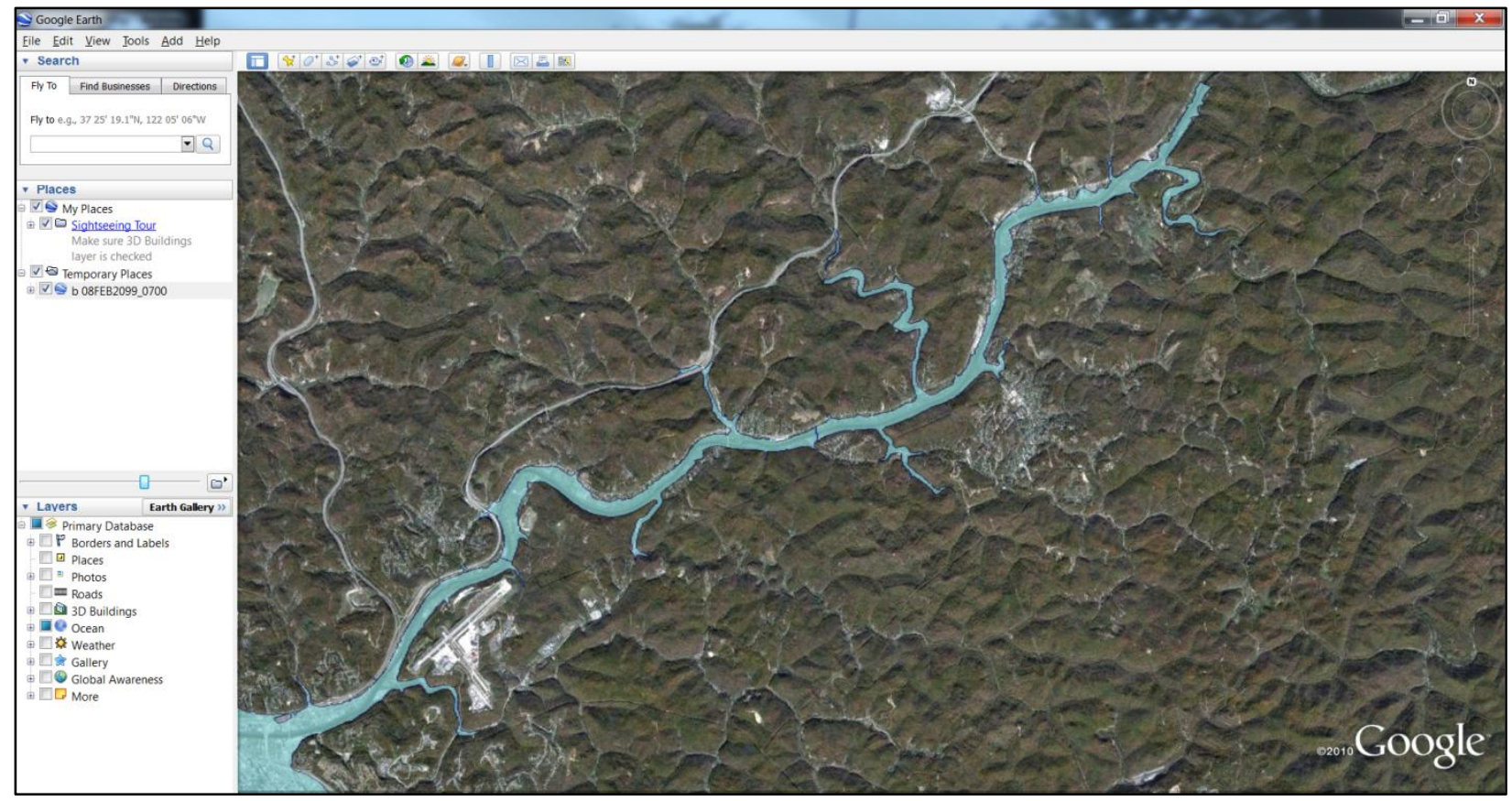

Figure 35: Inundation with Assigned Transparency

\subsubsection{Display Analysis Layers}

Once the inundation has been imported, Google Earth provides several analysis tools to study the impacts of the flood. First, the inundation is viewed in a two-dimensional plan view, and Google Earth has several built-in layers that are used to identify critical infrastructure. These layers include city labels, transportation systems, and the locations of emergency services facilities and public health and healthcare providers. To turn on these layers, the Layers menu in the Google Earth sidebar is used to display the desired information on the virtual globe. The city 
labels are viewed by checking the Borders and Labels category, and the transportation systems and labels are added by checking the Roads category. Critical infrastructure is found by expanding the More category, followed by Place Categories, and the applicable layers are chosen. Figure 36 shows the impacts of the flood on critical infrastructure, such as transportation systems, emergency responders, hospitals, and schools. Thus, this view offers a means of determining important evacuation centers and the affected transportation routes, which is beneficial to emergency response planning.

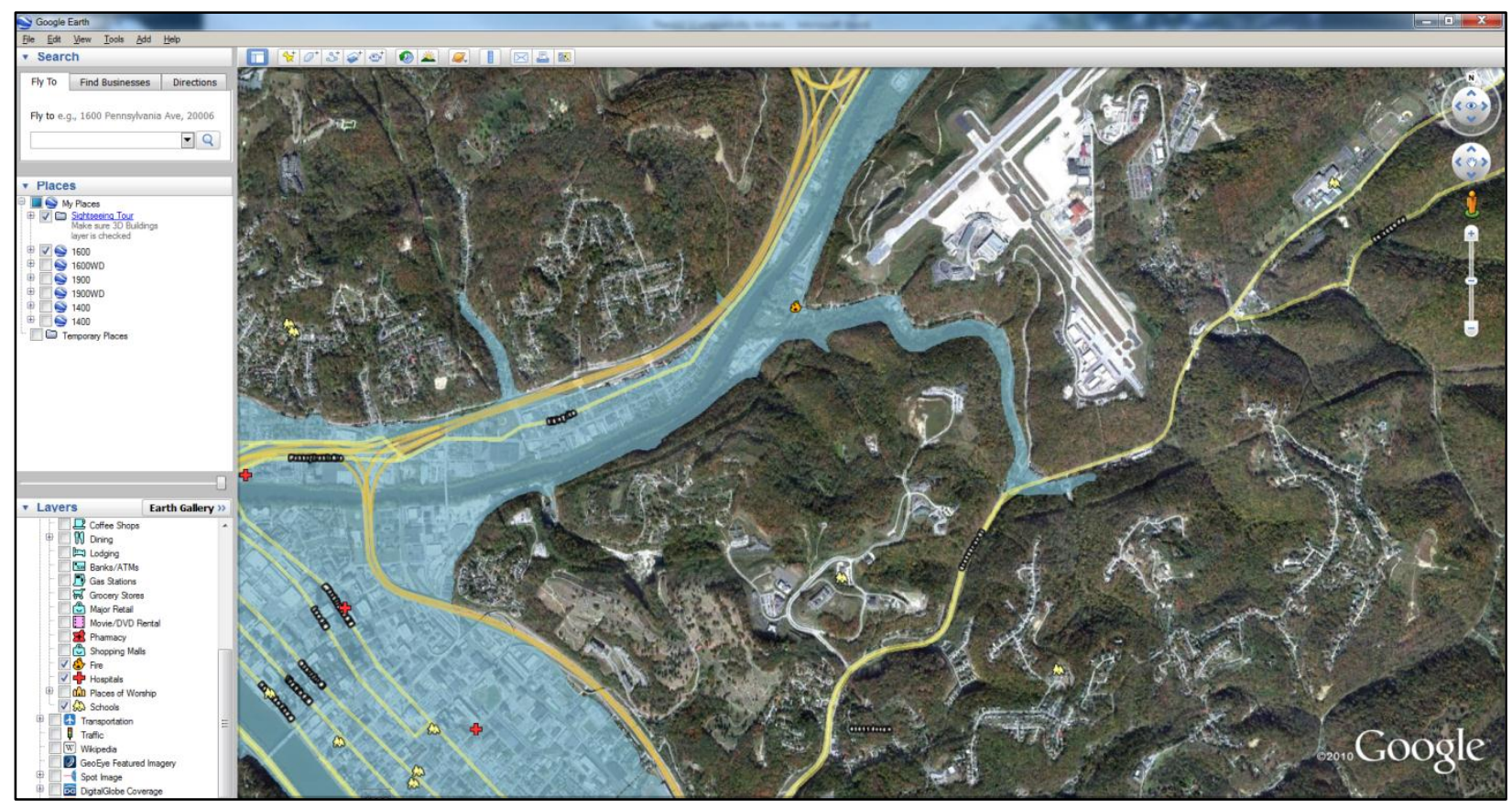

Figure 36: Plan View with Critical Infrastructure

\subsubsection{Enter Ground-Level View}

Google Earth offers the capability to view projects from ground-level. To enter GroundLevel View, the orange human icon on the right side of the screen is selected and dragged to the desired area. Once in this view, the arrow keys are used to navigate the virtual globe. Figure 37 illustrates the inundation displayed on the three-dimensional topography. The inundation remains two-dimensional, showing the extents of the flood overlain on the existing topography 
without any water depths. However, this view is still useful to examine the effects of the topography on the flood's movement downstream.

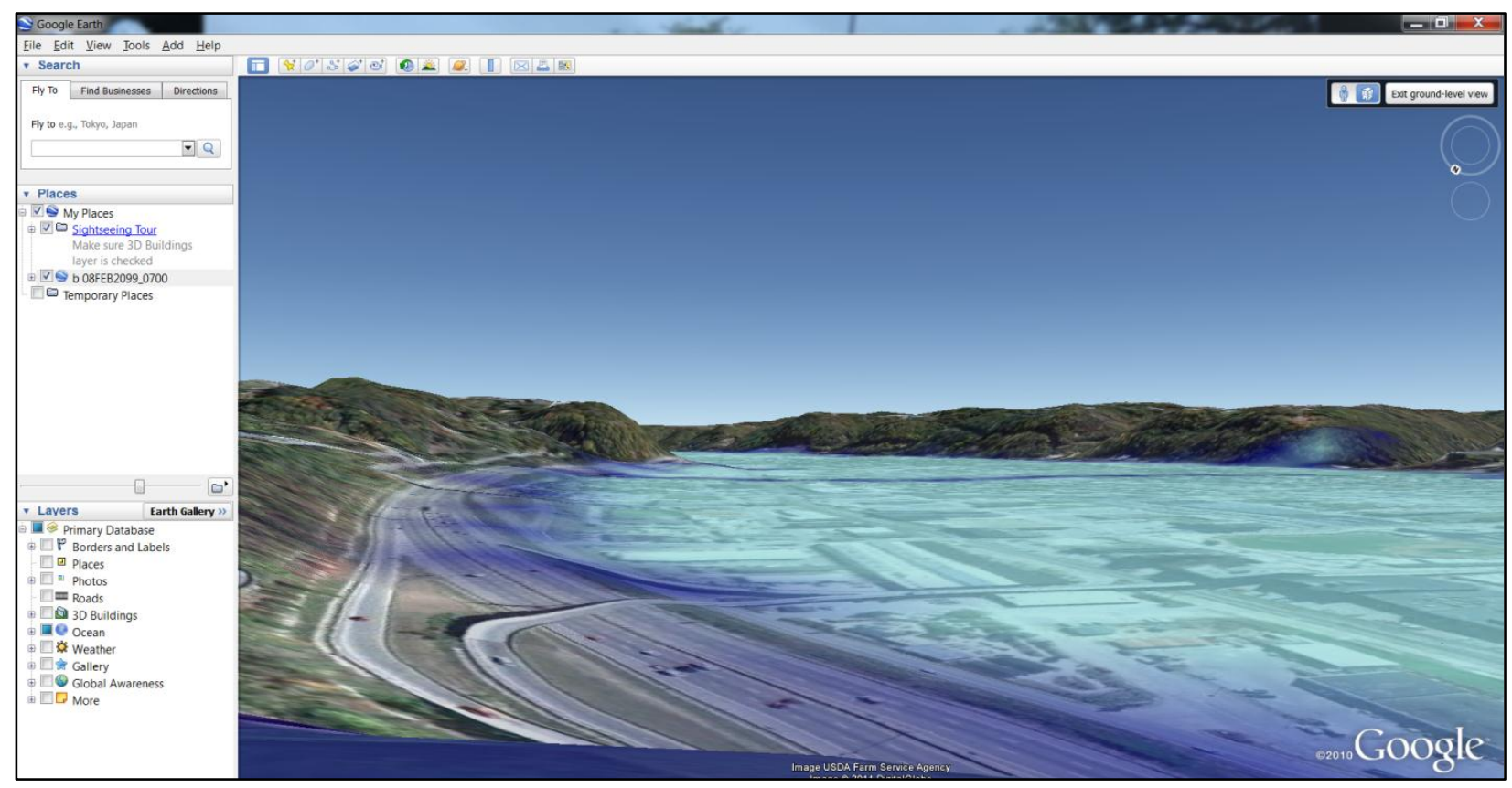

Figure 37: Ground-Level View

\subsubsection{Display Three-Dimensional Buildings}

Google Earth also contains a database of three-dimensional structures that can be displayed. While in Ground-Level View, these structures are activated by checking the 3D Buildings category in the Layers menu in the sidebar. Although the database only contains a select number of structures, the structures provide landmarks to enhance the spatial reference for the analysis of the inundation, as illustrated in Figure 38. 


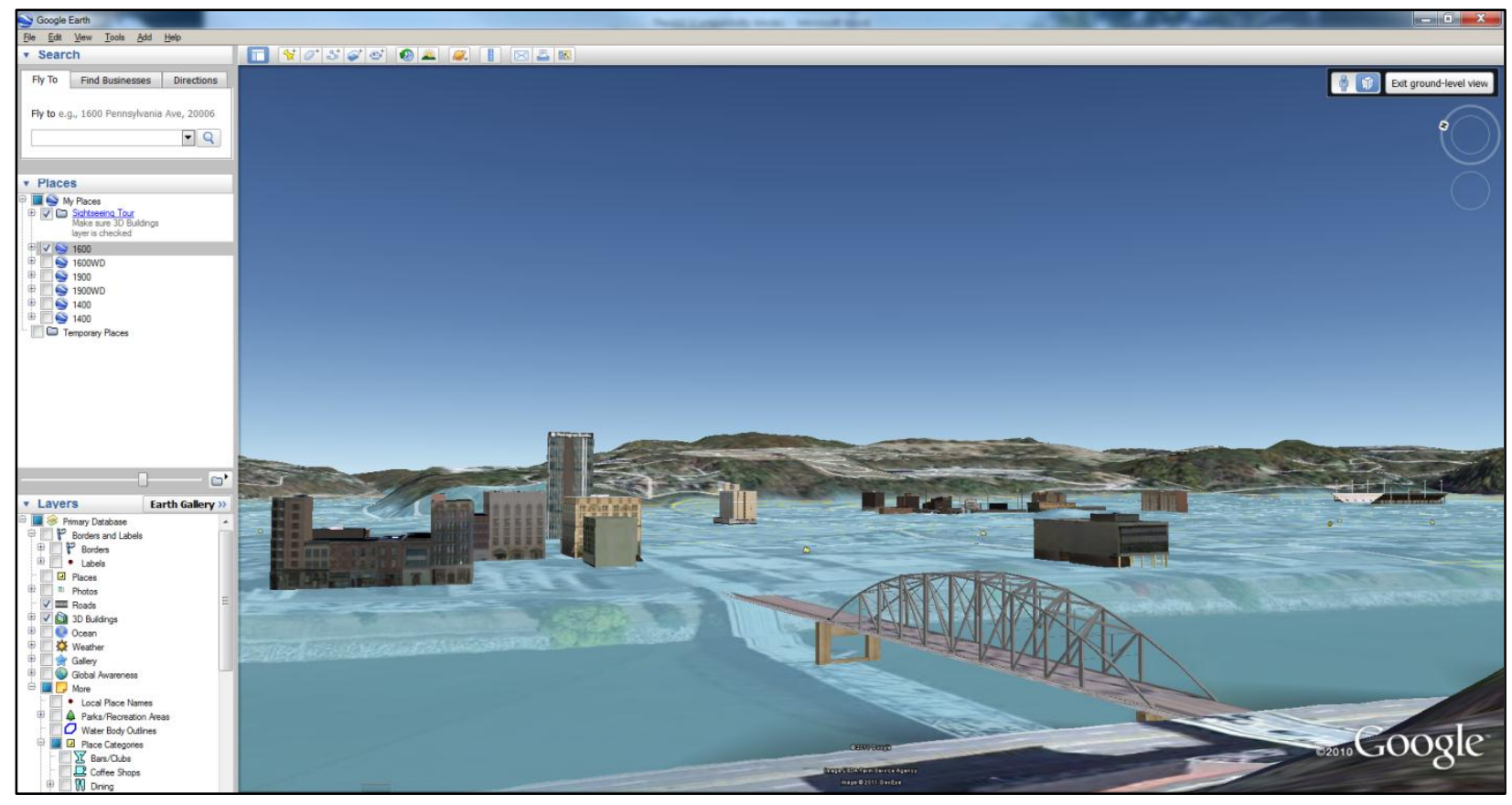

Figure 38: Ground-Level View with 3D Buildings

\subsection{Overview of Created Maps}

For this research, a dam failure was simulated for a candidate river system using HECRAS. Hourly intervals were specified for the output data to ensure that the entire flood event was captured in practical time steps for emergency response. The crucial hours started at the time of dam failure and ended at the time of the peak flood at the last cross-section in the study area. Because of the length of the flood event, intervals of three hours were chosen to map the flood's propagation through the study area. These intervals allowed for key periods of the rising and falling limbs of the event to be mapped for each section of the study area. Maps were produced at three-hour intervals for each of the 23 map areas for 16 separate times after dam failure, resulting in a total of 368 maps.

Sections 3.6.1, 3.6.2, and 3.6.3 present maps produced using the separate mapping procedures used in this research. Section 3.6.1 illustrates three inundation maps produced by the Terrain Tiles procedure, each showing a different time step for a candidate river segment. The 
first map depicts the inundation during the hour when the dam fails. The second map displays the maximum inundation. The third map represents the falling limb of the event, when the inundation waters have begun to recede. Similarly, the maps in Section 3.6.2 show the same time steps, but with the water depths for the inundation classified. Section 3.6.3 illustrates the inundation from the two previous sections imported into Google Earth. The mapping procedures and outputs are further discussed and analyzed in Section 4.0. 


\subsubsection{Terrain Tiles Maps}

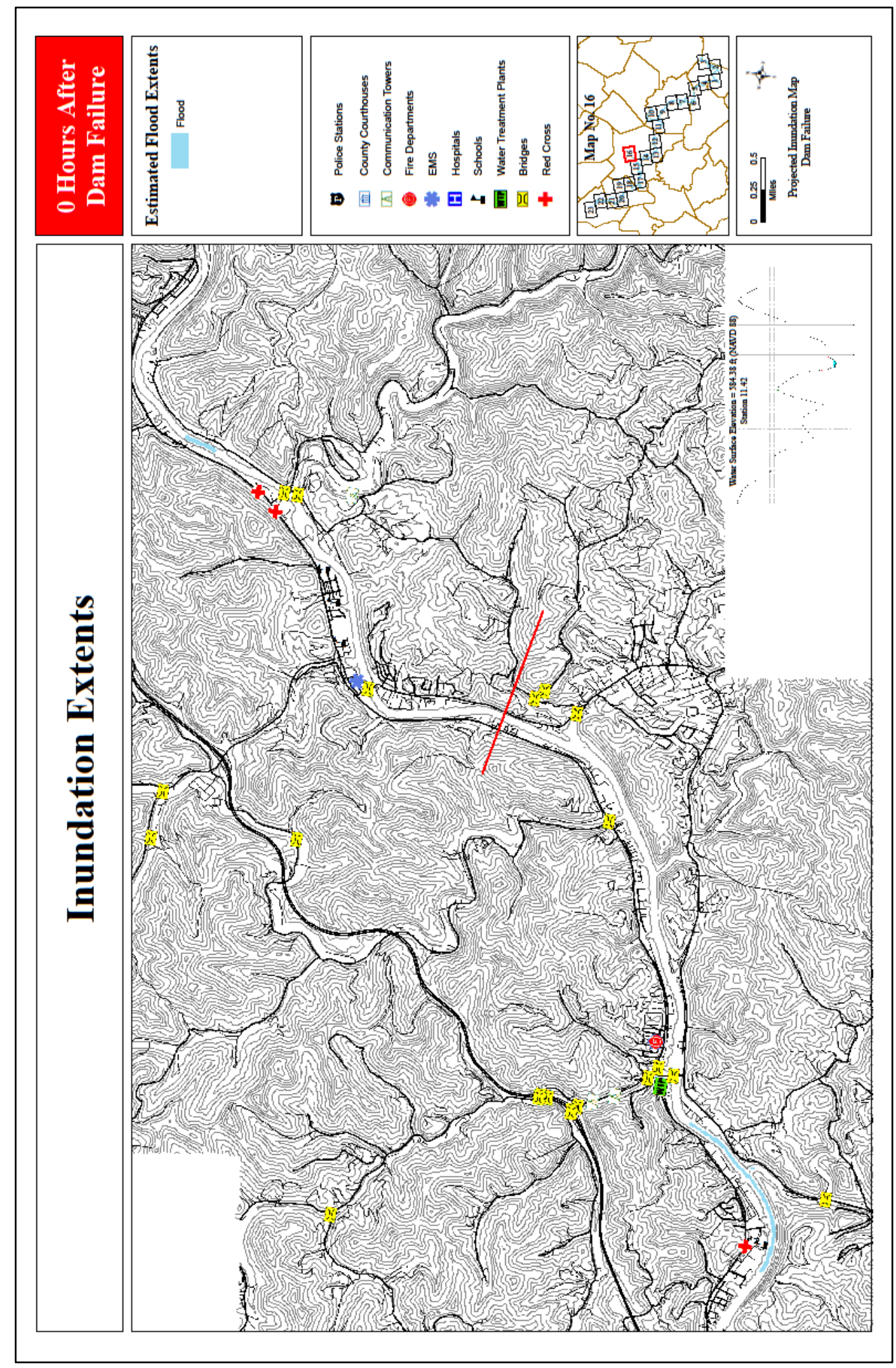

Figure 39: Flood Extents at 0 Hours 


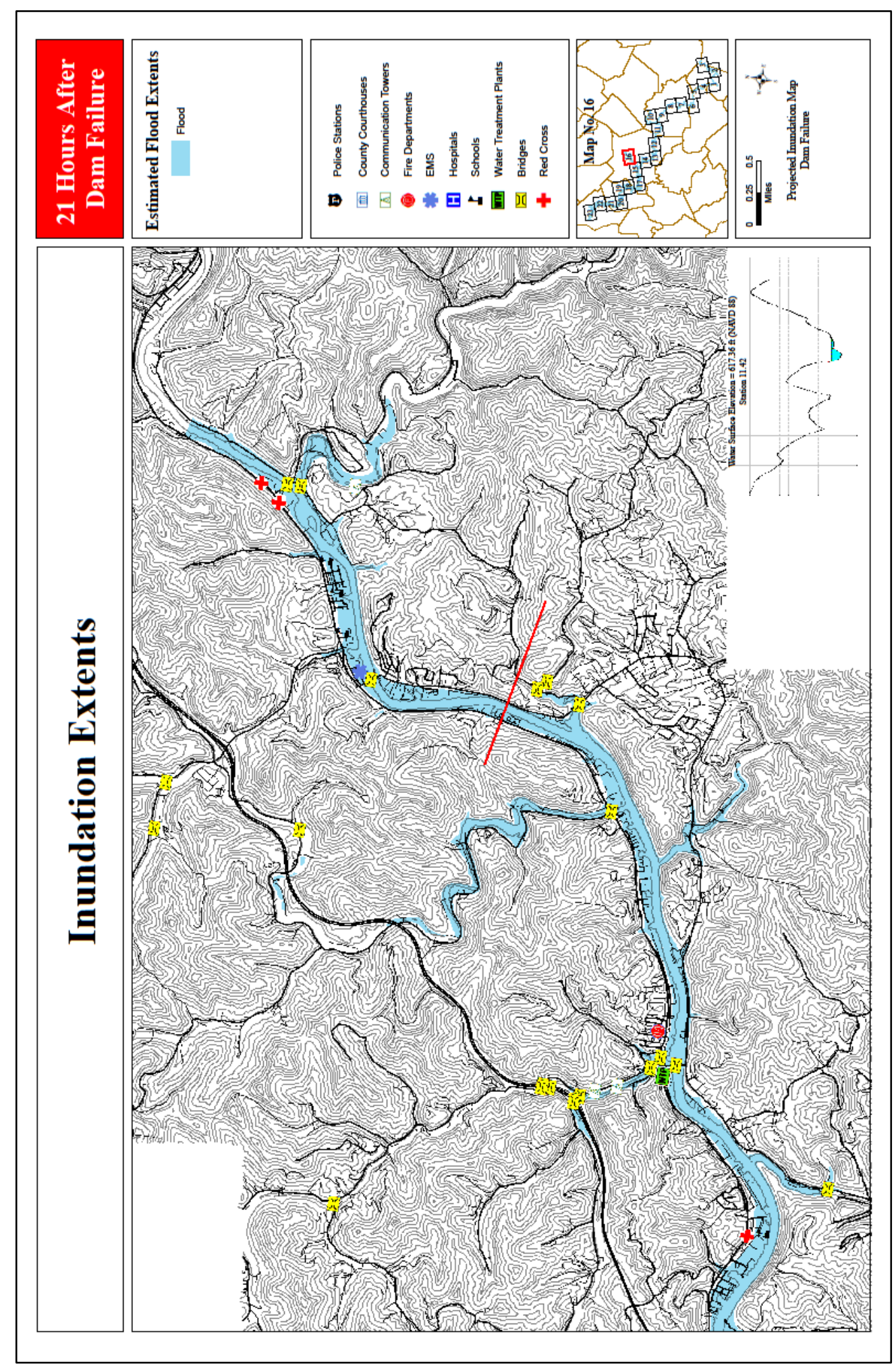

Figure 40: Flood Extents at 21 Hours 


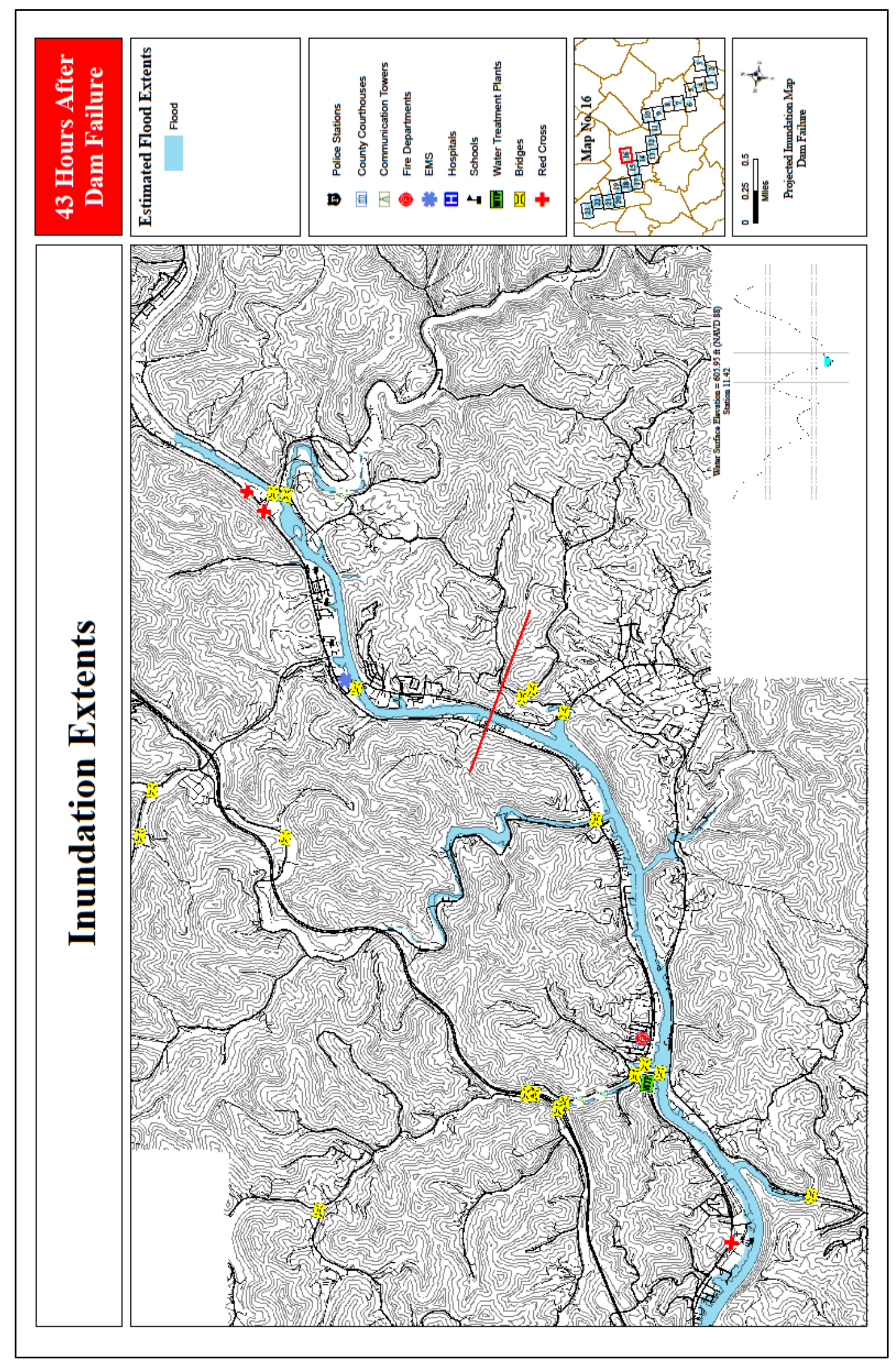

Figure 41: Flood Extents at 43 Hours 


\subsubsection{Water Depth Maps}

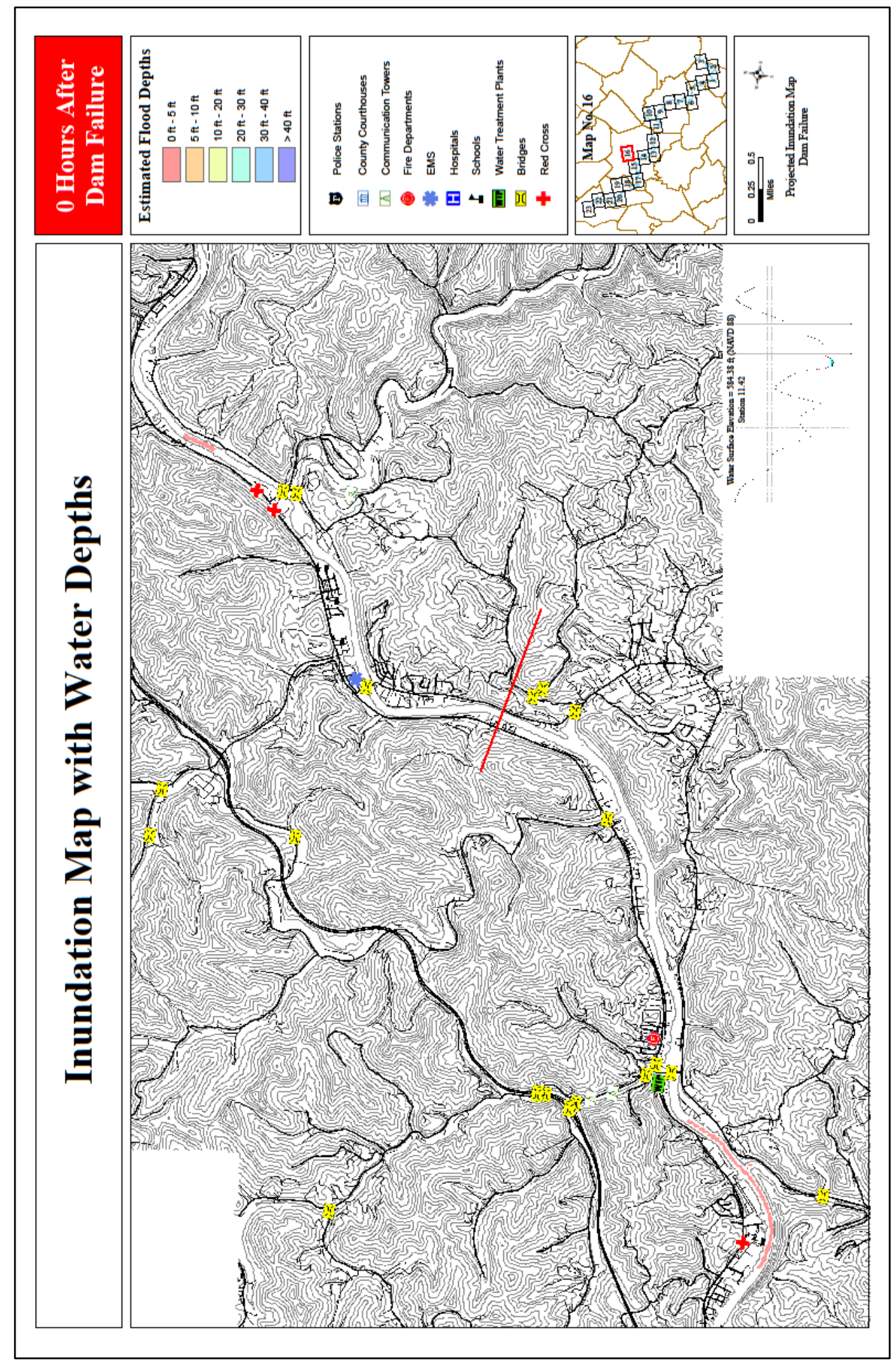

Figure 42: Water Depths at 0 Hours 

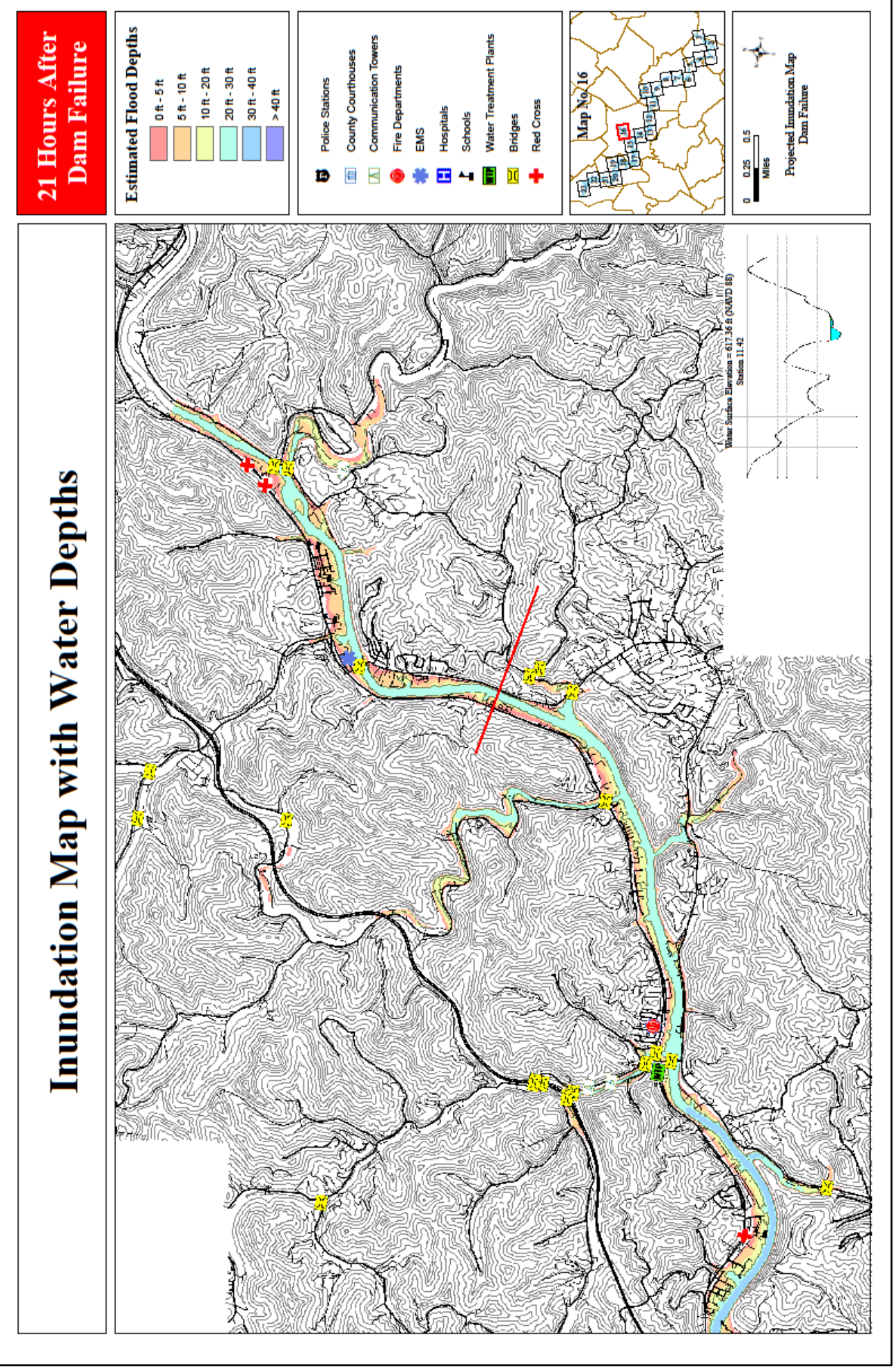

Figure 43: Water Depths at 21 Hours 


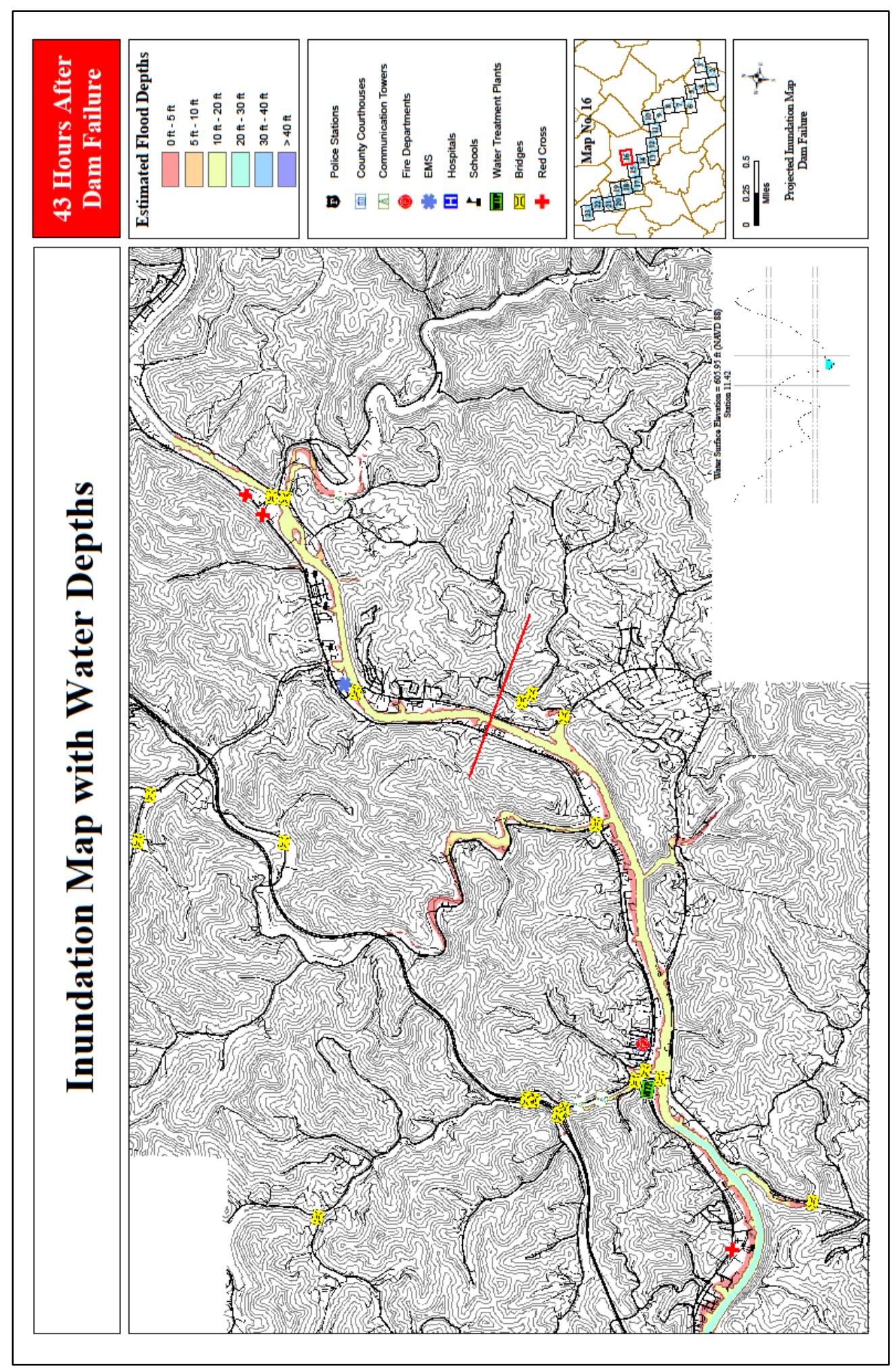

Figure 44: Water Depths at 43 Hours 


\subsubsection{Google Earth Maps}

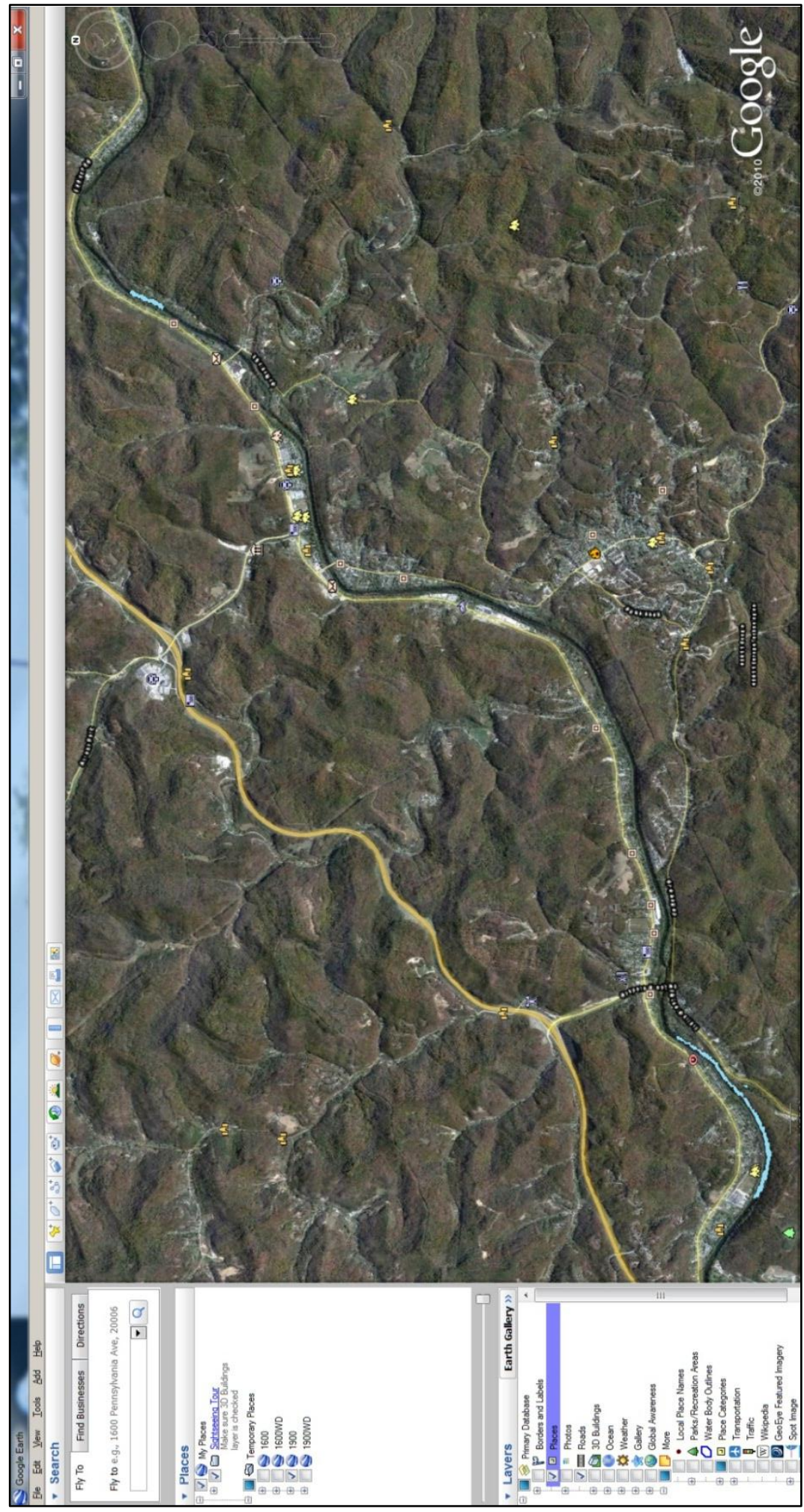

Figure 45: Flood Extents at 0 Hours in Google Earth 


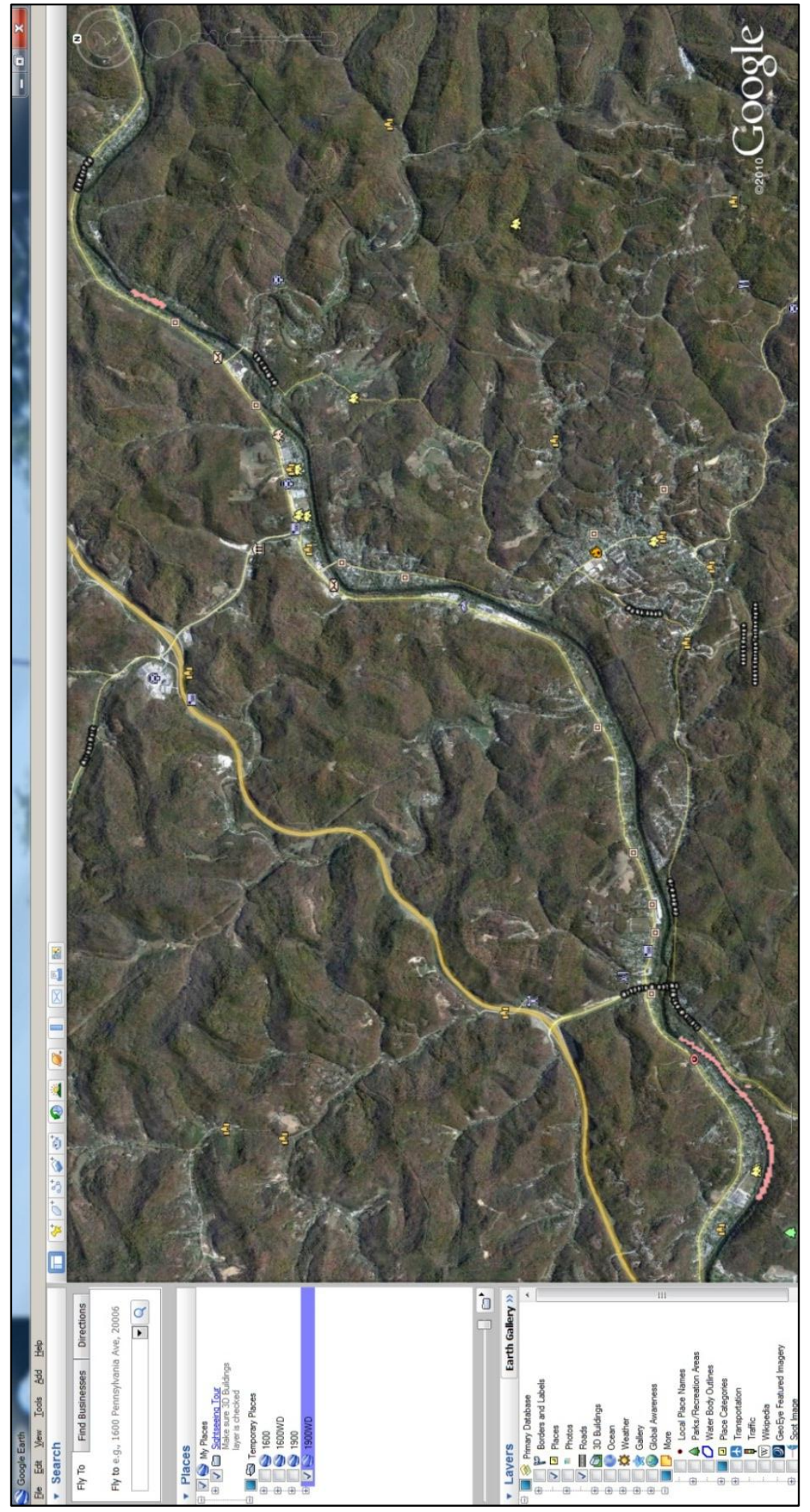

Figure 46: Water Depths at 0 Hours in Google Earth 


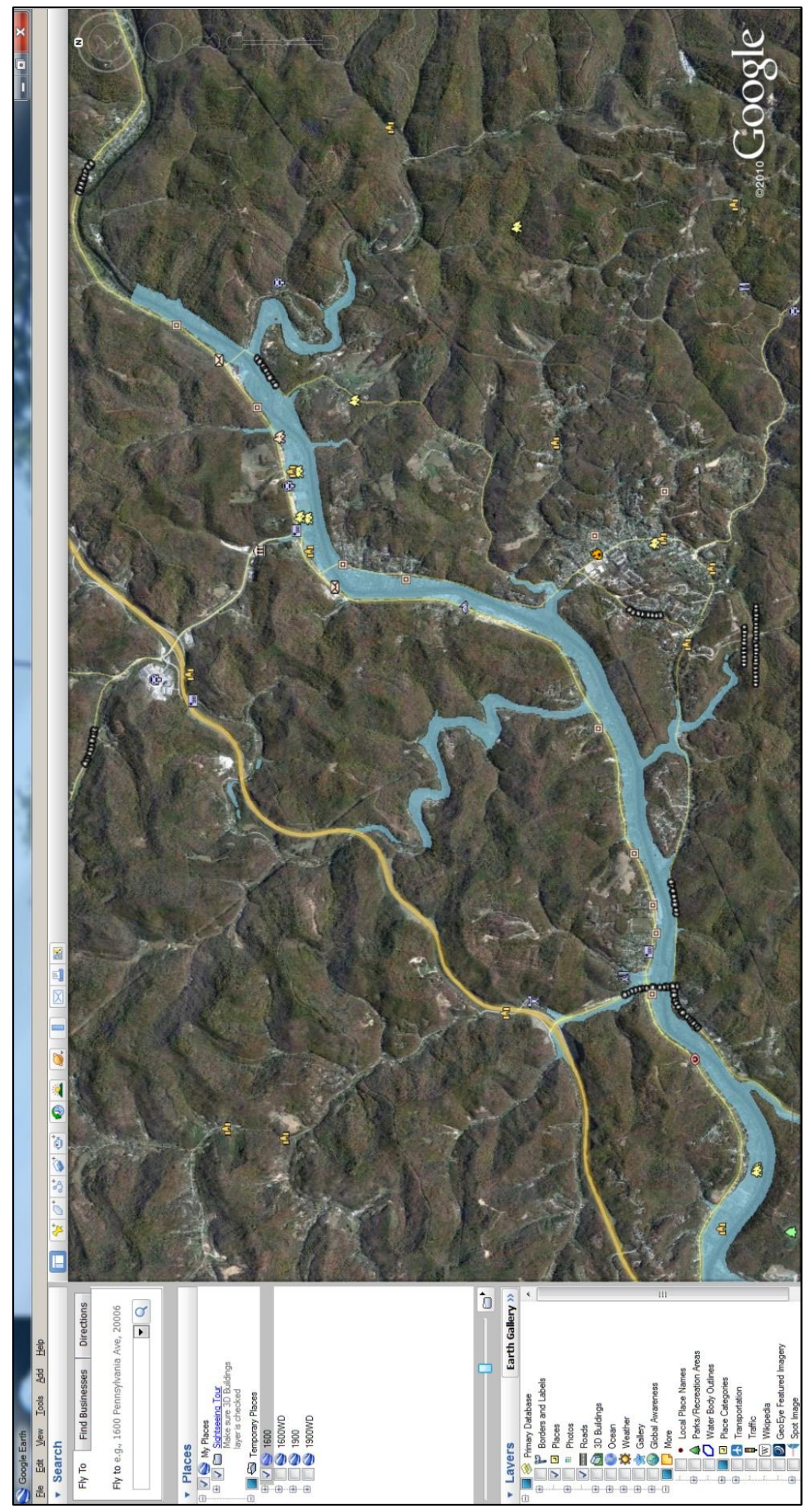

Figure 47: Flood Extents at 21 Hours in Google Earth 


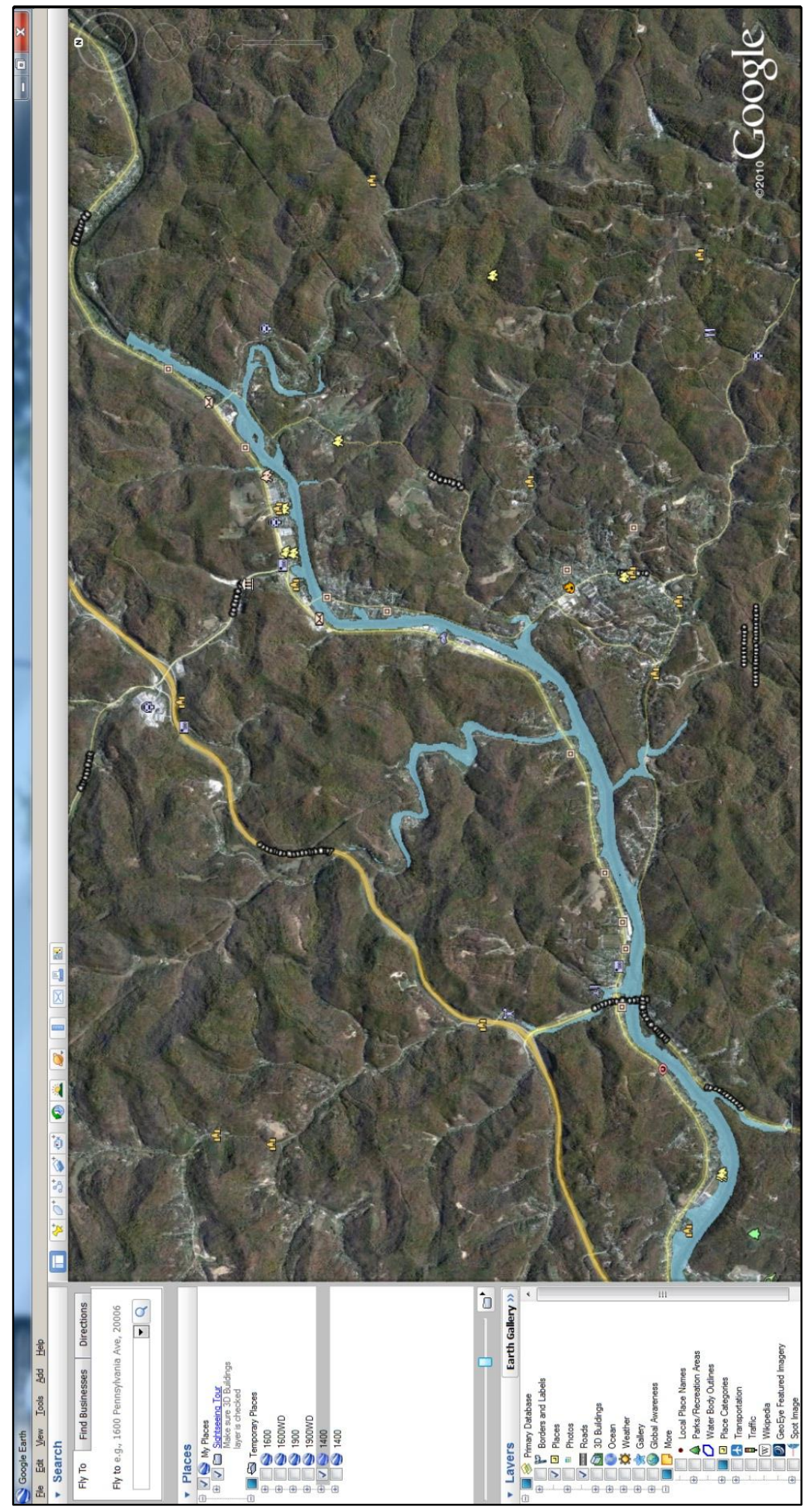

Figure 49: Flood Extents at 43 Hours in Google Earth 


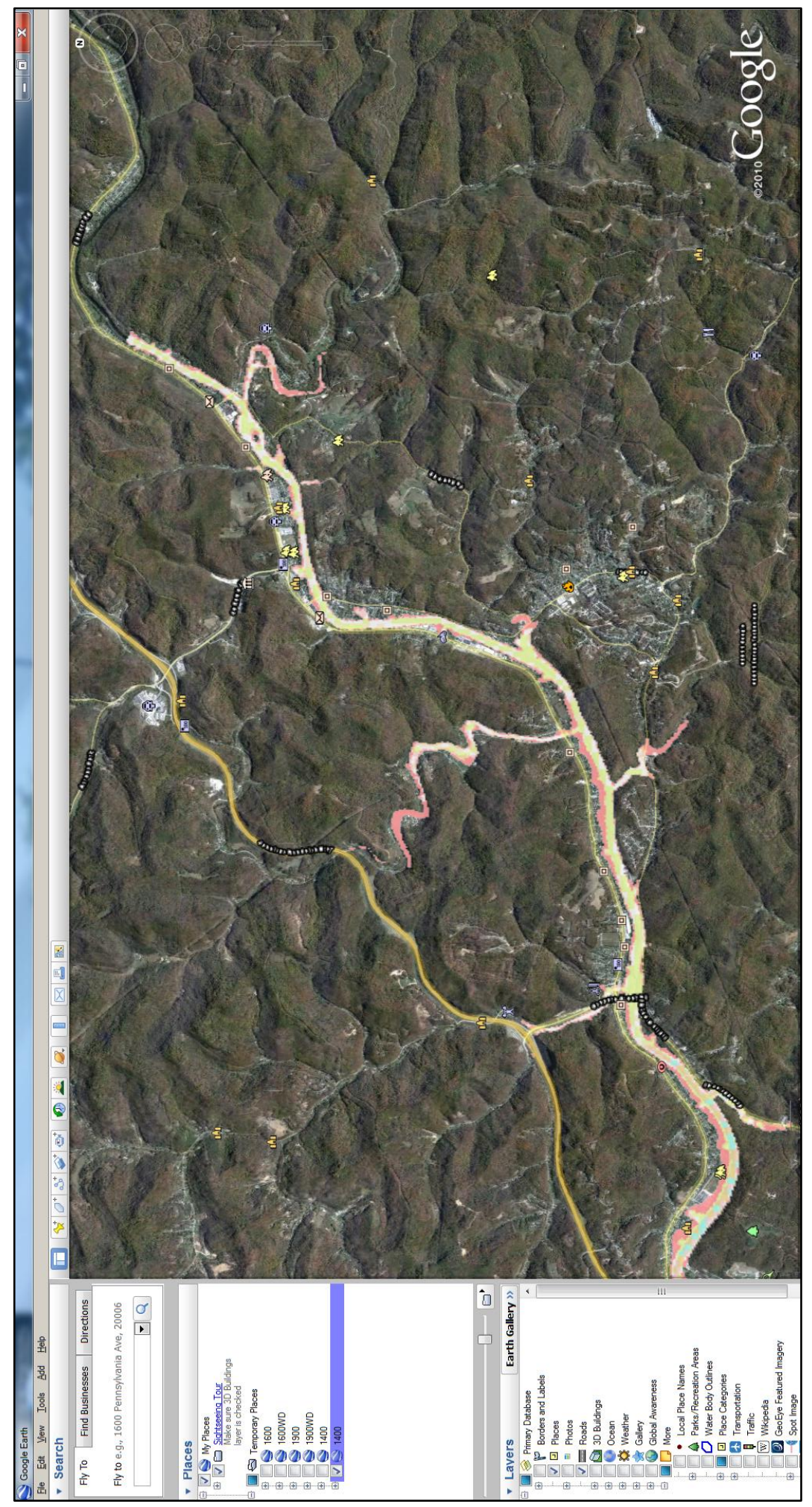

Figure 50: Water Depths at 43 Hours in Google Earth 


\subsection{Analysis of Mapping Methods}

Once the maps have been developed, an analysis is performed in order to evaluate the output from each method in regards to ease of development, display of critical information, and accessibility. This analysis focuses on the benefits and weaknesses of using these methods and is related to the comparison between paper and virtual maps.

\subsection{Terrain Tiles Strengths}

The output derived from the Terrain Tiles procedure is a high-quality inundated area, as shown in Figure 51. The terrain tiles break up the river reach into smaller segments, allowing HEC-GeoRAS to process data for each individual tile rather than for the entire reach. As a result, the inundation generated is an accurate representation of the flood's movement downstream from the dam. The inundation conforms to topographic controls on the landscape and accurately represents flow around river bends and into tributary streams. Thus, the resulting maps show the full impacts of the flood on critical infrastructure sectors located along the main river channel and in outlying areas. Furthermore, the Water Depth Grids procedure provides further visualization of the severity of flood levels with clear distinctions between water depth intervals. These features are beneficial to emergency response planning by allowing agencies to view the full extents of the flood at a particular time as well as the depth of water at key points. 


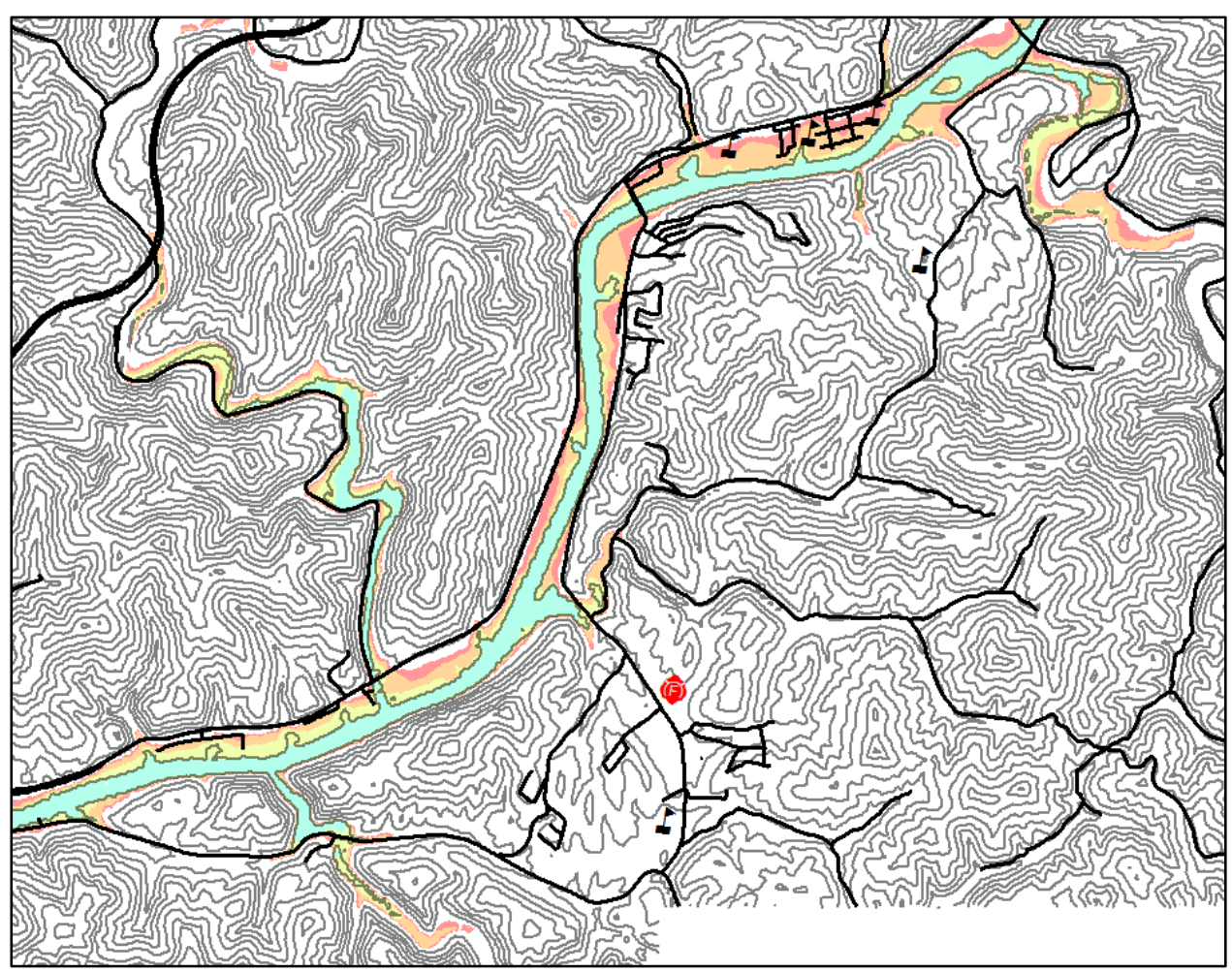

Figure 51: Terrain Tiles Inundation with Water Depths

\subsection{Terrain Tiles Weaknesses}

Although this method has many strengths in regards to the quality of the output produced, the method has several weaknesses regarding the setup and file management. The initial setup must be performed by the user, and this process is very labor-intensive, requiring the creation of clipped DTMs and the terrain tiles. Additionally, once the setup is complete, HEC-GeoRAS can take long periods of time to compute the inundation. This processing time varies depending on the size of the study area and the number of terrain tiles, but for this application, the inundation for the smallest river reach took four hours. For the entire study area, the process ran for 18 to 48 hours. Once the processing has completed, the resulting file sizes are very large, which can be difficult to manage. For instance, the inundation for the entire study area required 190 gigabytes of memory for a single hour after the dam failure. Since 16 hours were modeled for 
this research, the total memory requirement exceeded three terabytes. Hence, the file sizes that result from this method must be considered. Once the inundation has been generated, another step that must be performed to study the impacts is to add the FEMA critical infrastructure sectors. This data can be difficult to obtain for a particular study area and may have to be created by the user. Furthermore, to provide a spatial reference for the inundation, background imagery such as contours or aerial photography must be acquired and inserted manually into the maps. Due to the overlay feature in ArcGIS, the critical infrastructure sectors may interfere with the assessment of the flood's true extent and impact. For instance, Figure 52 shows a transportation route that is highlighted in green covering the outer boundary of the inundation. As a result, the two-dimensional display properties leave uncertainty as to the viability of using this route for emergency response.

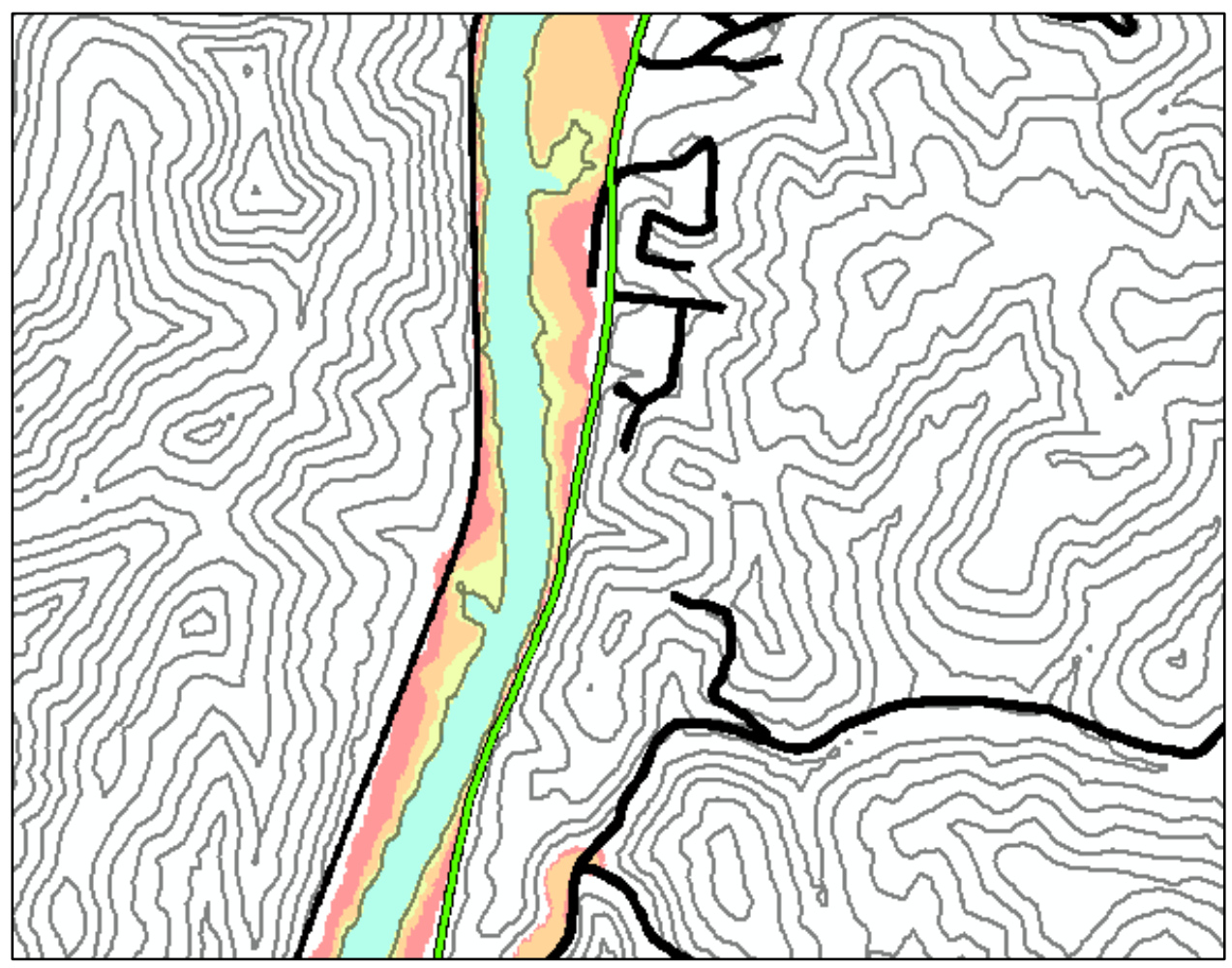

Figure 52: Terrain Tiles Overlay Issues 
After the maps are created, online file sharing may also prove to be problematic. The uploaded maps and associated files are in the form of ArcGIS layers, and the personnel from various agencies who need access to the maps may not be familiar with the GIS software. This lack of familiarity could result in misinterpretation of the information that the maps contain. These weaknesses may cause the Terrain Tiles procedure to be unsuitable for some applications where map files and printouts must be disseminated among numerous departments and agencies.

\subsection{Google Earth Strengths}

The benefits of Google Earth are a direct result of the virtual globe environment. After importing the inundation from ArcMap, the flood appears in its correct geographic location on the surface of the globe. Since Google Earth already contains aerial images, topography, and critical infrastructure, no further data acquisition and manipulation are required once the inundation is generated. Also, Google Earth provides an interactive map, allowing for the entire study area to be viewed much more easily than with a series of paper maps. The inundation can be shown in either a two-dimensional plan view similar to a paper map, or in a three-dimensional Ground-Level View which shows the topography more easily than a contour map. GroundLevel View can also be used to provide further analysis on the impacts of the inundation that may not be readily apparent in a two-dimensional view. For example, the highlighted route in Figure 52 is overlain on the inundation, which hinders the determination of whether the route remains a functional means of transport during the flood. However, viewing this transportation route in Ground-Level View, as shown in Figure 53, reveals that the flood clearly impacts this route, indicating that alternate routes should be investigated for emergency transport. Hence, 
Ground-Level View can be used in both emergency planning and response to illustrate the actual consequences of the inundation.

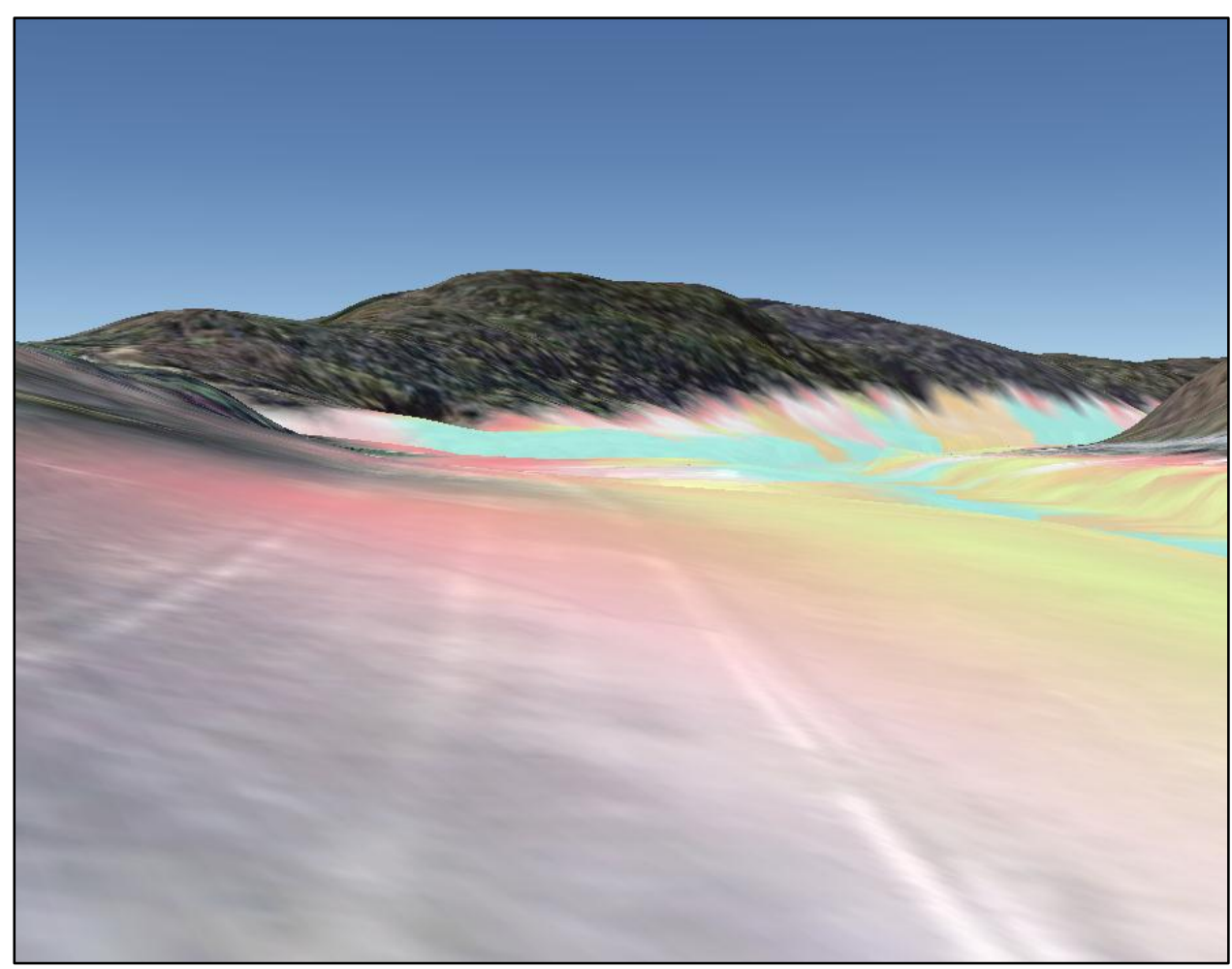

Figure 53: Google Earth Ground-Level View

Furthermore, Google Earth supports online file sharing across organizations, allowing users to access the maps in the field using Android phones and tablets, iPhones, and iPads. The Google Earth environment is a user-friendly medium for the display of the inundation, as the simplicity of the program removes the steep learning curve associated with technical mapping software. As a result, the impacts of the flood can be understood and evaluated by users of all levels of technical experience. Also, the lack of processing tools in Google Earth prevents the corruption of the inundation data produced in ArcGIS Desktop. These aspects make Google Earth an effective tool for sharing vital information about the flood among emergency response agencies. 


\subsection{Google Earth Weaknesses}

While the virtual maps produced by Google Earth can provide many benefits, there are also a few weaknesses to using this method. First, Google Earth does not perform inundation calculations; thus, the inundation must be produced in ArcMap using the Terrain Tiles procedure. Also, the Google Earth environment does not allow for the arrival times and water depths of the inundation to be easily shown. Changes in inundation over time are best shown by a side-by-side comparison of a particular area at different time steps, which cannot be easily performed within Google Earth since only one inundation is effectively displayed at once. Also, while the classified water depth grids can be imported into Google Earth, there is no legend to explain the water depths corresponding to each color, which can cause confusion among users who are not familiar with the development of the virtual map. Furthermore, the color-coded inundation appears to be represented by geometric shapes, obscuring the clear divisions between the water depth intervals. Figure 54 illustrates the display of the water depths in Google Earth, which contains far less detail than the water depths shown in Figure 51. Thus, using Google Earth to display water depths may lead to confusion in the delineation of the areas where the high flood levels necessitate immediate evacuation, possibly putting lives in danger. 


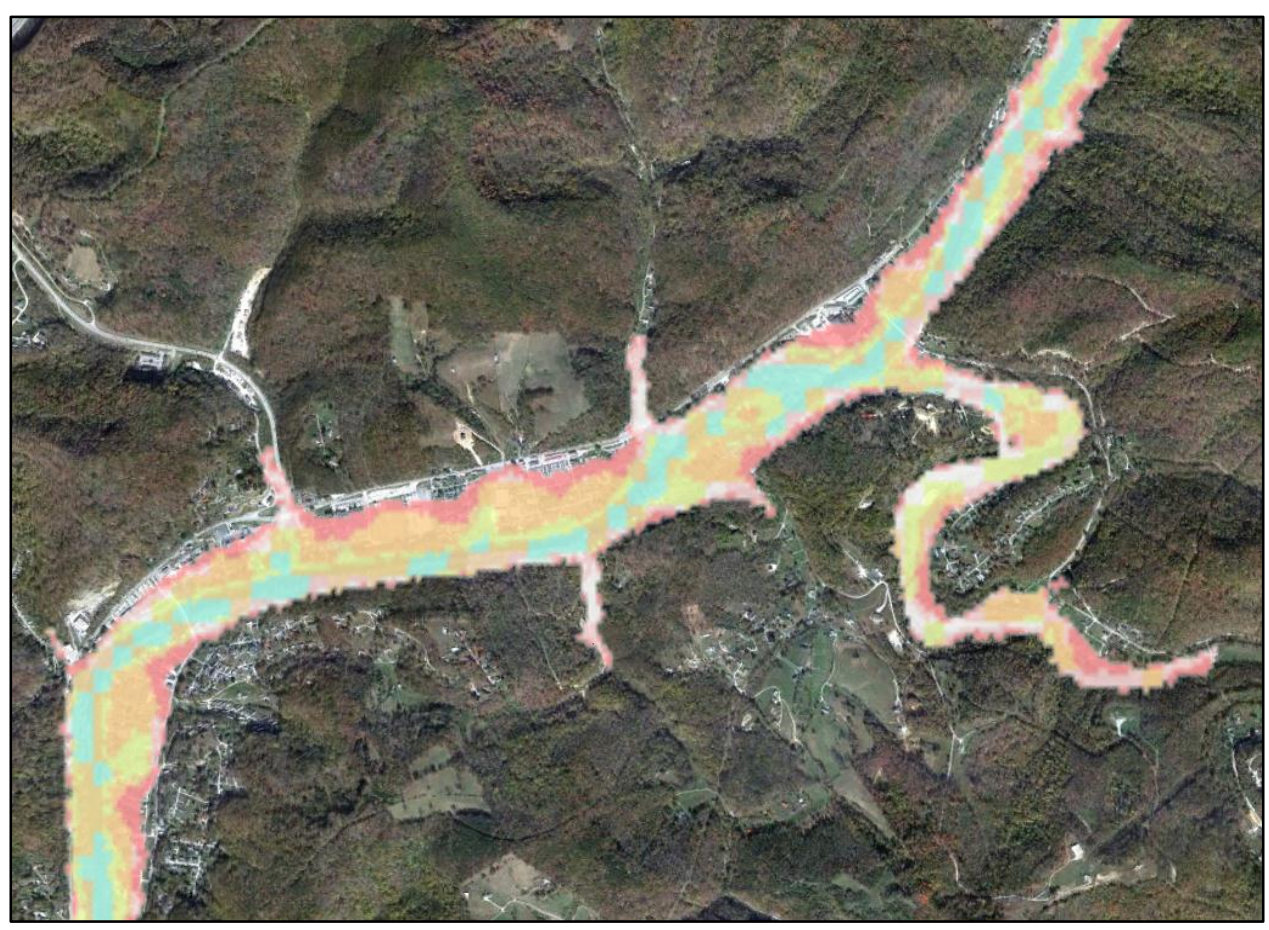

Figure 54: Groogle Earth Water Depths

Further weaknesses of this procedure are related to the online sharing capability of

Google Earth. While Google Earth is an effective means of distributing the inundation maps, the storing of the information online can be problematic. Since the consequences of a dam failure are sensitive information, posting the maps online can provide a greater risk of access and use by unauthorized persons, which may pose a security threat. As a result, these aspects of using Google Earth for the production of inundation maps must be considered for each application. 


\subsection{Conclusions}

Floodplain management serves a crucial role in the prevention of flood damage to property and the public. Through the use of inundation maps, engineers and emergency responders analyze the flood impacts resulting from a potential dam failure and develop mitigation procedures for inclusion in Emergency Action Plans. The inundation is generated based on a HEC-RAS model of a dam and river network, and HEC-GeoRAS, ArcGIS, and Google Earth are used to create maps from the data. ArcGIS produces a paper inundation map, while Google Earth provides the capability for virtual inundation maps. While both formats use the same data, the presentation of the critical information varies. Thus, an assessment of the strengths and weaknesses of the two mapping procedures was performed.

For this research, a dam failure was modeled for a river, and the resulting inundation was mapped using both the Terrain Tiles and Google Earth procedures. An analysis of the two mapping procedures identified the benefits and potential drawbacks of each based on criteria relating to the ease of development, display of critical information, and accessibility. The strengths of the Terrain Tiles procedure are that the time-stepped inundation maps clearly show the arrival times of the flood into key areas and that the water depth intervals provide a visualization of the severity of the flood. However, a weakness of this mapping procedure is that the critical infrastructure data and background imagery may be difficult to obtain and the incorporation of this data into the maps is a very labor-intensive process. Further weaknesses relate to online file sharing, as the uploaded ArcGIS files require knowledge of GIS software for the interpretation of the maps. On the other hand, Google Earth offers a user-friendly file sharing environment that does not require technical software experience. Also, the uploaded data cannot be corrupted since Google Earth does not contain ArcGIS processing tools. Further 
benefits are that Google Earth contains critical infrastructure and background imagery and that the inundation can be viewed in two-dimensional and three-dimensional perspectives. Weaknesses of the Google Earth procedure are that the inundation must still be produced in ArcGIS, that the water depths and arrival times of the inundation are not as clearly displayed as in ArcMap, and that the online file sharing may pose security issues.

Based on this analysis of the benefits and drawbacks of each mapping procedure, a determination was reached as to the appropriate uses of each in floodplain management. Since the Terrain Tiles procedure displays arrival times and water depths more clearly, these maps should be used during the development of mitigation measures for Emergency Action Plans. Due to the user-friendly online file sharing offered by Google Earth, these maps should be used during an actual emergency response, as the maps could be accessed in the field by various agencies performing emergency protocol. Future development of the Google Earth procedure may include the refinement of displaying arrival times and water depths, as well as the ability to view a three-dimensional inundation in Ground-Level View. These improvements would help to further advance the development and use of inundation maps by floodplain managers and emergency agencies. 


\subsection{References}

Bond, Leslie A. "Dams and Floodplain Management". National Dam Safety Program Technical Seminar \#16. LA Bond Associates. Emmitsburg, MD. 18 Feb. 2009. Conference Presentation.

Environmental Systems Research Institute, Inc. (ESRI). "What is ArcGIS?” ArcGIS Resource Center. 26 May 2011. Web. 14 Jul. 2011A. <http://help.arcgis.com/en/arcgisdesktop/10.0/help/index.html\#/What_is_ArcGIS/00v200 $\underline{000007000000 />.}$

Environmental Systems Research Institute, Inc. (ESRI). “What is ArcGIS Desktop?” ArcGIS Resource Center. 26 May 2011. Web. 14 Jul. 2011B.

< $\underline{\text { http://help.arcgis.com/en/arcgisdesktop/10.0/help/index.html\#/What is ArcGIS Deskto }}$ p/00v200000005000000/>.

Federal Emergency Management Agency (FEMA). “The National Flood Insurance Program”. United States Department of Homeland Security. 11 Aug. 2010. Web. 10 Aug. 2011. <http://www.fema.gov/plan/prevent/floodplain/index.shtm>.

Google. “Desktop”. Google Earth. Web. 14 Jul. 2011.

〈http://www.google.com/earth/explore/products/desktop.html >.

Merwade, Venkatesh. "Tutorial on using HEC-GeoRAS with ArcGIS 9.3”. Purdue University. Nov. 2010. Web. 12 Jul. 2011. 〈http://web.ics.purdue.edu/ vmerwade/education/georastutorial.pdf $>$.

Sherry, Luke, and Jeana Gowin. "HEC-GEORAS WORKSHOP”. 2010 IAFSM Conference. Christopher B. Burke Engineering, Ltd. Tinley Park, IL. 9 Mar. 2010. Conference Presentation. 
Tate, Eric. "Introduction to HEC-RAS". Center for Research in Water Resources. Apr. 1999.

Web. 14 Jul. 2011. <http://www.ce.utexas.edu/prof/maidment/grad/tate/research/

RASExercise/webfiles/hecras.html>.

United States Army Corps of Engineers (USACE). HEC-GeoRAS GIS Tools for Support of

HEC-RAS using ArcGIS. Version 4.3.93. Feb. 2011. Web. 12 Jul. 2011A.

$<$ http://www.hec.usace.army.mil/software/hec-ras/documents/HEC-

GeoRAS_43_Users_Manual.pdf>.

United States Army Corps of Engineers (USACE). "HEC-RAS Features”. Web. 14 Jul. 2011B.

〈http://www.hec.usace.army.mil/software/hec-ras/hecras-features.html〉.

United States Army Corps of Engineers (USACE). "Memorandum for MSC Commanders,

Districts, Laboratories, and FOA's”. 20 Nov. 2008. Web. 31 Aug. 2011.

<http://www.iwr.usace.army.mil/docs/rmc/RMC DCG Memo 20Nov08.pdf $>$.

United States Army Engineer Research and Development Center (ERDC). "Risk Analysis for

Dam Safety”. 27 Jan. 2010. Web. 23 Aug. 2011.

$<$ http://www.erdc.usace.army.mil/pls/erdcpub/www_welcome.navigation_page?tmp_nex

t_page $=1367415 \&$ page $=$ All $>$.

United States Department of Homeland Security (DHS). "Use of the Defense Production Act to

Reduce Interruptions in Critical Infrastructure and Key Resource Operations During

Emergencies”. 25 Apr. 2008. Web. 22 Aug. 2011.

$<\underline{\text { http://www.fema.gov/library/file?type=publishedFile\&file=final_ip_report_to_congress }}$

080305.pdf\&fileid=56099f80-3584-11de-baca-001185636a87> .

WVGISTC. West Virginia GIS Technical Center, 2011. Web. 10 Jan. 2011. $\langle$ http://wvgis.wvu.edu/index.php $>$. 